WellBeing International

WBI Studies Repository

1986

\title{
Social Ecology and Behavior of Coyotes
}

\author{
Marc Bekoff \\ University of Colorado \\ Michael C. Wells \\ University of Colorado
}

Follow this and additional works at: https://www.wellbeingintlstudiesrepository.org/acwp_ena

Part of the Animal Studies Commons, Behavior and Ethology Commons, and the Comparative Psychology Commons

\section{Recommended Citation}

Bekoff, M., \& Wells, M. C. (1986). Social ecology and behavior of coyotes. Advances in the Study of Behavior, 16, 251-338.

This material is brought to you for free and open access by WellBeing International. It has been accepted for inclusion by an authorized administrator of the WBI Studies Repository. For more information, please contact wbisr-info@wellbeingintl.org.

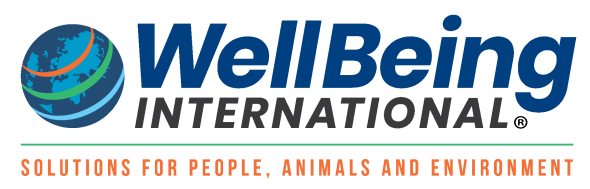




\section{Social Ecology and Behavior of Coyotes}

Marc Bekoff and Michael C. Wells

University of Colorado

\section{INTRODUCTION}

Coyotes, Canis latrans, are medium-sized members of the order Carnivora (weight: about 8-20 kg; length: approximately 1-1.4 m) that range from as far south as Costa Rica and Panama (Vaughan, 1983), throughout the continental United States and Canada, to northern Alaska (Young and Jackson, 1951; Gier, 1968; Bekoff, 1977a, 1978a, 1982). Within, and perhaps outside of, these general boundaries the range of coyotes appears to be expanding due primarily to their high reproductive potential, great dispersal ability, and opportunistic food habits (Vaughan, 1983). Coyote expansion has also been facilitated by the elimination of large competitors such as gray wolves (Canis lupus), with whom they usually compete unsuccessfully (Gier, 1975; Carbyn, 1982) and avoid (Fuller and Keith, 1981). Furthermore, coyotes show a marked ability to compensate for increased human exploitation (Knowlton, 1972; Sterling et al., 1983). They are able to exist and reproduce successfully in extremely diverse habitats ranging from sea level to 2000-3000 m, including deserts, open grasslands, broken and dense forests, and large cities such as Los Angeles, California (Howell, 1982; Wirtz et al., 1982). As Gier (1975) stressed, neither altitude, latitude, nor vegetation restricts their survival.

The family Canidae, to which coyotes and 36 other species belong, is 1 of 7 polytypic families in the order Carnivora. Other members of this diverse order include the ursids, procyonids, mustelids, viverrids, hyaenids, and felids (Ewer, 1973; Eisenberg, 1981). Extensive bibliographies concerning life histories and social ecology of various carnivores can be found in Mech (1970), Kruuk (1972), Schaller (1972), Fox (1975), Bekoff (1978a), Bekoff et al. (1981a, 1984), Eisenberg (1981), Macdonald and Moehlman (1982), and Moehlman (1983). Long-term field studies of identified individuals of known genetic relatedness are limited in number (Bekoff et al., 1984).

In the genus Canis, there are eight recognized species, including wolves (C. lupus), domestic dogs (C. familiaris), dingos (C. dingo), Simien foxes (C. simensis), and side-striped (C. adustus), black-backed (silver-backed, C. mesomelas), and golden (C. aureus) jackals (for details see Ewer, 1973; Stains, 1975). Although there are 19 recognized subspecies of coyotes, subspecific classification seems to be of limited value because of the wide-ranging movements of, and interbreeding among subspecies by, this peripatetic, adaptable canid (Nowak, 1978).

\section{WHY STUDY COYOTES?}

Coyotes are ideal animals in which to study numerous aspects of behavior because of their ability to adapt to diverse environments. They show great intraspecific variation in social behavior and social organization, enabling behavioral patterns to be analyzed as phenotypic adaptations to local conditions (Bowen, 1978; Bekoff and Wells, 1980, 1981, 1982; Andelt, 1982, 1895; Bekoff, 1983; Bekoff et al., 1984; Wells and Bekoff, 1982; for a general review of intraspecific variability see Lott, 1984). Two major aims of research in social biology are to explain variation in social behavior in terms of biological function (Clutton-Brock and Harvey, 1976) and to predict patterns of social interaction from knowledge of resource distribution (McCracken and Bradbury, 1981). Both of these goals may be achieved by studying coyotes. 
In addition to exemplifying ways in which proximate conditions influence their behavior, coyotes can be compared to other canids, as well as to other carnivores and vertebrates. Behavioral similarities may also be found in some social insects (Andersson, 1984). Thus, comparative and evolutionary questions concerned with social behavior, ecology, and life history strategies can be investigated (Kleiman and Brady, 1978; Bekoff et al., 1984). Although the comparative method may be better at suggesting hypotheses than at testing them (Steams, 1983), little progress will be made if comparative data are neglected.

Finally, because of the damage inflicted by some individuals on populations of domestic animals, coyotes are, and historically have been, controversial predators (see Young and Jackson, 1951; Gier, 1968; Bekoff, 1977a, 1978a, 1982; and Andelt, 1982, Kellert, 1985, and references therein). Over the past century, the management of problem populations and individuals has met with limited success, often because so little was known about the basic population biology and behavior of the species. The few data that were available were usually ignored or simply overlooked because of their seemingly superficial relevance to the problems at hand. However, there is increasing evidence that information stemming from behavioral/ecological and population studies, such as the way in which food resources influence social organization and how carrion attracts coyotes to sites where they might otherwise not venture, may be useful in control programs (Gier, 1968; Lehner, 1976; Todd and Keith, 1976; Bekoff, 1979a, 1982; Bekoff and Wells, 1980; Jones and Woolf, 1983).

Our purpose here is to summarize a long-term study of coyotes that was conducted in the Grand Teton National Park, in the northwest comer of Wyoming (Fig. 1). As will become obvious, there is remarkable agreement in the results stemming from a limited number of field projects concerned with the social behavior and behavioral ecology of coyotes (Bowen, 1978, 1981, 1982; Camenzind, 1978; Andelt, 1982, 1985; Bekoff and Wells, 1982), and some general principles concerning social ecology, scent marking, predatory behavior, time budgeting, and reproductive and care-giving patterns can be developed that are applicable not only to coyotes but to many other carnivores (Kleiman and Eisenberg, 1973; Macdonald and Moehlman, 1982; Moehlman, 1983; Bekoff et al., 1984).

\section{SOCIAL RELATIONSHIPS, KINSHIP PATTERNS, AND REPRODUCTIVE SUCCESS}

\section{A. SOCIAL ECOLOGY, SOCIAL ORGANIZATION, AND SOCIAL STRUCTURE}

Behavioral patterns are subject to natural selection, and behavior, like any other attributes of an animal (Lorenz, 1981), contributes to individual survival. Eisenberg (1981, p. 405) views social organizations as phenotypic characters. Indeed, animals are biological systems, behavioral characteristics are phenotypes, and general principles of organic evolution as we understand them apply to the study of behavior (Bekoff and Byers, 1985).

Among the very few undisputed "facts" in the fields of ethology and behavioral ecology is that the way in which behavior contributes to individual survival and reproduction is closely linked to ecological conditions. The term social ecology is used here simply to highlight the intimate association between social behavior and ecology, a relationship stressed by Crook (1964) in his pioneering work on variation in social organization of closely related weaver birds (Ploceinae) and differences in diet and habitat.

The terms social organization and social structure mean different things to different people, and often it is difficult to differentiate meaningfully among their many uses. As Crook (1965, p. 162) stressed, the phrase social organization should not be used "...as a blanket variable, obscuring the complex nature of the process it denotes." It is useful, however, "...in that it denotes a complex of behavioral characteristics 
determining the mode of dispersion of a population and the inter-individual encounters within it. It allows for quick comparisons between taxa which differ markedly in the type of social life they show."

Crook and other researchers (e.g., Seidensticker et al., 1973) include both spatial relationships and social interaction patterns in their definitions of social organization. A group's social organizational pattern may also refer to relationships between individuals and other features of the environment (Fisler, 1969; Seidensticker et al., 1973). However, van Schaik and van Hooff (1983) suggest that the term social organization be limited to describing processes of social interaction and their patterns of distribution among group members; the multiplicity of relationships among all group members must be detailed (Pearl and Schulman, 1983).

According to van Schaik and van Hooff (1983), spatial relationships and group composition (size, age, and sex of group members, genetic relationships) provide information on the group's social structure. While social structure and social organization obviously may be closely related, one kind of social structure can result from different types of social organization.

From a methodological perspective that is relevant to the study of wide-ranging species such as coyotes, researchers using only radiotelemetry to track animals would technically be providing data on social structure; in some cases, social organization patterns may be inferred from spatial relationships among identified individuals. But, as Waser (1974) and others have pointed out, analyzing spatial relationships alone can produce erroneous conclusions about social relationships; individuals may be interacting at various distances using visual, auditory, or olfactory signals without actually being in close proximity. Basically, without direct observations, data on social interaction patterns are incomplete and suspect.

Our review of the literature indicates that the terms social organization and social structure are usually used synonomously, but that the former phrase is used most frequently to refer to spatial relationships, group composition, and social interaction patterns. We will adopt this use of the term social organization (perhaps van Schaik and van Hooff's distinction needs to be heeded when only radiotelemetry is used), but encourage researchers to be clear about what it is they are studying. Finally, as will become evident below, discussing species-typical social organization frequently obscures the rampant intraspecific variability that characterizes carnivores and numerous other animal groups (Bekoff et al., 1984; Lott, 1984) and masks a wide variety of adaptational syndromes based on ecological constraints (Kleiman and Eisenberg, 1983, p. 359).

\section{B. ASSESSING KIN RELATIONSHIPS}

An obvious requirement for a detailed analysis of social organization is that information on identified individuals should comprise the major portion of the data set, and in-depth studies require that genetic relationships be determined whenever possible. Movement patterns of identified individuals of known genetic relatedness also must be documented (Frame et al., 1979; Bekoff and Wells, 1982; Mech and Hertel, 1983; Bekoff et al., 1984). These data enable one to assess the relative roles of kin selection (Hamilton, 1963, 1964; Williams, 1966; Alexander, 1974; West-Eberhard, 1975; Wilson, 1975; Vehrencamp, 1979; Boorman and Levitt, 1980) and other possible, though not necessarily mutually exclusive, pathways [reciprocity, mutualism, indirect effects (Wilson, 1980)] in the evolution of different forms of social behavior such as food sharing, care giving, cooperation, and altruism.

Kin relationships in social groups, as measured by the coefficient of genetic relationship, $r$, vary among, and even within, species of social carnivores (Macdonald and Moehlman, 1982). For species exhibiting complex patterns of social organization such as coyotes, wolves, golden and black-backed jackals, African wild dogs (Lycaon pictus), African lions (Panthera leo), and dwarf mongooses (Helogale parvula), 
kin selection alone may be too simplistic to account for observed behavioral interactions (Frame et al., 1979; Reich, 1981; Bekoff and Wells, 1982; Macdonald and Moehlman, 1982; Moehlman, 1983; Rood, 1983a).

\section{ASSESSING KIN RELATIONSHIPS}

A major goal of most studies concerned with the evolution of social behavior and the ways in which individuals adapt to more immediate conditions is to provide reliable estimates of how that individual's behavior affects its inclusive (direct and indirect, Brown, 1980, 1983) reproductive fitness (Hamilton, 1963; Grafen, 1982). Causal relationships between behavior and fitness are almost impossible to demonstrate precisely, especially for long-lived, wide-ranging species, hence, the establishment of Sealander's law, "You can't measure fitness in the field, you have to take it into the lab," and corollary, "You can't measure it in the lab either" (as stated in Mock, 1983, p. 63).

For coyotes and most other species, determining individual direct or indirect fitness under any condition is virtually impossible, but educated guesses about relationships between behavior and fitness are interesting, and often are fairly accurate. Modification of some of the measurements that Howard (1979) suggests for calculating estimated reproductive success (ERS) in diploid vertebrates may be helpful in providing quantitative estimates of ERS in various taxa.

\section{METHODS OF STUDY: ETHOGRAMS, SAMPLING, AND RADIOTELEMETRY}

\section{A. GENERAL COMMENTS}

Many field studies concerned with social behavior and behavioral ecology are seriously weakened by methodological (sampling, analytical) flaws (Bekoff and Mech, 1984; Green and Grant, 1984; Laundré and Keller, 1984; Schleidt et al., 1984). Often, essential information about basic behavioral patterns is not provided. As Hinde (1970) and others have stressed, the generation of theories, models, and hypotheses that guide future research must be based on a solid descriptive foundation.

A major reason for the presence of shortcomings in field research in behavioral ecology is that researchers with varied backgrounds are attracted to the area and bring with them their own respective skills and weaknesses. Certainly, almost all studies are marred by a variety of shortcomings, but the number of flaws can be reduced by following some simple, standard guidelines.

\section{B. ETHOGRAMS AND SAMPLING TECHNIQUES}

Comparative analyses of social interaction patterns and the behaviors that are used rely on basic descriptive data, especially when frequencies or rates or occurrence of certain actions are used to differentiate closely related species such as members of the genus Canis (Bekoff, 1972a,b, 1974, 1977b, 1978b; Kleiman and Eisenberg, 1973; Bekoff et al., 1975; Kleiman and Brady, 1978). Schleidt et al., (1984) have stressed the importance of standardizing the way in which behavioral descriptions and observations are reported so that comparative studies can be done reliably. In the present study, we used basic ethograms developed by Scott and Fuller (1965), Fox (1969a,b, 1970, 1971), Bekoff (1972a,b, 1978b), Peters and Mech (1975), Zimen (1975, 1981), and Lehner (1978a,b) and modified them where necessary.

Adequate sampling methods must also be used. J. Altmann (1974), Lehner (1979), and Green and Grant (1984) provide guidelines that are applicable to virtually all types of behavioral research projects. 


\section{QUANTITATIVE ANALYSES}

In any study of social behavior, interaction patterns and spatial relationships must be rigorously analyzed. Multivariate statistics are useful for studying social organization, basic behavioral patterns, and ecological relationships (Hazlett, 1977; Colgan, 1978; Bekoff, 1977b, 1978c; Wells and Bekoff, 1981, 1982; Bekoff and Wells, 1982; Hilborn and Steams, 1982; Hughes, 1983; Williams, 1983; also see Batschelet, 1965). For example, MacCracken and Hansen (1982) found that multivariate analyses were useful for detecting seasonal patterns of food habits of coyotes in southeastern Idaho that were not apparent using univariate statistics. Likewise, we have used various multivariate procedures to analyze scent marking (Section V), predatory behavior (Section VI), and care giving (Section IX).

\section{RADIOTELEMETRY AND THE STUDY OF SOCIAL ORGANIZATION}

Although detailed analyses of social behavior and social organization must rely most heavily on direct observation of study animals, coyotes, and many other wide-ranging species, are difficult to observe directly for long periods of time or throughout their home range. Furthermore, many species are nocturnal and secretive. In these cases, radio tracking can be used to supplement direct observation. Reviews of techniques, potential problems associated with equipment, and the precision with which animals can be located can be found in Amlaner and Macdonald (1980), Cheeseman, and Mitson (1982), and Mech (1983).

Macdonald (1980) has correctly stressed that it is often very difficult to assess reliably the social significance of movements of radio-tagged animals. Interpretation of these radio-tracking data, especially with respect to a species' social organization, must be done with care. In addition to not knowing what the interacting animals are doing, or even if they are actively engaged in one activity or another, it is difficult to assess whether their movements are independent of, or correlated with, one another. Dunn (1979) has developed a technique that is useful in differentiating between independent and correlated movements.

\section{Radio Tracking and Sample Size.}

An important methodological problem with radio tracking free-ranging animals is that home range or territory size estimates are often directly positively related to the number of locations that are gathered (Bekoff and Mech, 1984; Laundré and Keller, 1984, and references therein). For coyotes (Laundré and Keller, 1984) and other species, insufficient sample sizes often have been used to estimate space use. About 150 locations are often necessary for an accurate estimate of space use in coyotes (Hibler, 1977; Woodruff and Keller, 1982; Laundré and Keller, 1984), but the number of locations that constitutes an adequate sample may vary with a species' size, season (presence of snow), habitat, sex, age, social status (resident, transient), reproductive condition, food resources, and the presence or absence of conspecifics or other species (Fritts and Mech, 1981; Carbyn, 1983). What is sufficient for one individual may be inadequate for another animal.

Suffice it to say, field workers relying heavily on telemetry need to show that sample size is not a confounding variable. Furthermore, they must realize that the conclusions that they draw concerning social behavior and social organization are limited in scope (Laundré and Keller, 1981; Messier and Barrette, 1982) and need to be verified by direct observation.

\section{E. THE STUDY SITE, METHODS, AND SUBJECTS}

The majority of data in our study of coyotes were collected by direct observation, on an almost daily basis, of individuals living in the area of Blacktail Butte (BTB) in the southeast comer of the Grand Teton National Park, about $20 \mathrm{~km}$ north of the town of Jackson, Wyoming, $5 \mathrm{~km}$ east of the village of Moose, 
and about $1 \mathrm{~km}$ west of Kelly (Fig. 1). The mean annual temperature at Moose is about $2.41^{\circ} \mathrm{C}$ (U.S. Department of Commerce Weather Bureau records, 1950-1975), ranging from a monthly mean of $15^{\circ} \mathrm{C}$ in July to $-10^{\circ} \mathrm{C}$ in January.

FIG. 1. The main study site at Blacktail Butte. The hatched area is about $10 \mathrm{~km}^{2}$ and represents the territory in which the pack lived. Observation points are marked with stars; most observations were made from the Butte (from Lipetz, 1980).

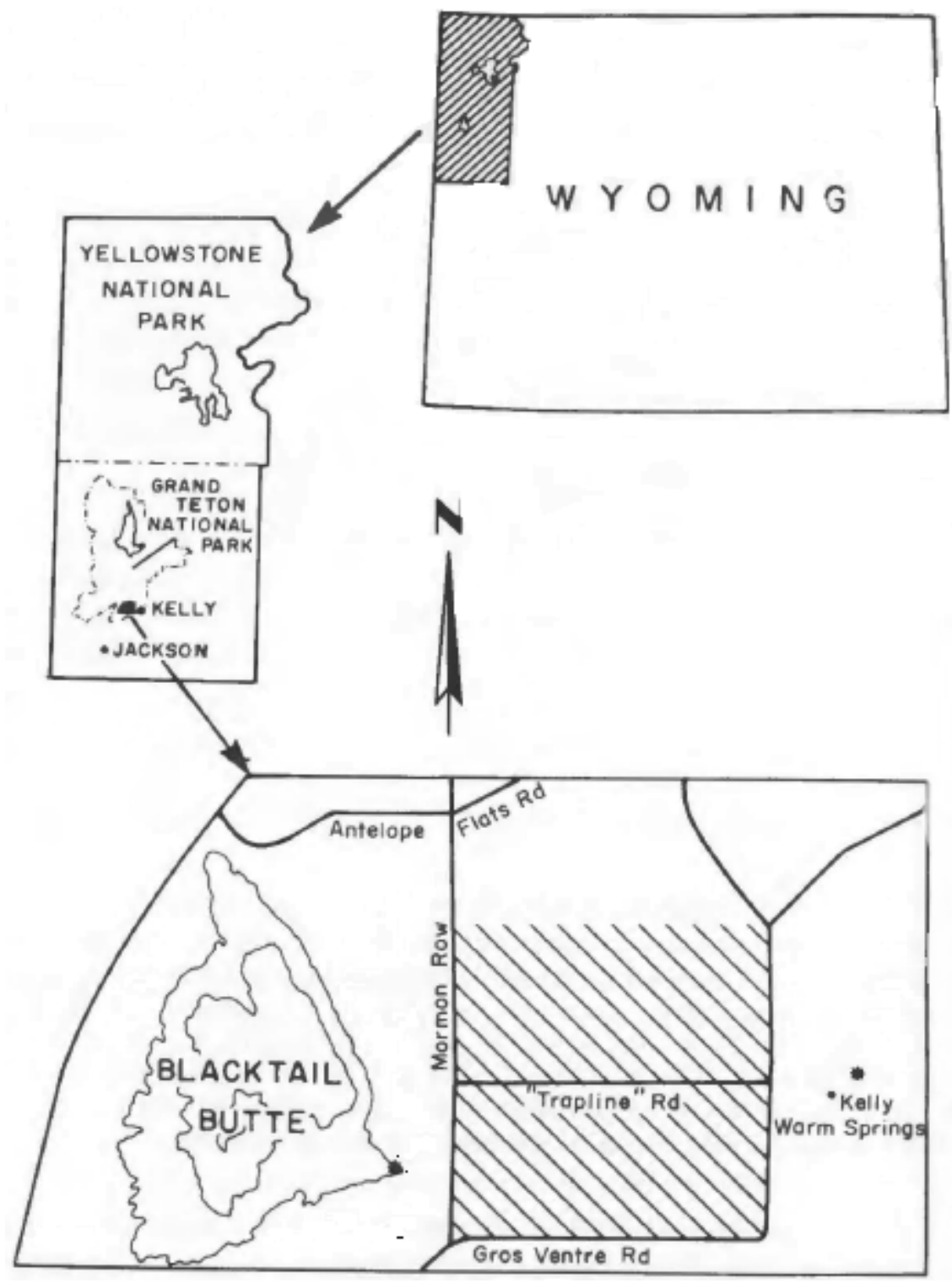

Individuals and groups comprising this relatively unexploited population were observed for $1024 \mathrm{hr}$ during $4155 \mathrm{hr}$ of field work between September 1977 and February 1983. Observational data were supplemented by information gathered by radio tracking. Details concerning data collection, trapping, 
tagging, and telemetry can be found in Bekoff and Wells $(1981,1982)$, Wells and Bekoff $(1981,1982)$ and Lipetz and Bekoff (1982).

FIG. 2. Social groups of carnivores are usually composed of genetically related individuals. This figure is a pedigree for the main pack of coyotes that we studied. After the original pack mother (1) left the group in late 1980, a strange and presumably unrelated female (mother 2), about 1.5-2.5 years old, joined the pack and mated with the original pack father (1) in 1981 . Then, after he left the pack in spring 1981, his son, male helper B21, mated with the new female in 1982 and 1983. In 1982, the help that B21 provided to male ' 81 and female B36 was reciprocated when B21 and the new female's pups were born. Mother 2 was the only coyote to join the pack during the study.

PACK PEDIGREE: 1977-1983

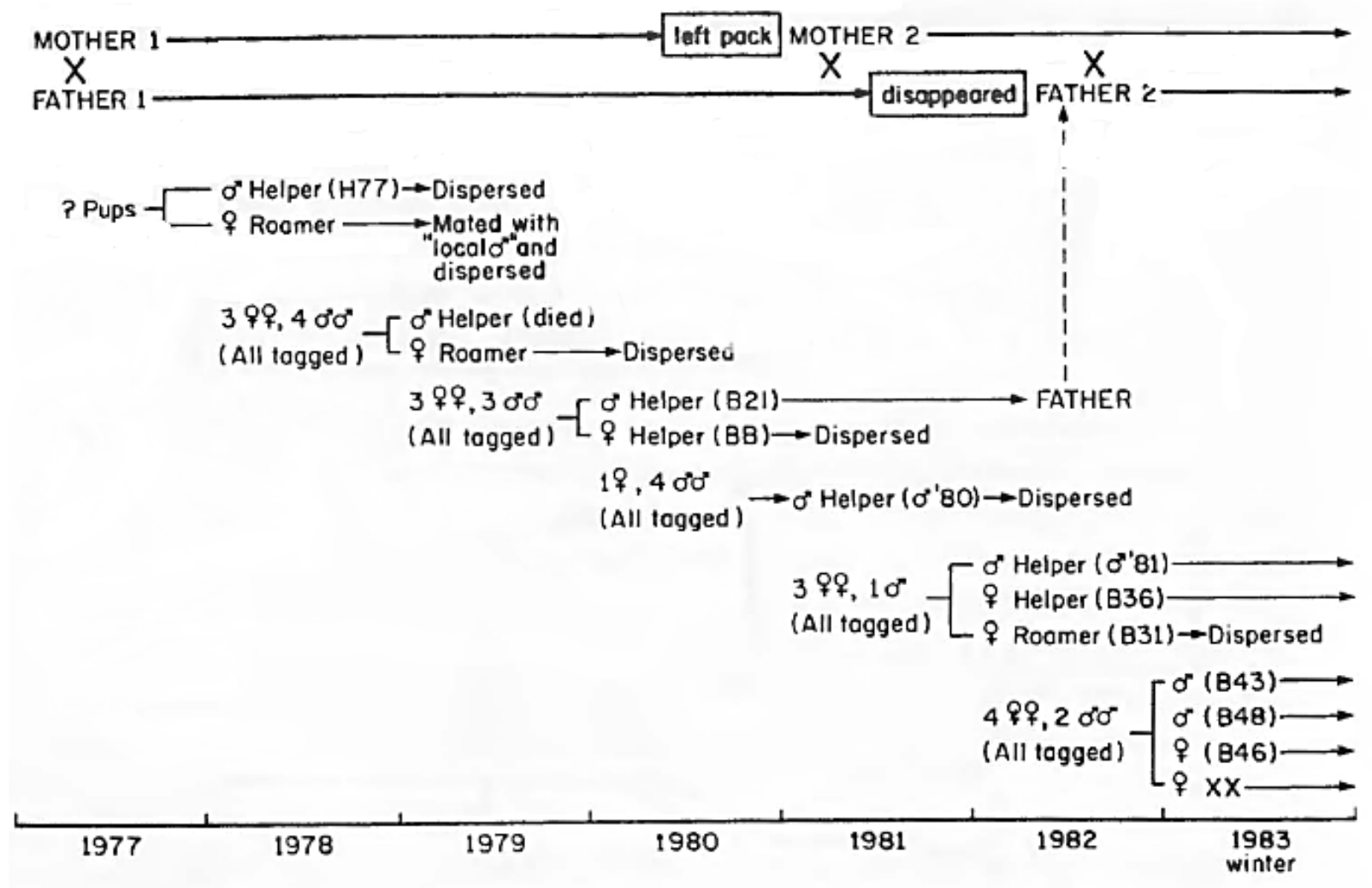

Fifty-six coyotes (28 males and 28 females) were tagged of which 43 were also fitted with radio collars. Numerous other individuals, including Father 1 (Fig. 2), were easily identified because of distinct coat or other physical characteristics, gait, or because of the presence of nonfunctional radio collars used in a previous study (Tzilkowski, 1980). A pedigree for the main pack is presented in Fig. 2. Tagged coyotes were studied for an average of 311 days and all identified animals were located or seen for an average of 338 days (range $=24-1267$ days). Mother 1 , Father 1 , male B21, and Mother 2 were seen for 1250, 1050, 850, and 1267 days, respectively. Individuals were trapped throughout their home range or territory. Laundré and Keller (1983) found that coyotes were usually caught in grids of low use, but most of their traps were also located in areas of low use. Drewek (1980) reported that trapped females were more excitable and more difficult to handle than were males, but we found no sex differences in behavior in the coyotes that we trapped. Handling did not cause any apparent changes in the subsequent behavior of any individuals. Whereas other researchers have experienced low recovery rates for pups marked at 
dens because the pups were tagged outside of their intensive study area (Nellis and Keith, 1976), we rarely experienced this problem.

Space use analyses were performed using a package of Hewlett Packard BASIC programs called SPACE-OUT (Bekoff et al., 1982). The area of the convex polygon enclosed by $95 \%$ of all locations (closest to the geometric center of each individual's home range or territory) was used in our studies of space use to avoid overestimating area due to infrequent long distance forays (Andelt, 1982; Bowen, 1982; Bekoff and Wells, 1982). In most instances, the 95\% area was not much smaller than the total $(100 \%)$ home range (territory) estimate. Fewer visual and radio locations were needed to provide an accurate estimate of home range or territory area for resident coyotes than for transient individuals (see Fig. 4 in Bekoff et al., 1984; also see Bekoff and Mech, 1984).

\section{NATURAL HISTORY AND SEASONAL ECOLOGY OF COYOTES}

Although there have been relatively few detailed studies of the social behavior, social organization, and behavioral ecology of coyotes, perhaps more is known about the natural history of this canid than of any other carnivore (Murie, 1940; Young and Jackson, 1951; Gier, 1968; Bekoff, 1977a, 1978a, 1982) with the possible exception of wolves. A great deal of information on coyotes stems from management and control interests. Although the main emphasis of such research has not been directly concerned with behavior or ecology, a wealth of information is contained in many natural history studies of this remarkable carnivore. Indeed, some general "popular" treatises on coyotes contain essential details on population dynamics, feeding ecology, reproductive behavior, movement patterns, and other data that are required by biologists interested in (1) how proximate factors influence the behavior of coyotes and (2) the possible ways in which various behaviors, life history patterns, and population characteristics have evolved.

To familiarize the reader with our study area, this section briefly summarizes some aspects of the behavior and ecology of coyotes living around Blacktail Butte, including patterns of social organization, food resources, reproduction, dispersal, and mortality (details are provided below). Although the timing of the events, such as courtship and mating and the seasonal availability of different food types, may vary in different locales as a function of latitude or altitude (Hamlett, 1938; Young and Jackson, 1951; Gier, 1968; Bekoff, 1977a, 1978a), the basic scheme (Fig. 3) remains applicable for many areas in which coyotes reside.

\section{A. SOCIAL ORGANIZATION}

The patterns of social organization shown by different species and by members of the same species can be qualitatively and quantitatively differentiated (Wilson, 1975, pp. 16ff, lists 10 qualities of sociality; see also Eisenberg, 1981). Following Bowen's (1978) scheme, we classified coyotes into four different categories: (1) transients: single individuals showing no site attachment. Camenzind (1978) reported that about one-half of the transients, or nomads, he observed, were less than 1 year of age, whereas Andelt (1982) found that $21 / 25(84 \%)$ of the transients he observed were healthy adults and only $2 / 25$ (8\%) were less than 1 year old (also see Pyrah, 1984); (2) solitary residents: lone animals living in a defined home range, but not defending its boundaries; (3) resident mated pairs: male and female occupying, but not defending, a defined home range. The mated pair is the basic social unit in coyotes. Bowen (1978), Camenzind (1978), and Andelt $(1982,1985)$ reported that mated pairs were territorial; (4) packs. Individuals could be classified in different categories during their lives. 
FIG. 3. Annual changes in food resources and patterns of reproductive behavior shown by coyotes living around Blacktail Butte (from Bekoff and Wells, 1982).

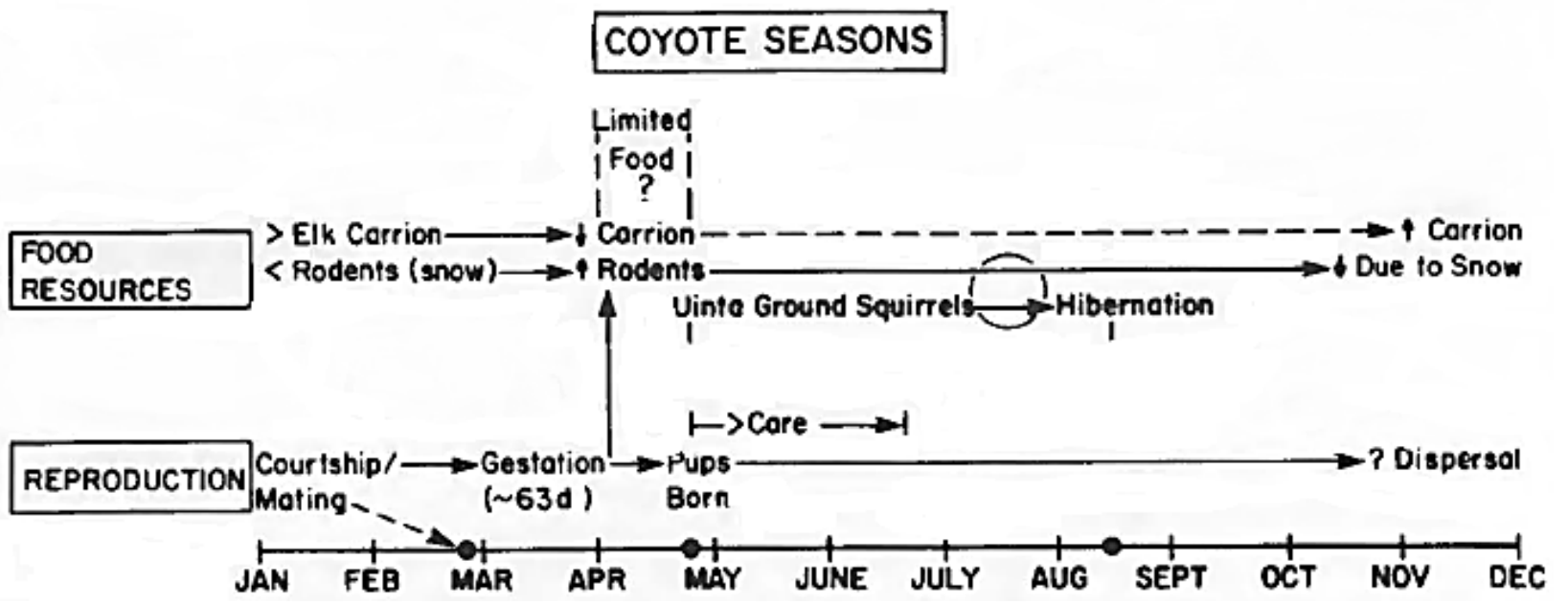

General Characteristics of the Pack.

The pack (Fig. 2) was a close-knit, cohesive social unit. They shared in territorial defense, parents often received help in rearing young, and they ate, rested, played, foraged, and traveled together regularly (see Bowen, 1978). When separated, contact was maintained through a variety of vocalizations (McCarley, 1975; Lehner, 1978a,b, 1982). When pack members were reunited, there were extensive greeting ceremonies incorporating active and passive submission (Schenkel, 1967; Fox, 1971), vocalizations (Lehner, 1978b; Peters, 1984), and social play. There also was extensive overlap among individual territories.

Dominance Relationships. Agonistic interactions resulting in clear-cut dominance were observed very rarely (see Section VII,B), and were were unable to study dominance relationships in any detail. The only predictable relationships that prevailed throughout the study involved interactions between the mated pair and other group members. Neither of the paired coyotes regularly dominated the other, but each of them was able to dominate all other group members. Helpers typically dominated younger siblings until the latter were about 6-9 months of age, after which clear-cut dominance relationships could not be detected. The relationships among other individuals were not well defined. When animals were feeding on carrion, agonistic interactions occurred, but possession of a piece of food was rarely contested. Lockwood (1976) found that he was able to identify only extremes in rank among captive wolves, but he observed no consistent order among midranking individuals.

Although young coyotes interacted similarly to captive pups among whom clearly defined dominance relationships were established (Fox and Clark, 1971; Bekoff, 1972a, 1974, 1977c, 1978b; Knight, 1978; Bekoff et al., 1981b), we could not gather enough information to make any general statement concerning the development of social status under field conditions. The robustness of data concerning the development of dominance relationships among very young pups raised in a variety of captive settings, and the similar patterns of social interaction that we observed around dens, leads us to conclude that dominance relationships among wild littermates may well be established very early in life, as they appear to be in some populations of red foxes (Henry, 1985; but see Garrott et al., 1984). It also is possible that relative social status may play some role in later patterns of behavior, including dispersal (Bekoff, 1977c; 
Lindstrom, 1982). Detailed data are needed concerning the development of dominance relationships and the stability of these relationships over time.

\section{B. FOOD RESOURCES}

Coyotes living in and around the area of BTB depended mainly on human-hunter-killed elk (Cervus elaphus) carrion during winter months (December-March) and fed primarily on various small rodents during the remainder of the year (see Camenzind, 1978; and Weaver, 1977, 1979, concerning research done in the same general area of the park). From mid- to late April to mid-August, Uinta ground squirrels (Spermophilus armatus) were the major food source; they hibernate during the rest of the year. Weaver $(1977,1979)$ reported that rodents appeared in 12 and $79 \%$ of scats collected in winter and summer, respectively, and ungulate remains, predominantly elk, were found in 87 and $20 \%$ of scats collected during winter and summer, respectively.

From about the beginning of April to the time ground squirrels emerged from hibernacula, food resources may be limited because carrion is depleted and snow cover makes it difficult for coyotes to catch small rodents other than squirrels. This time period coincides with the second half of pregnancy, and possibly with maternal lactation, and during this period reproductive females may be energetically stressed (Bekoff and Wells, 1981).

Because of changes in hunting policies within park boundaries between 1977 and 1982, elk carrion was unevenly distributed during the course of study and we were able to analyze the way in which winter food availability influenced behavior and social organization. Basically, where carrion was abundant, clumped, and defendable, packs of coyotes were observed; some, but not all juveniles dispersed during the first year of life. When carrion was scarce and spread out geographically, resident mated pairs and solitary coyotes were observed. Bowen (1978) and Camenzind (1978) reported strikingly similar results.

\section{REPRODUCTIVE PATTERNS}

Courtship activities began in late December-early January, and copulation usually occurred in late February. There is a long proestrous period (Kennelly and Roberts, 1969; Bekoff and Diamond, 1976), estrus lasts about 2-5 days (Kleiman, 1968), and ovulation occurs about 2-5 days before the end of female receptivity. Coyote females and males show an annual cycle of sexual receptivity (Kennelly, 1978; Green et al., 1984) and almost invariably mate only once a year.

Typically only one pair in a pack reproduces. Observations of (1) actual matings accompanied by the copulatory tie (during which the penis is "locked" inside of the vagina; Grandage, 1972) that indicates successful intromission and of (2) rejection of all suitors by the reproducing female except the one male who was observed to copulate successfully, indicate that coyotes form monogamous pair bonds (see Section IX,A,2). After a gestation period of about 63 days, pups were born in a subterranean den that usually had been previously partially dug by badgers (Taxidea taxus) or ground squirrels. Details about development and care giving are provided below (Section IX,B).

\section{DISPERSAL AND MORTALITY}

Despite the existence of many theories concerning various aspects of mammalian dispersal (Bekoff, 1977c, 1985; Frame et al., 1979; Gaines and McClenaghan, 1980; Greenwood, 1980; Dobson, 1982; Bekoff et al., 1984; Moore and Ali, 1984), very little is known about long-distance movements in wideranging carnivores such as coyotes (Andelt, 1982; Bekoff et al., 1984). Questions concerning (1) why specific individuals leave their natal site while other littermates do not, (2) the fates of dispersers with respect to survival and reproduction, and (3) actual routes of movement are largely unanswered (Bekoff 
et al., 1984). Dispersing coyotes seem to move about like bumper cars, "bouncing off" of other individuals and different places until they settle down (Bekoff, 1985).

In our study area, dispersal of juveniles usually began in fall and continued throughout winter. In most instances, individual dispersal was a gradual process that occurred over a period of weeks (see Messier, 1985). All young born to a resident mated pair dispersed before they were about 9-10 months of age. Fifty-seven percent $(57 \%, 16-28$; yearly range $=25-80 \%)$ of the coyotes born into the main pack left their natal area during the first year of life. There were no notable sex differences in dispersal. Andelt (1982) reported a $22 \%$ dispersal rate by juvenile coyotes living on the Welder Wildlife Refuge in Texas.

Coyotes that spent their first 10-11 months of life with their parents and some older siblings and littermates typically did not disperse. Some of these nondispersing coyotes became helpers whereas others, called "roamers," remained on the periphery of their natal territory and rarely interacted with relatives (Fig. 2). Pack formation was facilitated by natal philopatry (Waser and Jones, 1983) shown by nondispersing offspring that remained in close proximity to parents and other group members during their first year of life. The incorporation of nondispersing and nonreproducing offspring into existing packs appears to result from strong social bonds that are established among all group members.

Dispersal was associated with heightened mortality in our, and other, coyote populations (Tzilkowski, 1980; Pyrah, 1984), and may be one of the most risky ventures undertaken by a juvenile animal. Of 16 identified yearlings of known origin who dispersed, at least $9(56 \%)$ were known to have died shortly after leaving their natal group. Because we could only determine the fate of dispersers if they were subsequently resighted, if radio collars from dead individuals were returned to us (collars were marked with our names and addresses and the study was known widely), or if carcasses were found, this represents a minimum estimate. On the other hand, of five radio-collared nondispersing juveniles, only one $(20 \%)$ died during the first year of life.

Andelt (1982) estimated that between 36 and $64 \%$ of 11 pups $<6.5$ months of age died of natural causes during his study. Furthermore, he noted that transients suffered much higher mortality (males: 42\%; females: 66\%) than did resident coyotes (males: 26\%; females: 7\%). The average mortality rates for coyotes living on the Welder Wildlife Refuge and in Alberta, Canada were 32 and 45\%, respectively (Andelt, 1982; Bowen, 1978). Fifteen (27\%) of the coyotes we marked were known to have died during our study. Comparative data can be found in Gier (1968), Bekoff (1977a, 1982), and Andelt (1982).

Various aspects of coyote behavior and social ecology will now be considered in detail. After presenting information on scent-marking and predatory behavior, we will concentrate on different aspects of social behavior and social organization including space use, group composition, reproductive and care-giving behavior, and the profound influence that food resources have on social organization.

\section{SCENT MARKING AND ECOLOGICAL ASPECTS OF CHEMICAL COMMUNICATION}

Studies of olfactory communication and the ways and patterns in which animals distribute various glandular secretions, urine, and feces throughout their environment are of considerable interest to behavioral scientists because of their relationship to diverse, but interrelated, topics including reproductive habits, space use and territorial behavior, movement, feeding ecology, development (Quayle, 1983), and sex differences. General reviews and extensive references on this topic can be found in Ewer (1968, 1973), Ralls (1971), Eisenberg and Kleiman (1972), Peters and Mech (1975), Henry (1977), Macdonald (1980), and Gosling (1982). Detailed field studies of chemical communication in coyotes are limited; two behavioral/ecological analyses are based on interferences drawn from patterns of 
urine deposition on snow-covered ground ("yellow snow"; Barrette and Messier, 1980; Bowen and McT. Cowan, 1980) and only one study provided data based on direct observation (Wells and Bekoff, 1981).

We studied patterns of urination and defecation in order to (1) differentiate between simple elimination and "scent marking," (2) provide descriptions of the various behavioral patterns that are used to deposit urine or feces, (3) analyze sex differences in elimination or marking, (4) describe the behavioral contexts in which various types of elimination are performed, (5) study seasonal patterns in scent deposition, (6) assess how group size and other social factors influence marking, and (7) determine if, and how, the spatial distribution of chemical signs functions in the acquisition or maintenance of a territory, an area that is defended most of the time by pack members against (usually) conspecific intruders who do not belong to the group.

We also compared our results, based on direct observation, with data collected by "yellow snow" analyses (Barrette and Messier, 1980; Bowen and McT. Cowan, 1980). This type of comparison is unique and also is necessary for assessing the level of agreement between the two approaches, because in some cases, reading snow signs is the only practical method of data collection. Nonetheless, the uncertainty associated with reading snow signs must be taken into account (Bekoff, 1980).

\section{A. ELIMINATION "VERSUS" MARKING}

Although various researchers have suggested that scent marking should be differentiated from simple elimination (Kleiman, 1966; Barrette, 1977), this might be a difficult task, especially in studies relying on snow sign. For example, Barrette and Messier (1980) considered all urine sign encountered in snow to be potential scent marks, whereas this would not have been the case for free-ranging domestic dogs (Bekoff, 1979c). However, Barrette and Messier's assumption might not be grossly misleading for coyotes at least (see below). Indeed, the possibility exists that all bodily excretions are potential marks to the recipient, regardless of the sender's intent (Dunbar, 1977; Bekoff, 1979c). Furthermore, the chemical composition of urine deposited during simple elimination may not differ from that of urine ejected during marking, and the effects of sniffing the signs may also be similar.

\section{Marking Criteria}

One main criterion for marking that appears to be applicable in many instances is that the stream of urine is directed at some conspicuous object (Kleiman, 1966; Peters and Mech, 1975; Bowen and McT. Cowan, 1980). Kleiman (1966) also suggested that urine marking might be distinguished from elimination when urination is elicited by familiar landmarks or novel stimuli and when it is repeated frequently on the same object. Under field conditions, especially when individuals cannot be continuously observed or when yellow snow is used to analyze urination patterns, it is extremely difficult to differentiate elimination from marking using these criteria. It is highly likely that the detectability of snow signs by a human is related to the conspicuousness of an object on which scent was originally deposited. Also, a landmark that was conspicuous might be so defined because the sign was located by the researcher.

Because of the difficulty of differentiation between elimination and marking and the inaccuracy associated with reading snow signs (Bekoff, 1980), and also because we were able to observe our subjects, we attempted to distinguish elimination from marking using three main criteria to characterize marking: (1) A coyote was observed to sniff a spot and then eliminate directly over it. (2) Ground scratching occurred after urinating (or defecating; ground scratching was never observed before urinating or defecating, see Bekoff, 1979b,c, 1980). Camenzind (1978) used this criterion solely. (3) The stream of urine was directed at a previously known urine deposit made by the same or another coyote. Another useful criterion, 
especially in snow-tracking studies, is that a smaller amount of urine is usually expelled during marking than during simple elimination (Peters and Mech, 1975; Henry, 1977; Macdonald, 1980).

\section{B. POSTURES ASSOCIATED WITH ELIMINATION AND MARKING}

Four main postures were observed: Urination postures included the raised-leg urination (RLU) or "male leg lift," the squat urination (SQU), and the forward-lean urination (FLU). Coyotes (Harrington, 1982) and other canids (Bekoff, 1979b) may perform an elimination posture without actually depositing any urine that is detectable to the observer. Such "pseudourination" (Harrington, 1982) or "dry marking" (Bekoff, 1979b) usually occurs in the presence of other animals. Bekoff (1979b) suggested that RLU posture may also serve as a visual display in domestic dogs but data for coyotes are inconclusive. Detailed descriptions are provided in Sprague and Anisko (1973), Beach (1974), Peters and Mech (1975), and Bekoff (1979b). The defecation (DEF) posture resembled the SQU, however, the DEF squat $(\bar{X}=7.14$ $\mathrm{sec}, \mathrm{SD}=3.12)$ lasted significantly longer than the SQU posture $(\bar{X}=1.64 \mathrm{sec}, \mathrm{SD}=0.45)$.

\section{URINATION POSTURES AND THEIR ASSOCIATION WITH MARKING CRITERIA}

Two major questions were considered in these analyses (details are provided in Wells and Bekoff, 1981): (1) Could the various postures be differentiated and by what criteria? (2) How closely was each posture associated with marking criteria? The proportion of RLU's associated with (1) prior sniffing (92.8\%) and (2) subsequent ground scratching (25.4\%), and (3) in which the urine stream was directed at a previously observed urination $(39.8 \%)$, was significantly greater than the proportion of SQU's or FLU's that were observed in conjunction with these three marking criteria.

We also studied the ways in which they were interrelated for RLU's and SQU's. A significantly higher proportion of SQU's (12.0\%) was performed in the absence of any of the defining criteria (RLU's $=5.5 \%$ ), whereas a significantly greater percentage of RLU 's (11.6\%) incorporated all three criteria. Furthermore, a significantly higher proportion of RLU's (94.5\%) than SQU's (88\%) were marks, according to the criteria used to differentiate marking from simple elimination. Our data suggest that SQU's are more important in marking than previous studies have indicated. Different methodologies may be important to consider when comparing various urination postures. Based on an analysis of snow-tracking and observational data, we found that SQU's are grossly underestimated when snow tracking is used.

\section{Elimination "versus" Marking Revisited}

Our analysis of elimination versus marking suggests that the assumption that all urine sign found in snow may be potential marks (Barrette and Messier, 1980) is not necessarily grossly incorrect. In fact, because such a high percentage of RLU's and SQU's were "marking" by our criteria, and because our data may even be underestimates due to the difficulty of observing "everything" (for example, sniffing accompanied by slight, or no, head movements) associated with elimination even under optimal field conditions, we decided to use the terms elimination and marking synonymously for urinations deposted by either RLU's or SQU's (though the two postures could be differentiated; Wells and Bekoff, 1981).

\section{SEX, AGE, AND MARKING}

There was clear sexual dimorphism (Fig. 4) and age differences in the use of different urination behaviors (see also Kleiman, 1966; Sprague and Anisko, 1973; Beach, 1974; Peters and Mech, 1975; Bekoff, 1979b). Adult males performed the RLU posture over $78 \%$ of the time, never were observed to squat, and assumed the FLU position about $22 \%$ of the time. Adult females assumed the SQU posture $97.5 \%$ of the time and only performed the RLU four times (2.5\%); females never performed the FLU. Lastly, juveniles never exhibited the RLU position and performed SQU's (46.7\%) and FLU's (53.3\%) about the same 
proportion of time. Thus, given that a RLU was observed, the probability that it was performed by an adult male was 0.96 , the probability that it was performed by an adult female was 0.04 , and the probability that a juvenile performed the RLU was 0 . On the other hand, if a SQU was observed, the probabilities that it was performed by an adult male, adult female, or a juvenile were $0,0.96$, and 0.04 , respectively. Multivariate analyses showed that posture was the only variable separating males from females and that posture was not important without consideration of sex (Fig. 4, top). Furthermore, males could not be discriminated from females on variables other than posture (Fig. 4, bottom).

Although the trends that we observed for the relationship between sex, age, and marking postures are robust, there are few data with which we can directly compare our observations. In a study of captive coyotes, Mottus (1972) never observed males to perform RLU's. Nonetheless, our results strongly suggest that a researcher may estimate age and assign sex based on analyses of urination postures.

FIG. 4. Top: Clear-cut sexual dimorphism was evident in the elimination patterns displayed by male and female coyotes. This figure represents a two-dimensional plot of factor scores from a principal-components analysis showing that there was no overlap between males and females (from Wells and Bekoff, 1981). A second principal-components analysis was also performed in which sex was omitted from the variables considered. Results showed that posture was not important without considering sex (see Wells and Bekoff, 1981, for details). Bottom: The range of linear discriminant values for female and male coyotes cast on a female/male discriminant axis (from Wells and Bekoff, 1981). All urinations by known males were classified correctly, but two urinations by known females fell within the range of male discriminant scores. Sexes could not be discriminated on the basis of variables other than posture.
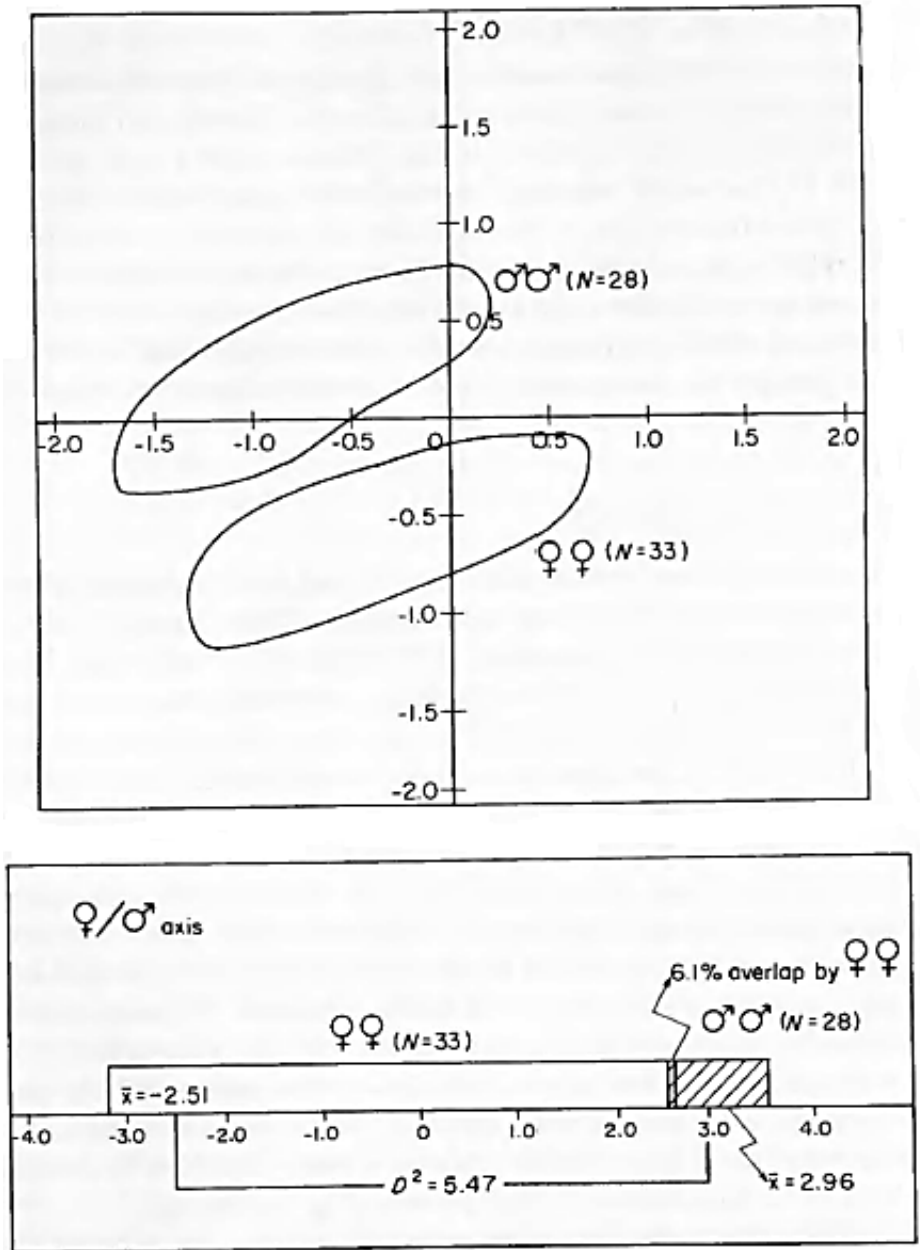
FIG. 5. Top: Monthly marking rates for urinations performed using the raised-leg (RLU) and squat (SQU) urination postures. The proportion of time that coyotes were active each month is also indicated. Marking rates were standardized to account for the actual time that coyotes were in view (coyote-hours) and active each month (from Wells and Bekoff, 1981). Bottom: Monthly marking and ground-scratching rates corrected for the actual total time that coyotes were in view each month when active and resting. GS, Ground scratching; RLU, raised-leg urination; SQU, squat urination; FLU, forward lean urination; DEF, defacation (from Wells and Bekoff, 1981).
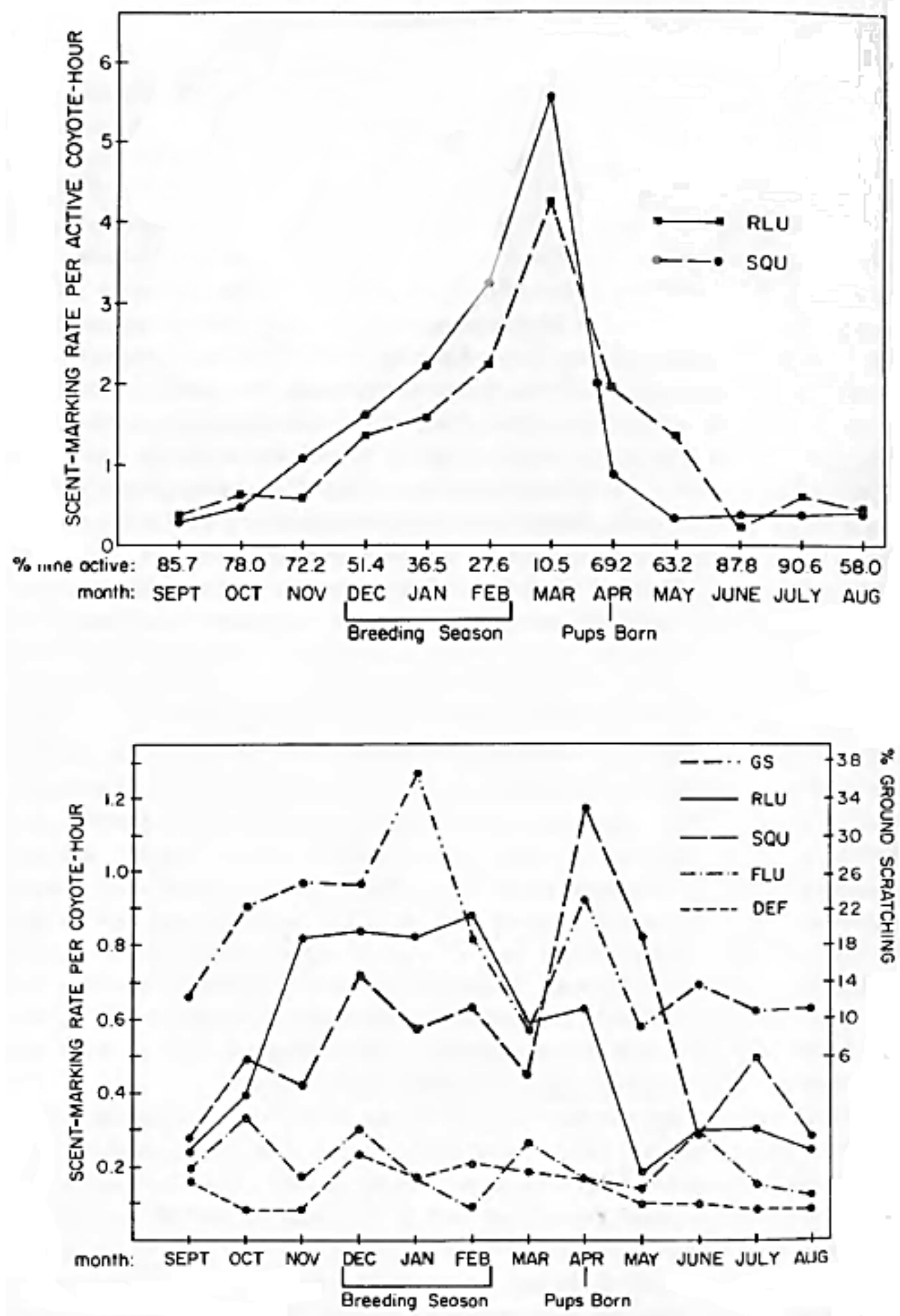


\section{E. SEASONAL TRENDS IN MARKING}

Although distinct seasonal variations were observed in marking rates, males and females were observed to mark throughout the year (Fig. 5). The negative correlation $(r=-0.99)$ between marking rate and the percentage of active time (standardized to account for coyote-hours of observation; Fig. 5, top) indicated that there was a baseline level of marking; as activity decreased, the frequency of marking increased to attain this level.

When marking rates were plotted against resting and active hours combined (Fig. 5, bottom), other trends became obvious. FLU's and DEF's were performed at a relatively low and stable rate throughout the year, whereas RLU's and SQU's were observed at higher rates and showed distinct seasonal variations. The significant increase in marking by RLU's between November and April when compared to RLU marking rate between May and October was associated with the onset of courtship (December) and extended through actual mating (mid-late February). Similar trends have been observed in captive coyotes (Mottus, 1972; Bekoff and Diamond, 1976). The sharp increase in SQU marking rates during spring (April and May) was associated with whelping and pup rearing. Lastly, ground scratching was performed at its highest rate during January, decreased during February and March, and increased again in April. Ground scratching and SQU were performed in conjunction most frequently during this period.

\section{Comparisons with Snow-Tracking Studies of Coyotes and Wolves}

Snow-tracking studies on coyotes have not documented increases in marking rates between November and March (Barrette and Messier, 1980; Bowen and McT. Cowan, 1980). Our data actually are in agreement with Barrette and Messier's (1980) and Bowen and McT. Cowan's (1980) results; seasonal changes in marking rate were small during the period of November to March. However, major changes in marking rates occurred before and after the winter breeding period. Because of the lack of snow-covered ground, snow-tracking studies are unable to document the annual changes in marking rates that we detected. Peters and Mech (1975) also found winter increases in RLU's and SQU's for wolves, and Rothman and Mech (1979) suggested that marking was important for synchronizing mating in newly paired wolves.

Another major factor that may account for the differences between our results and those stemming from yellow snow studies is that in the latter, marking rates are usually measured in marks/kilometer, which is not a measure of rate unless movement speed is taken into account and/or the actual amount of time spent in an area is determined (Barrette and Messier, 1980). The direction of movement also needs to be considered. In fact, snow-tracking results presented in terms of number of marks found per kilometer vary greatly. Ozoga and Harger (1966) reported overall rates of 0.89 marks $/ \mathrm{km}$ whereas Gipson and Sealander (1972), Barrette and Messier (1980), and Bowen and McT. Cowan (1980) listed marking rates of 5.47, 2.17, and 1.43 marks $/ \mathrm{km}$, respectively. Thus, differences between snow-tracking and observational studies are not unexpected.

\section{F. BEHAVIORAL CORRELATES, SEX DIFFERENCES, AND SOME LIKELY FUNCTIONS OF MARKING}

\section{Behavioral Correlates of Marking}

Coyotes of both sexes marked at different frequencies and rates during ongoing activity (Tables 1 and 2). Marking frequency was standardized to account for the frequencies with which the different activities were observed and the corrected values (marks/activity frequency) were then ranked. Four of the six (66.7\%) top-ranking behaviors were associated with food (hunting, digging for carrion or rodents, at carrion, and eating). While traveling, coyotes marked almost twice as frequently as they did during hunting. 
We also measured the number of minutes between successive marks. Coyotes marked about every 26 min while traveling and about every 78 min while hunting. Marking was also performed at frequent intervals during aggressive encounters and during other food-related activities, including digging and eating.

Sexual dimorphism was also apparent when we analyzed the frequency with which each elimination posture was associated with different activities (Table 2). In captive wolves, a higher percentage of RLU's than of SQU's was associated with aggression whereas the opposite relationship was found for "friendly" behaviors. For coyotes, RLU's were also more strongly associated with aggressive behavior, but we do not know if males were more aggressive than females. Neither RLU's or SQU's were strongly associated with playing or vocalizing, other highly social behaviors.

TABLE 1. THE RATE OF MARKING (MARKSIACTIVITY FREQUENCY) AND INTERVALS (MINUTES) BETWEEN MARKS DURING DIFFERENT ACTIVITIES ${ }^{\mathrm{a}}$

\begin{tabular}{|lcccc|}
\hline & & & \multicolumn{2}{c|}{ Intervals between } \\
Activity & Rate & (rank) & marks & (rank) \\
\hline Travel & 0.79 & $(1)$ & 26.0 & $(4)$ \\
Hunt & 0.41 & $(2)$ & 77.4 & $(8)$ \\
Dig & 0.38 & $(3)$ & 9.9 & $(1)$ \\
Aggression & 0.35 & $(4)$ & 13.6 & $(2)$ \\
At carrion & $(5)$ & 71.0 & $(7)$ \\
Eat & 0.32 & $(6)$ & 21.4 & $(3)$ \\
Play & 0.26 & $(7)$ & 63.8 & $(6)$ \\
Lie & 0.12 & $(8.5)$ & 699.3 & $(11)$ \\
Roll on ground & 0.07 & $(8.5)$ & 33.5 & $(5)$ \\
Vocalize & 0.07 & $(10)$ & 128.7 & $(9)$ \\
Sit & 0.06 & $(11)$ & 157.0 & $(10)$ \\
\hline
\end{tabular}

${ }^{\mathrm{a}}$ From Wells and Bekoff (1981).

In contrast to aggressive behavior, SQU's were more closely associated with food-related activities such as hunting, eating, and directly marking food objects such as bones, ungulate carrion, and dead rodents. SQU'S and RLU's were directed at food items about 18.5 and $5.5 \%$ of the time, respectively. It is possible that marking food objects (or caches) may serve some type of bookkeeping function, indicating that food is no longer available at a specific site although food odors may still persist (Henry, 1977; Harrington, 1981). Defecations were performed proportionately more at carrion than any of the urination postures, producing a latrine effect also noted by Camenzind (1978) and Bowen and McT. Cowan (1980). Clumped feces were not found anywhere else in coyotes' home ranges or territories.

Sex Differences in the Functions of Marking. Marking by females may serve important functions that are distinct from those associated with male marking, and which may be easily overlooked, especially in snow-tracking studies in which SQU's are underestimated due to the difficulty of finding them. Generally, SQU's were associated with the acquisition and possession of food, with the denning season, and with the location of the den itself. High rates of marking around the den may help to develop and maintain sitespecific familiarity for young pups.

In contrast to SQU'S, RLU's were associated with courtship and mating, traveling, and aggression, and were performed at a high rate by some pack members in areas of high intrusion. Male marking is 
probably important in promoting reproductive synchrony and demonstrating mate possession, and may provide olfactory and/or visual signs concerning territorial boundaries.

TABLE 2. THE FREQUENCIES WITH WHICH URINATION POSTURES AND DEFECATION WERE OBSERVED IN ASSOCIATION WITH ONGOING ACTIVITY ${ }^{\mathrm{a}}$

\begin{tabular}{|lccccc|}
\hline Activity & RLU & SQU & FLU & DEF & Total \\
\hline Hunt & 12 & 78 & 7 & 12 & 109 \\
& $(6.6 \%)$ & $(32.2 \%)$ & $(8.2 \%)$ & $(22.2 \%)$ & $(19.4 \%)$ \\
Travel & 127 & 94 & 58 & 28 & 307 \\
& $(70.2 \%)$ & $(38.8 \%)$ & $(68.2 \%)$ & $(51.9 \%)$ & $(54.6 \%)$ \\
Eat & 4 & 28 & 5 & 1 & 38 \\
& $(2.2 \%)$ & $(11.6 \%)$ & $(5.9 \%)$ & $(1.8 \%)$ & $(6.8 \%)$ \\
Roll on ground & 1 & 1 & 0 & 0 & 2 \\
& $(0.6 \%)$ & $(0.4 \%)$ & & & $(0.3 \%)$ \\
Dig & 3 & 9 & 2 & 1 & 15 \\
& $(1.7 \%)$ & $(3.7 \%)$ & $(2.3 \%)$ & $(1.8 \%)$ & $(2.7 \%)$ \\
Lie & 6 & 8 & 3 & 7 & 24 \\
& $(3.3 \%)$ & $(3.3 \%)$ & $(3.5 \%)$ & $(13.0 \%)$ & $(4.3 \%)$ \\
Play & 2 & 2 & 4 & 0 & 8 \\
& $(1.1 \%)$ & $(0.8 \%)$ & $(4.7 \%)$ & & $(1.4 \%)$ \\
Aggression & 14 & 8 & 1 & 2 & 25 \\
& $(7.7 \%)$ & $(3.3 \%)$ & $(1.2 \%)$ & $(3.7 \%)$ & $(4.4 \%)$ \\
Vocalize & 1 & 1 & 1 & 0 & 3 \\
Sit & $(0.6 \%)$ & $(0.4 \%)$ & $(1.2 \%)$ & & $(0.5 \%)$ \\
& 1 & 0 & 1 & 0 & 2 \\
At carrion & $(0.6 \%)$ & 18 & $(1.2 \%)$ & & $(0.3 \%)$ \\
& $(6.6 \%)$ & $(7.4 \%)$ & $(5.9 \%)$ & $(8.2 \%)$ & $(8.2 \%)$ \\
\hline
\end{tabular}

${ }^{a}$ From Wells and Bekoff (1981). The numbers in parentheses are percentages standardized to account for the frequencies with which the different activities occurred.

FIG. 6. The percentage of group marks observed on a monthly basis (actual percentage) and the percentage of group marks adjusted to account for monthly differences in group sizes (from Wells and Bekoff, 1981).

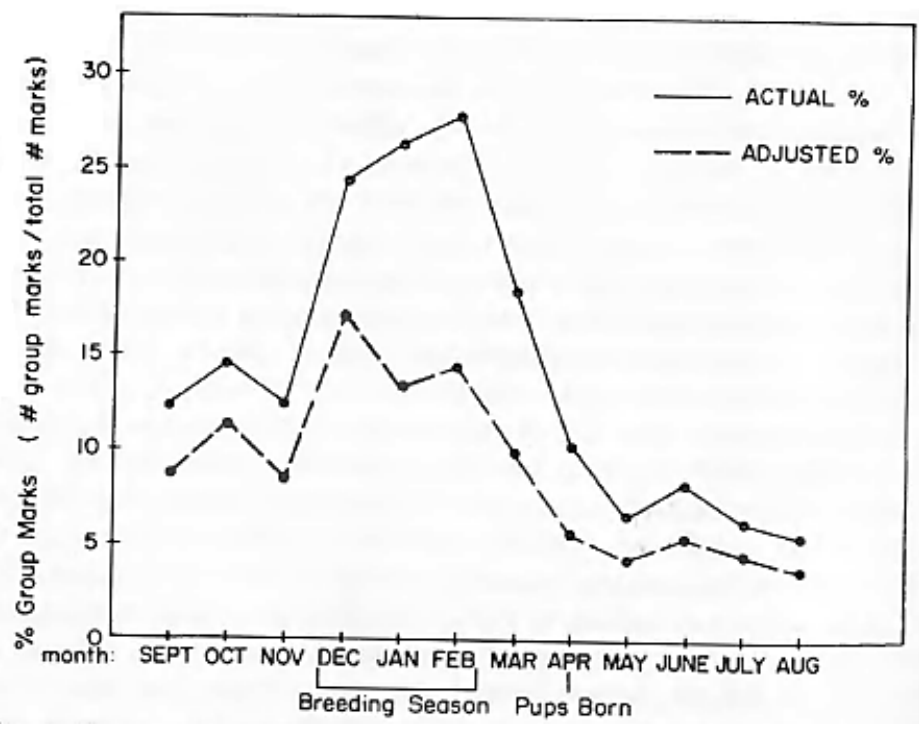




\section{Group Influences on Marking and Ground Scratching}

a. Marking Rates. Group size influenced marking rates (Table 3, Fig. 6) (see also Barrette and Messier, 1980; Bowen and McT. Cowan, 1980). A significantly higher marking frequency per coyote was observed for groups of three individuals than for solitary animals, pairs, and groups of four animals. There was no difference in marking rate for singletons and pairs, but individuals in groups of four showed higher rates than did single animals or pairs. Barrette and Messier (1980) reported higher marking rates, in terms of marks per kilometer, for pairs (2.8) than for single coyotes (1.25). Peters and Mech (1975) found no relationship between estimated wolf pack size and individual marking rates. In wolves, marking is typically performed by dominant animals, and consequently the number of marking wolves is independent of group size. Our results indicate that all coyotes in a group may mark, but at different rates.

TABLE 3. RELATIONSHIPS AMONG COYOTE GROUP SIZE, RATES OF MARKING (MARKSICOYOTE), AND GROUND SCRATCHING (GS) ${ }^{\mathrm{a}}$

\begin{tabular}{|cccc|}
\hline Group size $(\boldsymbol{M})$ & Marks/coyote & GS & $\begin{array}{c}\text { Percentage of } \\
\text { marks followed by GS }\end{array}$ \\
\hline $1(505)$ & 0.38 & 20 & 10.3 \\
$2(160)$ & 0.33 & 18 & 16.8 \\
$3(78)$ & 0.71 & 35 & 21.0 \\
$4(39)$ & 0.58 & 17 & 18.7 \\
$5(14)$ & 0.01 & --- & -- \\
$6(6)$ & 0.06 & --- & -- \\
\hline
\end{tabular}

${ }^{a}$ From Wells and Bekoff (1981). N, Frequency observed.

b. Series Marking. Series marking, in which more than one coyote marked in succession, also was observed (Fig. 6). Forty-six of $76(60.5 \%)$ series marks involved 2 coyotes, 25 (32.9\%) involved 3 animals, and $5(6.6 \%)$ involved 4 individuals. The highest percentage of group marks was observed between December and March. This trend also was obvious when the percentage of group marks was corrected to account for monthly differences in group size.

c. Ground Scratching. Ground scratching also showed a significant increase in groups of three coyotes compared to solitary animals, but there were no significant differences among all other group sizes. When the percentage of marks followed by ground scratching for single coyotes was compared to the overall percentage for groups of two to four individuals, a significant difference was detected. The increase in ground scratching in groups of two or more coyotes is consistent with Barrette and Messier's (1980) results.

d. Ground Scratching as a Composite Signal. Often discussed as a visual display (Bekoff, 1979b,c) or as part of a composite signal (Bekoff, 1979c) combining visual and olfactory cues, the act of ground scratching may stimulate other coyotes to do likewise. Actually, all visual components of scent marking may be releasers for marking by nearby animals (Golani and Keller, 1975; Bekoff, 1979b) and may explain why in some species there is increased marking in larger groups. Along these lines, Barrette and Messier (1980) reported that solitary coyotes did not perform ground scratching. Bowen and McT. Cowan (1980) observed increased ground scratching at territory edges, where a coyote could be observed in the act of scratching. Also, a visible slash or odor produced by foot glands might be encountered by potential intruders at a later time. 
3. The Spatial Distribution of Marks and Its Relationship to Territorial Behavior: Is There a Division of Labor among Pack Members?

Combined marking patterns displayed by all members of the main pack were analyzed. First, we calculated the marking frequencies in known denning areas, in areas of high intrusion (there was an actively defended boundary) by nonpack coyotes, and in low intrusion areas. Marks were nonrandomly distributed among the different areas; SQU's occurred most frequently around the major denning areas and in high intrusion areas whereas RLU's were mainly observed in areas of high intrusion. However, individual differences may be important to consider. For example, frequency data analyzed for two individuals throughout the year indicated that at least for the reproductive male (Father 1, Fig. 2) and his first mate (Mother 1, Fig. 2), RLU's (Fig. 7a) and SQU's (Fig. 7d) were randomly distributed throughout the group's territory.

a. Division of Labor in Individual Marking Patterns. Frequency measures can lead to misleading conclusions because they do not take into account the amount of time spent in a given area. Rate measures are more precise. Based on yearly calculations, about the same percentage of time was spent by the group in denning areas (31.2\%) and areas of low (34.7\%) and high intrustion (34.2\%). However, overall combined marking rates were greatest in areas of high intrusion ( 0.72 marks $/ \mathrm{hr})$ than in denning (0.08 marks $/ \mathrm{hr}$ ) or low intrustion (0.21 marks/hr) areas. There were no differences in marking rates between denning and low intrusion areas when viewed on an annual basis.

Once again, individual variation needs to be considered. For example, during the winter months, both Father 1 and Mother 1 showed random marking rates throughout their territory (Fig. 7c and f) but both individuals showed highest marking rates in and around denning areas during summer (Fig. $7 \mathrm{~b}$ and e). These data suggest that pack members other than the mated pair were more likely to mark in areas of high intrusion during winter. If some individuals mark more on territory boundaries and in areas of high intrusion while others distribute their scent throughout a territory, then an intruder that ignores a mark on a boundary or trespasses where no scent was deposited, is still likely to encounter urine sign within a group's territory. A division of labor in marking among pack members may ensure that most of a territory, including its borders, are covered with scent.

b. Marking and Its Suggested Role in Territorial Behavior. For most mammals, including canids and other carnivores, the question of whether or not marking is important in territorial behavior is an open one, because sufficient data do not exist (Eisenberg and Kleiman, 1972; Macdonald, 1980; Gosling, 1982; Gorman and Mills, 1984). One not only has to demonstrate that a given group or individual is territorial, but it also must be shown that marking is closely related to the acquisition and/or maintenance of a specific defended area. For coyotes and other wide-ranging species, these are difficult tasks (Gipson and Sealander, 1972; Macdonald, 1980; Bekoff, 1977a, 1982). Furthermore, the emphasis on marking and possible territorial functions has overshadowed other important functions that marking may serve such as in allowing sex recognition, synchronizing reproductive behavior, and labeling depleted food caches. Nonetheless, circumstantial evidence and "gut feelings" do indicate that marking and territorial behavior are closely associated in various mammals.

c. Summary. Our results along with Bowen and McT. Cowan's (1980) data suggest that marking by coyotes may serve some territorial function, but the data are not clear-cut. Furthermore, individual differences must be given more consideration. There is no solid evidence that marks serve as some type of barrier through which trespassers will not go (Scott, 1967; Peters and Mech, 1975; Bekoff, 1979b; Rothman and Mech, 1979; Bowen and MeT. Cowan, 1980). In addition, scent marks may serve as signals to avoid another pack's territory (Peters and Mech, 1975; Rothman and Mech, 1979), but whether potential trespassers are avoiding the pack's marks or the pack itself is not clear. Field observations of 
coyotes have shown that neighboring coyotes will trespass frequently into a pack's territory, and there is no evidence that indicates that scent deposits are avoided. A voidance occurred when the resident animals were encountered.

FIG. 7. Three-dimensional plots of the distribution of urine marks shown by Dad (pack father 1) and Mom (pack mother 1) throughout their territory around Blacktail Butte. The observation point indicated here refers to the star on the left in Fig. 1. The percentage of marks found in different grids is indicated by the height of the $z$ axis. Overall frequency distributions are shown in $a$ and $d$, and summer and winter rates of marking are presented in the other four plots. The two summer peaks were located in denning areas.

(a) Dad: Frequency Distribution of Raised-leg Urinations ("RLU")

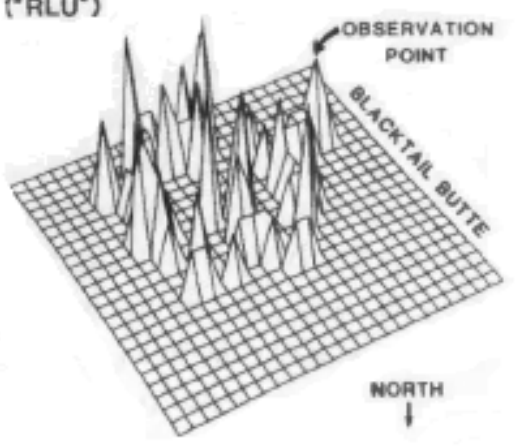

(b) Dad: Summer "RLU" Rate

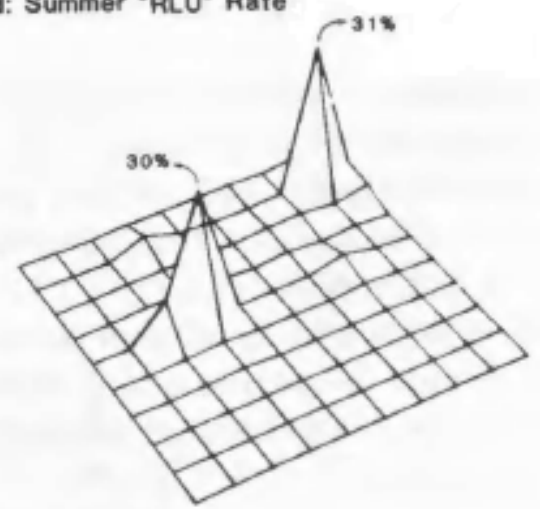

(c) Dad: Winter "RLU* Rate
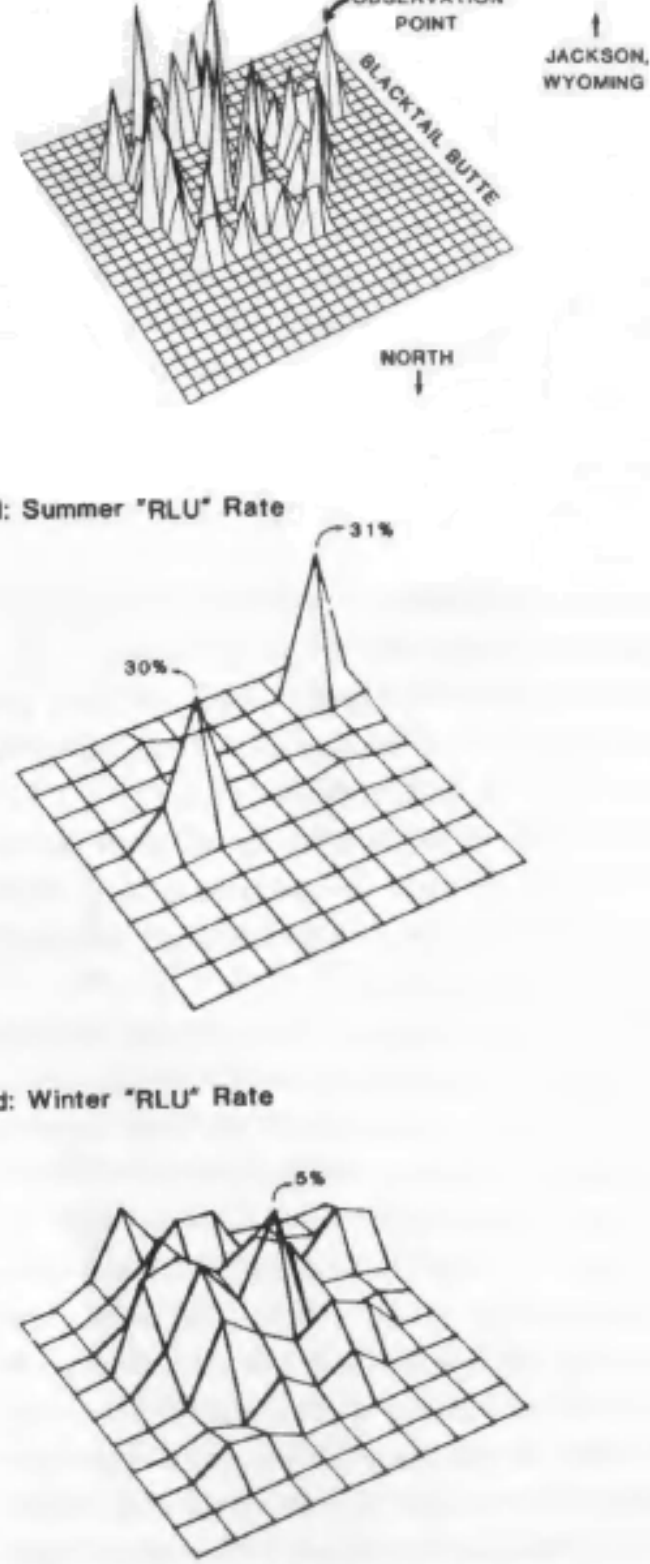

(d) Mom: Frequency Distribution of Squat Urinations ("sou")

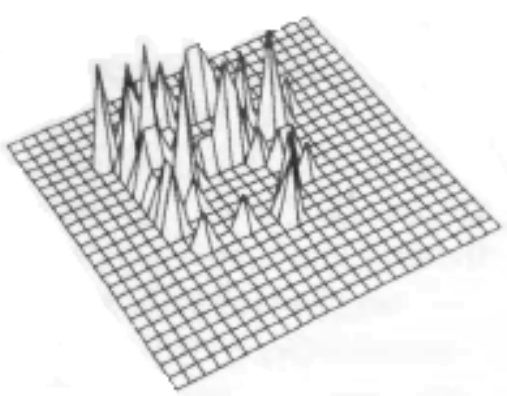

(e) Mom: Summer "sou" Rate

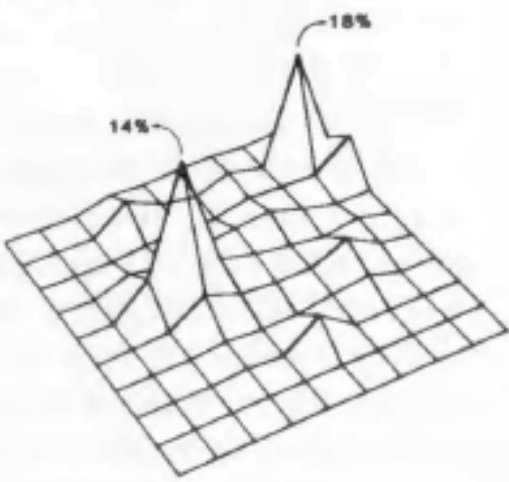

(f) Mom: Winter "SQU" Rate

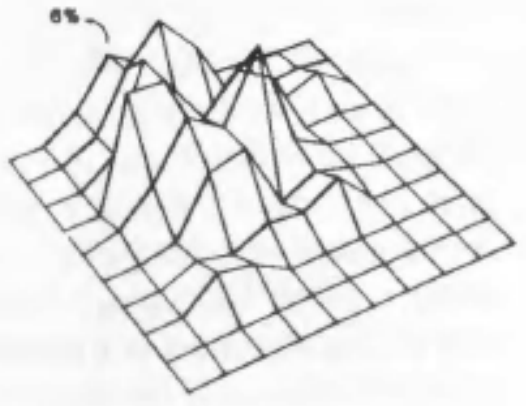

Basically, our data indicate that, among other functions, scent deposits may advertise territorial boundaries, and that this information can be used in different nonexclusive ways. Odors may (I) inform 
trespassers that they are trespassing and to avoid other animals when they are encountered (Gosling, 1982) and (2) indicate to residents that they are in their own territory. Marks deposited randomly throughout a territory may serve as reinforcers. As Gorman and Mills (1984) noted, one should expect to find that marks are distributed in a way that maximizes their chances of being encountered. Environmental landmarks and vocalizations may also be useful for spatial orientation (Lehner, 1978b, 1982). Future research should concentrate on determining the type of division of labor among group members that is involved in scent marking for territorial purposes. Our results suggest that a mated pair may play less of a role than other individuals.

\section{BEHAVIORAL AND ECOLOGICAL ASPECTS OF PREDATION}

\section{A. PREDATION ON SMALL MAMMALS}

An understanding of the ways in which animals acquire food and of the diverse, but interrelated, variables that influence how food is gathered, are necessary ingredients for a comprehensive analysis of the behavior and ecology of any species (Ewer, 1968, 1973; Eisenberg and Leyhausen, 1972; Kruuk, 1972; Schaller, 1972; S. A. Altmann, 1974; Curio, 1976; Rowe-Rowe, 1978; Eisenberg, 1981; Andelt, 1982; Bekoff, 1983; Macdonald, 1983; Terborgh, 1983; Bekoff et al., 1984; Gittleman, 1984; van Orsdol, 1984). Here we discuss various topics related to predatory habits of coyotes on major small $(<1 \mathrm{~kg})$ prey items such as voles (Microtus spp.), Uinta ground squirrels, and pocket gophers (Thomomys talpoides). Intraspecific predation is rare (Polis et al., 1984).

Rodents constitute the bulk of live prey in coyotes' diets living on our study area and at other locations. Usually, coyotes hunt small rodents singly, although two or more coyotes may hunt together but not necessarily cooperatively. Data concerning cooperative or coordinated hunting endeavors for prey of any size are limited to general accounts (Hamlin and Schweitzer, 1979; Rathbun et al., 1980). It is not obvious that coyotes hunt cooperatively on any regular basis, even for prey larger than themselves. Detailed data similar to those presented here are very limited because of the difficulty of observing predation on small prey under field conditions (Kruuk, 1978; Macdonald, 1980).

\section{B. FOOD HABITS, ESTIMATED NEEDS, AND PREY SELECTION}

\section{Food Habits}

Coyotes are versatile and opportunistic predators that eat a wide variety of items (live animal and carrion, plant, and inanimate objects), the percentage of which by volume and weight varies individually, seasonally, and regionally (Young and Jackson, 1951; Gier, 1968; Bekoff, 1977a). Korschgen (1957) listed 56 animal, 28 plant, and 6 miscellaneous food items for coyotes living in Missouri. Coyotes will even fish (Springer, 1980), swim (Barklow and Chamberlain, 1984), and climb trees (P. K. Anderson, personal communication) for food. Overall, about $90 \%$ of coyotes' diet is mammalian flesh. During winter months, especially in northern locales, much of the coyote's diet is made up of the carrion of large game animals, especially ungulates. In spring and summer there typically is an increase in the percentage (by volume and weight) of various rodents (Bekoff, 1977a; see also Weaver, 1977, 1979; Camenzind, 1978; Bowen, 1978).

\section{Energetic Needs}

Gier (1975) estimated that captive coyotes require about $600 \mathrm{~g}$ of food a day, but the energy demands of wild individuals may be three times greater than those of captive animals (Litvaitis and Mautz, 1980). Energetic needs undoubtedly depend on weather, the nature of intraspecific and interspecific encounters, including competition for various resources, reproductive condition, and food availability. Based on data 
collected during daylight periods of observation when voles and ground squirrels were available as prey (mid-April to mid-August), we estimated than an individual coyote on our study area consumed about 930 $\mathrm{g}$ of food daily (see below). This is undoubtedly an underestimate because not all predatory attempts or captures were observed, especially at night.

\section{Prey Selection of Large Species}

Coyotes and other medium-sized predators will attempt to kill large, wild ungulates with occasional success (Murie, 1940; Young and Jackson, 1951; Bekoff, 1977a; MacConnell-Yount and Smith, 1978), and may even be harassed by them in return (Berger, 1979; Lipetz, 1980; Lipetz and Bekoff, 1980, 1982; Byers and Byers, 1983; Reynolds, 1983). However, in most instances large prey animals do not constitute a major food supply except when alternative resources are limited or when young, old, sick, or otherwise defenseless (for example, domesticated) individuals are encountered (but see Hewson, 1984). In one captive study of coyote-sheep encounters, latency to attack plus killing time averaged about $1 \mathrm{hr}$, and there was significant individual variability (Connolly et al., 1976). Defensive behavior by sheep deterred coyotes only $31.6 \%$ of the time.

The precise impact that coyotes have on wild and domestic populations of large ungulates is hard to assess reliably, because of the difficulty of distinguishing "coyote kills" from those of other predators, including domestic dogs (Ogle, 1971; Davenport et al., 1973). In our study area (Fig. 3) and in other regions, large ungulates are typically consumed by coyotes as carrion, especially during winter (Murie, 1951; Bekoff, 1977a; Weaver, 1977; Camenzind, 1978; Houston, 1978). Ogle (1971) listed five criteria that possibly could be used to distinguish deer killed by coyotes from those consumed as carrion. These included (1) large patches of hide leading to the carcass, (2) separation of the vertebral column in the thoracolumbar region of adults and at the atlas of fawns, (3) nasal and maxillary bones chewed away, (4) chewed ribs, vertebrae, and scapulae, and (5) widely scattered limbs. However, we have observed similar patterns on carcasses known to be carrion.

In contrast to adults, fawns (for example, mule deer, Odocoileus hemionus, and pronghorn, Antilocapra americana) are much more vulnerable to coyotes and other predators. Fawns will be taken when they are readily available (Murie, 1940; Young and Jackson, 1951; Truett, 1979; Andelt, 1982; Byers and Byers, 1983; Hamlin et al., 1984) or when other food resources are less abundant. Hamlin et al. (1984) reported that coyotes in north central Montana were responsible for about $90 \%$ of the summer mortality of mule deer fawns, and that fawn mortality was lowest when microtine rodent populations were high. They also found that the mortality rate of fawns was not related directly to population levels of coyotes.

\section{PREDATORY SKILLS}

\section{Basic Behavior Patterns}

Despite widespread interest in coyotes as predators on large game species and livestock, there are suprisingly few data from systematic field studies of coyote predatory behavior. In general, predation may be viewed as three-part series of events consisting of prey detection, capture, and consumption (Wells and Bekoff, 1982). Movement by prey is a key stimulus for initiating predatory sequences. Detailed ethograms are presented in Fox (1969b, 1971), Bekoff (1978b), and Vincent and Bekoff (1978). Bekoff (1978b) listed 25 different acts including searching, orienting, approaching, stalking, following, chasing, sniffing, licking, pawing, pouncing, pinning, biting, lifting, carrying, tossing, withdrawing, and eating. Under field conditions, Wells and Bekoff (1982) found that the time devoted to searching was the most lengthy component of hunting sequences and that it correlated significantly with total sequence duration. Also, 
only the duration of stalking was related to hunting success. Mean stalk duration of successful hunting sequences was significantly longer and more variable than for unsuccessful attempts.

Coyotes and many other carnivores are adapted for a cursorial existence and hunt mainly by pursuit. Ozoga and Harger (1966) reported that coyotes chased deer an average distance of only about $55 \mathrm{~m}$ and two long, futile attempts of 4.32 and $4.64 \mathrm{~km}$ were observed. Chase distance undoubtedly depends on a number of variables including mobility, which can vary with snow cover, grass height, and terrain, the physical condition of the predator and prey, and how experienced each is in these types of encounters. Vision and olfaction are primarily used, with the relative importance of each depending on habitat (Wells, 1978; Wells and Lehner, 1978; Wells and Bekoff, 1982; see below).

Actions used during capture attempts vary with prey type, size, and the way in which prey react to being chased or caught. A shearing bite and bite-and-tear sequences are commonly used on large prey, whereas for smaller mammals stalking and pouncing are employed, and biting is often accompanied by rapid shaking of the head from side to side. Bites oriented to the head, neck, and throat are frequently used on sheep and deer (Ozoga and Harger, 1966; White, 1973; Connolly et al., 1976), as are belly and rump attacks (Ogle, 1971). Squirrels are typically stalked, then rushed at and run down, whereas when hunting mice, coyotes usually stalk them and then pounce and stab at them with their forepaws (Wells and Bekoff, 1982).

Development of Predatory Behavior. Because of practical problems involved in watching small altricial animals of known age who remain in the vicinity of parents and possibly other caretakers during early life, and who also live in visually inaccessible places such as dens, developmental studies are generally conducted in captivity (Bekoff and Byers, 1985). This has been the case for detailed analyses of the development of predatory behavior in coyotes and other carnivores (Fox, 1969b, 1971; Rasa, 1973; Bekoff, 1978b; Vincent and Bekoff, 1978; Leyhausen, 1979; Markstein and Lehner, 1980; Biben, 1982). It also should be stressed that because of species differences in developmental rates, ontogenetic comparisons across taxa, even among closely related species, may be of limited value. For example, some of the less social canids appear to show more rapid motor development than do more social congeners (Fox, 1971; Bekoff, 1978b). Because predatory behavior requires various motor and cognitive skills working in conjunction with one another, cross-sectional age comparisons may be weakened in cases where developmental profiles of motor abilities differ.

The results of developmental analyses of predation in captive coyotes can be summarized as follows (Bekoff, 1978b):

1. There were distinct individual differences in the reaction of young coyotes to small prey such as chickens, mice, and rats. All individuals did not attempt to kill prey; some coyotes played with it, while other animals showed no interest at all. After continual exposure to prey, coordinated sequences of predatory acts developed in most pups. Observational and trial-and-error learning seem to be important in the acquisition and refining of predatory skills (Fox, 1969b). Increased motor abilities and coordination are also related to heightened success in predator-prey encounters.

2. There were no apparent sex differences in the ontogeny of predatory skills.

3. An individual's social rank was not correlated with prey-killing success.

4. Neither early social play nor combative experience with littermates or peers was correlated with later predatory success (Vincent and Bekoff, 1978), but previous play with prey may have a role in the development of predatory skills (Markstein and Lehner, 1980). It is interesting to note that Schaller (1972) found that stalking was an important component of predatory behavior in African lions, but that stalking was not observed in lion play. The repeated performance of predatory acts during play and other forms of activity may contribute beneficially to the general physical fitness of an individual and 
may also be important in overall physical training, including development of joints, bones, and muscles (Bekoff and Byers, 1981, 1985; Fagen, 1981; Bekoff, 1984). Perceptual (cognitive) abilities may also be enhanced as a result of play and other motor activities (Bekoff and Byers, 1981).

5. Social facilitation was observed. When two or more infants were placed together, there was a decrease in the latency to kill.

6. Young coyotes appeared to be using lie-of-the-hair as a directional cue for orientation to the head region of prey.

7. Blood did not appear to act as a sensitizer triggering the consummatory act of ingestion, as was found for infant wolves and gray foxes (Urocyon cineroargenteus; Fox, 1969b).

Quantitative field data on the development of predatory behavior are less detailed and can be summarized as follows (Wells and Bekoff, 1982):

1. There was no correlation between the number of acts performed in a predatory sequence and the age of coyotes. The mean length of hunting sequences was about the same for adults $(212 \mathrm{sec})$ and juveniles (201 sec) and mean durations of searching, orienting, and stalking were unaffected by age.

2. When corresponding cells in matrices describing two-act transitions were compared for adult-vole and juvenile-vole encounters (juveniles were 5-9 months of age), the same two acts occurred in sequence with about the same ranked conditional probability relative to all other pairs of acts (for example, search-orient, search-stalk, orient-pounce). These data suggest that by the time coyotes are about 59 months of age, predatory sequences resemble those of adults in structure and length [see (1) above].

3. Adults (27\%) and juveniles (18\%) were about equally successful $(p>0.05)$ in their encounters with small prey.

It usually is the case that information concerning almost all behavioral phenotypes is incomplete until developmental data are available (Bekoff and Byers, 1985), and this definitely holds for predatory skills. Systematic studies are needed for larger samples of captive and wild coyotes in order to gain a more thorough understanding of how predatory behavior develops and changes as a function of age and experience, and how individual differences emerge.

\section{ENVIRONMENTAL INFLUENCES ON PREDATORY SEQUENCES: A SENSORY ECOLOGICAL PERSPECTIVE ON HUNTING}

Predatory behavior and capture success can be strongly influenced by a number of environmental variables (Curio, 1976; Elliott, et al., 1977; Leyhausen, 1979; Wells and Bekoff, 1982; van Orsdol, 1984). Here we consider the effects of habitat, wind conditions, and prey type, but not age of prey (Hastings, 1984). Data are taken from Wells and Bekoff (1982).

\section{Habitat}

a. Grass Height. During summer, our field site was covered by short (<10 cm high; cropped by cows) and tall grass (up to $1 \mathrm{~m}$ high). Vole hunts took place predominantly in tall grass whereas squirrels typically were pursued in the short grass where they lived. Grass height, when compared to snow depth, wind conditions, and prey type, accounted for the greatest proportion of variability in the duration of search $(p=$ $0.05)$, orient $(p=0.02)$, and total sequence length $(p=0.009)$, and for the second largest percentage of variability in stalk duration $(p=0.06)$. Mean durations of search, orient, and stalk were significantly longer in short grass but total sequence duration was about the same in both short and tall grass (Table 4). Although voles were usually hunted in tall grass, mean search, orient, and total sequence durations were greater when they were hunted in short grass. The variability of act durations also was influenced by 
grass height. Stalk, orient, and total durations were more variable in short grass whereas search duration was about equally variable in both short and tall grass.

TABLE 4. MEAN DURATIONS (IN SECONDS) OF THREE PREDATORY ACTS AND TOTAL SEQUENCE LENGTH IN DIFFERENT HABITATS (SHORT AND TALL GRASS: SHALLOW AND DEEP SNOW) AND FOR ENCOUNTERS WITH FOUR DIFFERENT PREY TYPES ${ }^{a}$

\begin{tabular}{|c|c|c|c|c|c|c|c|c|c|c|c|}
\hline \multirow[b]{2}{*}{ Act } & \multicolumn{3}{|c|}{ Grass height } & \multicolumn{3}{|c|}{ Snow depth } & \multicolumn{5}{|c|}{ Prey type } \\
\hline & $\begin{array}{c}\text { Short } \\
(<10 \mathrm{~cm})\end{array}$ & Tall & $p$ & $\begin{array}{l}\text { Shallow } \\
(<10 \mathrm{~cm})\end{array}$ & Deep & $p$ & $\begin{array}{l}\text { Ground } \\
\text { squirrel }\end{array}$ & $\begin{array}{l}\text { Pocket } \\
\text { gopher }\end{array}$ & Vole & Grasshopper & $p$ \\
\hline Search & $\begin{array}{c}154.6 \\
(144.8)\end{array}$ & $\begin{array}{l}106.3 \\
(92.5)\end{array}$ & 0.004 & $\begin{array}{l}102.5 \\
(85.6)\end{array}$ & $\begin{array}{c}268.3 \\
(203.6)\end{array}$ & 0.002 & $\begin{array}{c}193.2 \\
(179.5)\end{array}$ & $\begin{array}{c}185.8 \\
(124.9)\end{array}$ & $\begin{array}{l}117.3 \\
(105.9)\end{array}$ & $\begin{array}{c}82.5 \\
(82.5)\end{array}$ & 0.001 \\
\hline Orient & $\begin{array}{c}54.8 \\
(69.4)\end{array}$ & $\begin{array}{c}33.9 \\
(33.3)\end{array}$ & 0.028 & $\begin{array}{c}27.4 \\
(20.6)\end{array}$ & $\begin{array}{c}181.4 \\
(326.9)\end{array}$ & 0.018 & $\begin{array}{c}56.7 \\
(55.9)\end{array}$ & $\begin{array}{c}44.6 \\
(29.3)\end{array}$ & $\begin{array}{c}47.0 \\
(95.6)\end{array}$ & $\begin{array}{c}17.7 \\
(17.8)\end{array}$ & NS \\
\hline Stalk & $\begin{array}{c}56.4 \\
(111.7)\end{array}$ & $\begin{array}{c}13.6 \\
(13.8)\end{array}$ & 0.016 & $\begin{array}{c}7.8 \\
(4.7)\end{array}$ & $\begin{array}{l}15.7 \\
(8.5)\end{array}$ & 0.05 & $\begin{array}{c}82.1 \\
(132.1)\end{array}$ & $\begin{array}{c}19.0 \\
(0 ; N=1)\end{array}$ & $\begin{array}{c}12.9 \\
(12.2)\end{array}$ & $\begin{array}{c}5.1 \\
(6.7)\end{array}$ & 0.001 \\
\hline $\begin{array}{l}\text { Total } \\
\text { duration }\end{array}$ & $\begin{array}{c}213.8 \\
(190.5)\end{array}$ & $\begin{array}{c}178.4 \\
(121.4)\end{array}$ & NS & $\begin{array}{c}144.2 \\
(101.3)\end{array}$ & $\begin{array}{c}299.1 \\
(289.0)\end{array}$ & 0.02 & $\begin{array}{c}289.7 \\
(230.7)\end{array}$ & $\begin{array}{c}198.3 \\
(133.9)\end{array}$ & $\begin{array}{c}188.8 \\
(145.7)\end{array}$ & $\begin{array}{c}98.7 \\
(76.6)\end{array}$ & 0.001 \\
\hline
\end{tabular}

Only vole hunts were used in the snow analysis. Means were compared by analyses of variance and Scheffe procedures (from Wells and Bekoff, 1982). Numbers in parentheses are standard deviations; NS, $p>0.05$.

b. Snow Depth. Major portions of the study site were covered with measurable snow from about December to April. Snow depth as well as grass height influenced hunting attempts on voles (squirrels were hibernating at this time; Table 4) because mobility and prey detection were more difficult, especially in deep snow. The mean durations of all acts, including total sequence time, were longer in deep snow ( $>$ about $10 \mathrm{~cm}$ but usually $<1 \mathrm{~m}$ ) than in shallow snow. Mean orient and total durations were also significantly more variable in deep snow.

\section{Wind Conditions}

Local wind conditions influenced hunting patterns but did not affect capture success (Table 5). Coyotes showed a significant tendency to approach voles from downwind, probably using olfactory cues to locate animals hidden in tall grass. There was no obvious relationship among orientation, approach, and wind direction when squirrels were hunted, most probably because they were visible to coyotes in the short grass where they lived and were sought most frequently. With the exception of searching, which was significantly longer when there was a crosswind between coyotes and prey, wind direction had little effect on mean act durations. Search, stalk, and total durations showed greatest variability when there was no wind. The least amount of variability was found for search, orient, stalk, and total durations when coyotes approached prey from downwind.

\section{Prey Type}

About the same number of acts per sequence (4.2-5.9) was used by adults, juveniles, and pups regardless of prey type. As mentioned above, ground squirrels typically were rushed and run down whereas coyotes usually pounced on and stabbed at voles with their forepaws When squirrels and gophers were hunted, search durations were significantly longer than when voles or grasshoppers were sought (Table 4), but prey type did not influence the duration of orienting. Stalking duration was longest for encounters with squirrels and showed greatest variability. In contrast, orienting was more variable in encounters with voles. The variability of mean search durations was about the same for attempts on 
squirrels and voles. Finally, the size of prey last eaten affected the interval to initiation of the next search by an individual coyote. As prey size increased, there was a longer wait until the next search began (also see Elliott et al., 1977; van Orsdol, 1984). The mean interval until the initiation of-the next search after voles, gophers, and squirrels were last eaten was 103, 339, and $607 \mathrm{sec}$, respectively.

TABLE 5. RELATIONSHIPS BETWEEN MEAN CAPTURE SUCCESS AND AGE OF COYOTES, PREY SPECIES, WIND DIRECTION, GRASS HEIGHT, AND SNOW DEPTH ${ }^{\mathrm{a}}$

\begin{tabular}{|llcc|}
\hline & Variable & $\begin{array}{c}\text { Mean capture success } \\
(\%)\end{array}$ & $\boldsymbol{p}$ \\
\hline Age & Pup $(n=49)$ & 45 & \\
& Adult $(n=348)$ & 27 & $<0.001$ \\
Prey type & Juvenile $(n=133)$ & 18 & \\
& Pocket gopher $(n=18)$ & 83 & \\
& Grasshopper $(n=50)$ & 54 & $<0.001$ \\
& Ground squirrel $(n=68)$ & 41 & \\
Wind direction & Vole $(n=394)$ & 18 & \\
& Downwind (prey was downwind from coyote) & 41 & \\
& Crosswind $(n=45)$ & 27 & \\
& Upwind $(n=115)$ & 22 & $<0.05$ \\
Grass height & No wind $(n=239)$ & 22 & \\
& Short $(<10 \mathrm{~cm} ; n=45)$ & 48 & $<001$ \\
Snow depth & Tall $(n=275)$ & 16 & \\
& Shallow $(<10 \mathrm{~cm} ; n=45)$ & 21 & \\
& Deep $(n=49)$ & 8 & \\
\hline
\end{tabular}

${ }^{\mathrm{a}}$ Means were compared by analyses of variance and Scheffe procedures (from Wells and Bekoff, 1982).

\section{Environmental Influences on Hunting Success}

Mills (1978) correctly stressed that it is very difficult to estimate hunting success because of the subjectivity associated with determining what constitutes an attempt to capture prey. We calculated capture rates only for those sequences in which we could determine visually that prey was being sought. Therefore, our estimates are probably inflated. For adults and juveniles, increased variability of predatory sequences was associated with higher rates of hunting success. When considering individual phases of predatory sequences, only the duration and variability of stalking were related to capture success. Average stalking duration during successful hunts was significantly longer (54 sec) than during unsuccessful attempts $(22 \mathrm{sec})$ and stalking duration was significantly more variable in successful hunts [coefficient of variation $(C V)=2.4$ ] than in unsuccessful efforts ( $C V=1.5)$. Elliott et al. (1977) noted that stalking duration was the most important variable influencing hunting success by lions.

The results of a discriminant function analysis in which the relative influences of (1) age, (2) prey species, (3) wind direction, (4) grass height, and (5) snow depth on capture success were assessed indicated that although grass height had the highest standardized discriminant coefficient (0.73), all variables combined could not reliably discriminate successful from unsuccessful attempts. Only $73 \%$ (387/530) of the sequences were correctly classified. The relationships between mean capture success and these five variables are presented in Table 5. Pups were more successful than older coyotes (pups hunted only grasshoppers) and adults and juveniles were about equally successful. Adult and juvenile coyotes enjoyed their highest success rate when they hunted gophers and were least successful in encounters 
with voles. Wind direction did not influence hunting success but other environmental factors did; coyotes were more successful when they hunted in short grass and shallow snow.

We also determined whether hunger, as measured by the time since the last meal, was associated with capture success. There was no relationship $\left(r_{\mathrm{s}}=0.09\right)$ between satiation and the outcome of the next predatory attempt. When these results are combined with our finding that there was a positive relationship between the size of the meal last eaten and the initiation of the next search, we can conclude that satiation retards searching but not catching and killing. This conclusion is in agreement with the suggestion of Leyhausen (1965) and Kruuk (1972) that catching and killing by carnivores are distinct from searching.

\section{Sensory Bases of Hunting: The Relative Importance of Vision, Olfaction, and Audition}

Analyzing how environmental factors influence hunting enabled us to study the sensory ecology (Suthers, 1978) of coyotes. Habitat and wind conditions, for example, can influence predatory behavior by affecting the way in which sensory cues are transmitted reciprocally between predators and prey. A study of captive coyotes showed that vision is relied on most heavily when hunting rabbits (Wells, 1978; Wells and Lehner, 1978), and that olfaction and audition were of lesser importance. That vision is also important in encounters with squirrels under field conditions was suggested by the fact that wind conditions had little or no effect on predatory behavior when squirrels were sought in short grass. Wells (1978) found that wind direction did not influence hunting when coyotes could see the rabbits they were pursuing.

The ability to alter behavioral patterns by using available environmental cues either singly or simultaneously, or to be able to switch between modalities when available sensory cues change, is a skill that is well developed in carnivore predatory behavior (Ewer, 1968, 1973; Eisenberg and Leyhausen, 1972; Curio, 1976; Elliott et al., 1977; van Orsdol, 1984). For example, when coyotes hunted voles in tall grass and visual cues were impaired, olfactory stimuli were used. Coyotes tended to approach voles in high grass from downwind, most probably using airborne odors. That wind did not directly affect capture success indicates that coyotes take advantage of wind when it is available, but that it is not needed to locate prey that are obscured from view. When wind was absent, the durations of search, stalk, and total sequence length were most variable, suggesting that coyotes probably adjusted to various prey stimuli by switching between olfaction and audition to complement visual cues. The presence of visual stimuli was associated with higher hunting success.

A Comparative Perspective on Sensory Bases of Predation. Other predators also have the ability to use their senses to varying degrees depending on available stimuli and sensory capabilities (Ewer, 1973). For example, red foxes (Vulpes vulpes), which possess a well-developed auditory system (Peterson et al., 1969; Isley and Gysel, 1975), seem to use auditory cues most heavily when hunting (Osterholm, 1964). Mills (1978) found that brown hyenas (Hyaena brunnea) showed a strong tendency to move upwind toward food and depended mainly on olfaction when foraging. Their dependence on odor cues is most probably related to their nocturnal habits and their dependence on carrion for food. Lions, when hunting, seem to rely on their senses in the order of vision, audition, and olfaction (Schaller, 1972) and do not seem to use wind extensively (Schaller, 1972; Elliott et al., 1977).

\section{E. SOME SPECULATIONS ON ENERGETICS}

Biologists interested in energy budgets need to consider how wild animals attain a favorable balance between energy that is invested in different activities and energetic gains that result from the performance of these behaviors. This is especially true for predatory behavior, where the costs and benefits of hunting efforts need to strike a balance over a period of time. Although this brief discussion is based mostly on 
estimates of various parameters, we present it here because there is suprisingly close agreement between some of our data and suggestions from other, more controlled, studies of coyote energetics. Also, we hope that other researchers will pursue some of the problems that we outline.

During the months when voles and squirrels were available as prey (mid-April to mid-August), individual coyotes (mean weight about $13 \mathrm{~kg}$ ) caught, on the average, 3.5 voles and 4.2 squirrels daily, based on daytime observations. Based on the approximate relative representation of different-aged prey eaten by coyotes in the vicinity of our study area (Weaver, 1977), we estimated average weights for voles and squirrels to be 25 and $200 \mathrm{~g}$, respectively. Therefore, coyotes consumed about $930 \mathrm{~g}$ of food per day. These data exclude the likely possibility that other prey species were occasionally caught and do not account for nocturnal predation, which could be significant. Also, it is obvious that we did not observe all captures.

Using estimated caloric equivalents (Cummins and Wuycheck, 1971), coyotes that we observed acquired about $1411 \mathrm{kcal}$ from squirrels and $123 \mathrm{kcal}$ from voles. The standard metabolic rate for captive coyotes has been estimated to be $7.38 \mathrm{ml}$ oxygen/ $\mathrm{kg} / \mathrm{min}$ (Shield, I 972). Based on this value, Litvaitis and Mautz (1980) calculated that a captive $12.9-\mathrm{kg}$ coyote would spend a minimum of $643 \mathrm{kcal}$ daily, and that this requirement could be met by consuming about 13 mice per day. Based on activity data collected during daylight hours, we estimated that a wild $10.5-\mathrm{kg}$ coyote would spend at least $1500 \mathrm{kcal} / \mathrm{day}$ (Bekoff, Wells, and Jansen, unpublished data). This need could be met by eating about 43 voles per day.

Litvaitis and Mautz's (1980) estimate for the daily energy needs for captive coyotes is less than one-half of the very conservative estimate that we calculated for kcal intake (1534). However, free-ranging animals may require up to three times more energy than captive individuals (Gessaman, 1973). Using this "correction factor" as a guide, Litvaitis and Mautz estimated that the number of mice needed by a captive coyote on a daily basis would be $39(3 \times 13)$. This number is very close to our estimate need of 43 voles per day.

Needless to say, several variables have been omitted in both studies. For example, differences in the weight of prey and caloric equivalents need to be considered along with seasonal and individual [age, sex, reproductive condition, life style (see below)] variations in energetic demands. However, even though there was some guesswork involved in our calculations, the close agreement between our estimates and those of Litvaitis and Mautz's stimulated us to present these data for use in future studies.

The study of coyote predatory behavior has helped us to learn a great deal about this highly successful predator. Our results show that differenct variables, including habitat, wind conditions, prey type, and age influence predatory behavior both singly and in combination with one another. Similar data are needed for coyotes living in other habitats and for other carnivores.

\section{BEHAVIORAL ECOLOGICAL ANALYSES OF DAYTIME ACTIVITY PATIERNS AND TIME BUDGETS}

\section{A. TIME AS A LIMITED AND VALUABLE RESOURCE}

Many resources that are required for survival and reproduction are potentially unlimited in supply, or the actual amount that is available is difficult to estimate reliably because it cannot be precisely measured. Time, however, is finite and measurable, and the amount of time that is available for one activity is related to the amount of time that is invested in other behaviors. Thus, for almost all individuals, time is a limited and valuable resource, the proper allocation of which may have critical importance for growth, maintenance, reproduction, and survival (S. A. Altmann, 1974; Coelho et al., 1979; Herbers, 1981; Brown, 1982; Leger et al., 1983). Numerous workers have stressed that there are close relationships between 
variables such as food availability, social organization, dominance status, and reproductive activities, and differential budgeting of time by individuals (S. A. Altmann, 1974; Bowen, 1978; Bekoff and Wells, 1981; Coelho et al., 1979; Brown, 1982; Leger et al., 1983; Terborgh, 1983). Lastly, time budget analyses may allow a researcher to make inferences about actual allocations of energy ("costs") to different activities.

\section{Coyote Time Budgets}

Very few detailed observational data are available concerning activity patterns and behavioral budgeting as they relate to social organization, feeding ecology, and reproductive behavior in wild coyotes (Bekoff and Wells, 1981). In an interesting study of coyotes in Idaho, Laundré and Keller (1981) inferred behavioral patterns from radiotelemetry signals, but their data were not substantiated by direct observation. Radiotelemetry is a valuable tool for studying nocturnal activity patterns but typically does not provide information about what the animals are actually doing. Though details on behavioral budgeting are lacking in most cases, there is a good deal of information stemming from radio-tracking studies dealing with daily activity rhythms (Ozoga and Harger, 1966; Gipson and Sealander, 1972; Bowen, 1978; Andelt and Gipson, 1979; Drewek, 1980; Laundré and Keller, 1981; Smith et al., 1981; Andelt, 1982).

We analyzed daytime budgets and activity patterns using focal animal sampling (see Harcourt and Steward, 1984, for a discussion of how sampling biases can influence results of budget analyses). Here we review some of our previous findings (Bekoff and Wells, 1981) and extend the data base in many areas with information collected over an additional 2.5 years. Some of our conclusions may be limited because we did not study nocturnal activity patterns. However, for the data in which we were interested, nighttime recording would have been extremely difficult, or impossible, because direct observations were mandatory in order to study the durations of various activities such as resting, playing, eating, and aggressive behavior. It is almost impossible to determine exactly what an animal is doing even though radio-tracking information indicates that it is moving, standing still, or in the vicinity of other individuals. Whether or not coyotes are more social at night (Smith et al., 1981) depends on one's definition of social, and this information is difficult to glean from nighttime radio-tracking data (Laundré and Keller, 1981).

Although coyotes are definitely active at night (Gipson and Sealander, 1972; Drewek, 1980; Laundré and Keller, 1981; Smith et al., 1981; Andelt, 1982), extensive daytime activity has also been noted, especially in unexploited populations (Andelt, 1982). For example, Laundré and Keller (1981) reported that during winter, coyotes living in Idaho were more active during the day. There also are sex, age, and seasonal variations in activity patterns and behavioral budgeting (Bekoff and Wells, 1981; see below). Gipson and Sealander (1972) noted that adults were more active at night, but that they foraged during daylight hours. They also reported that pups were more active during the day than were adults.

\section{Questions Asked, Definitions, and Terminology}

a. Questions. Some of the questions with which we attempted to deal included the following: (1) How did individuals budget their time and were there seasonal variations that were associated with differences in food availability or weather? (2) Was there any relationship between activity patterns and the type of social group in which individuals lived? (3) Did mated pairs living in different types of social groups differ in patterns of activity during the breeding season (which could be related to food resources; Fig. 3)? (4) Were there individual differences in time budgeting among coyotes living in packs?

b. Definition of Terms Used to Describe Activity Patterns. We studied seven major types of activities. All were mutually exclusive except at carrion. Definitions are as follows (Bekoff and Wells, 1981): 
1. Resting. Coyote was lying down on its side or stomach; often, it was impossible to determine if the animal was sleeping; occasionally the coyote would scan its surroundings. Sitting was not included here.

2. Traveling. Coyote walked or trotted at a slow, steady pace, averaging about $5 \mathrm{~km} / \mathrm{hr}$ and covering at least $200 \mathrm{~m}$; traveling during hunting was not included here.

3. Hunting. An active attempt was made to capture live small prey.

4. Eating. Coyote was obviously chewing on something that was subsequently ingested.

5. Playing. Definitions can be found in Bekoff and Byers (1981) and Bekoff (1984). Here, we considered social and inanimate object play (see Bekoff, 1972a, 1974; Bekoff and Byers, 1981, for descriptions).

6. Aggression. Fight or threat interactions during which there was a stand-off or one animal dominated another by displacing it or by forcing submission (see Schenkel, 1967; Fox, 1971; Fox and Clark, 1971; Bekoff, 1974; and Lehner, 1978a, for behavioral descriptions).

7. At carrion. Coyote was within approximately 5-20 m of (usually elk) carrion; occasionally carcasses of domestic cows and pronghorns were available, but not during winter. While at carrion, coyotes could engage in other activities such as resting, playing, fighting, threatening, or eating.

c. Definitions of Biological Seasons. "Seasons" were defined as follows: (1) Winter: December-March; (2) Spring/summer: April-July; (3) Fall: August- November.

d. Coyote-Hours. All data have been standardized for the number of coyote-hours of observation. For example, if two animals were observed for $10 \mathrm{hr}$, this would equal 20 coyote-hours.

\section{B. OVERALL SUMMARY OF ACTIVITY DATA}

General trends for the durations and frequencies of 12 activities for coyotes older than 4 months are presented in Table 6. These data are based on 1634 coyote-hours of observation. Because at carrion and other activities were not mutually exclusive activity, total percentage is $>100 \%$.

Coyotes rested for almost $50 \%$ of the total time that they were observed, and spent about equal proportions of time hunting and traveling. These 3 activities accounted for $93 \%$ of the total time that coyotes were observed performing each of these 12 activities. Coyotes played only $1 \%$ of the time and aggression was very rare.

Our data agree with Herber's (1981) suggestion that many species are inactive a great deal of time. Ikeda et al. (1982) reported that one black -backed jackal that they observed was active about $37 \%$ of the time during daylight hours and Mills (1978) observed that brown hyenas were active about $43 \%$ of 24-hr periods during winter and summer. Our data also support the idea that play is not necessarily a timeconsuming activity (Fagen, 1981; Martin, 1984; Bekoff and Byers, 1985). However, different forms of play may require considerable energy because of the amount of locomotion that is involved. Thus, time spent, energetic costs, and benefits gained, may not be directly related (Bekoff, 1978d; Bekoff and Byers, 1981, 1985). Furthermore, play interactions are probably very important in establishing and maintaining social bonds, especially among pack members (Bekoff and Wells, 1982), and in physical training (Bekoff and Byers, 1981, 1985). 
TABLE 6. OVERALL TOTALS FOR ACTIVITY DURATIONS (HOURS), FREQUENCIES, AND RATES/COYOTEHOUR $^{\mathrm{a}}$

\begin{tabular}{|lrccc|}
\hline Activity & Duration & Percentage of time & Frequency & Rate/coyote-hour \\
\hline Travel & 347.12 & 21.24 & 944 & 0.58 \\
Aggression & 11.57 & 0.71 & 223 & 0.14 \\
Eat & 42.30 & 2.59 & 370 & 0.23 \\
Hunt & 403.08 & 24.67 & 586 & 0.36 \\
Dig & 5.20 & 0.32 & 76 & 0.05 \\
Play & 16.33 & 1.00 & 145 & 0.09 \\
Lie & 784.35 & 48.00 & 868 & 0.53 \\
Roll & 1.43 & 0.09 & 48 & 0.03 \\
Vocalize & 13.27 & 0.81 & 161 & 0.10 \\
Sit & 9.33 & 0.57 & 134 & 0.08 \\
At carrion & 128.48 & 7.86 & 329 & 0.20 \\
\hline
\end{tabular}

${ }^{\mathrm{a}}$ Coyotes younger than 4 months are not included.

\section{SEASONAL VARIATIONS IN BEHAVIORAL BUDGETS}

\section{Overall Patterns in Fall, Winter, and Spring/Summer}

Seasonal variations in the amount of time devoted to seven activity patterns were reported by Bekoff and Wells (1981). With the addition of new data, differences were still obvious (Table 7; statistical analyses as in Bekoff and Wells, 1981), though there were some minor changes in how coyotes' behavioral budgets changed seasonally. All values have been standardized for coyote-hours and relative frequency (RF, Table VII) should be read as relative frequency per coyote-hour.

a. Resting. Coyotes rested for the greatest proportion of time during winter (57.4\%) and on average, each resting bout was longer $(\mathrm{MBL}=61.1 \mathrm{~min})$ than in fall or spring/summer. The proportion of time spent resting was significantly longer during snowy winters (72.0\%) than during winters when heavy snows did not occur (54.6\%; Fig. 8). The relative frequency of resting was about equal in fall and winter and greater than in spring/summer.

b. Traveling. Although less time was available for traveling during winter than during other seasons, the percentage of time spent traveling was about the same throughout the year. Travel frequency was lowest during winter and spring/summer but the average duration of each move was longest during winter. The low relative frequency and long mean bout length observed during winter (and early spring) when compared to other seasons is probably due to the difficulty of walking in deep snow that is experienced by coyotes (Murie, 1940; Carbyn, 1982) and other carnivores (Peterson, 1977; Fuller and Keith, 1980; Lindstrom, 1982; Telfer and Kelsall, 1984; also see Ramaswamy et al., 1966). It is interesting that the proportion of time spent traveling was almost identical during snowy (20.6\%) and nonsnowy (20.5\%) winters (Fig. 8). Overall, regardless of season and irrespective of snowfall, coyotes spend about $20 \%$ of their time on the move (also see Table 6).

c. Hunting. Coyotes hunted for small rodents least frequently and for the least proportion of time during winter. The mean bout length was about the same in winter and spring/summer and least during fall. The presence of snow made hunting for small prey a difficult task (see Section V,D). Coyotes spent 
significantly more time hunting during nonsnowy winters (19.5\%) than during snowy winters (3.3\%). Monthly trends are reported in Bekoff and Wells (1981).

TABLE 7. SEASONAL OCCURRENCE OF SEVEN ACTIVITIES ${ }^{a}$

\begin{tabular}{|c|c|c|c|c|c|c|c|c|}
\hline \multirow[b]{2}{*}{ Season } & & \multicolumn{7}{|c|}{ Activity } \\
\hline & & Rest & Travel & Hunt & $\begin{array}{c}\text { At } \\
\text { carrion }\end{array}$ & Play & Aggression & Eat \\
\hline Fall & $\mathrm{N}:$ & 104 & 128 & 151 & 23 & 21 & 29 & 72 \\
\hline \multirow[t]{3}{*}{ (176 hr) } & RF: & 0.59 & 0.76 & 0.86 & 0.13 & 0.12 & 0.16 & 0.41 \\
\hline & MBL: & 27.7 & 16.4 & 30.3 & 5 & 8.7 & 5.6 & 6.6 \\
\hline & \% Time: & 26.2 & 19.8 & 43 & 4.9 & 1.7 & 1.5 & 4.5 \\
\hline Winter & $\mathrm{N}:$ & 588 & 568 & 209 & 273 & 98 & 138 & 196 \\
\hline \multirow[t]{3}{*}{ (1043 hr) } & RF: & 0.56 & 0.54 & 0.20 & 0.26 & 0.09 & 0.13 & 0.19 \\
\hline & MBL: & 61.1 & 25.32 & 41.7 & 24.5 & 5.22 & 2.7 & 9.4 \\
\hline & \% Time: & 57.4 & 23 & 14 & 10.7 & 0.82 & 0.6 & 2.9 \\
\hline Spring/summer & $\mathrm{N}:$ & 176 & 248 & 226 & 33 & 26 & 56 & 102 \\
\hline \multirow[t]{3}{*}{ (414 hr) } & RF: & 0.42 & 0.60 & 0.55 & 0.08 & 0.06 & 0.7 & 0.25 \\
\hline & MBL: & 47.7 & 17.5 & 48.2 & 15.1 & 11 & 2.9 & 2.2 \\
\hline & \% Time: & 33.7 & 17.5 & 44 & 2 & 1.2 & 0.7 & 0.9 \\
\hline Total $N$ : & & 868 & 944 & 586 & 329 & 145 & 223 & 370 \\
\hline
\end{tabular}

${ }^{a}$ Data have been standardized for coyote-hours. $N$, Number; RF, relative frequency; MBL, mean bout length; statistical analyses as in Bekoff and Wells (1981).

FIG. 8. The percentage of time (standardized for coyote-hours of observation) spent traveling, resting, and at carrion during snowy and nonsnowy winters.

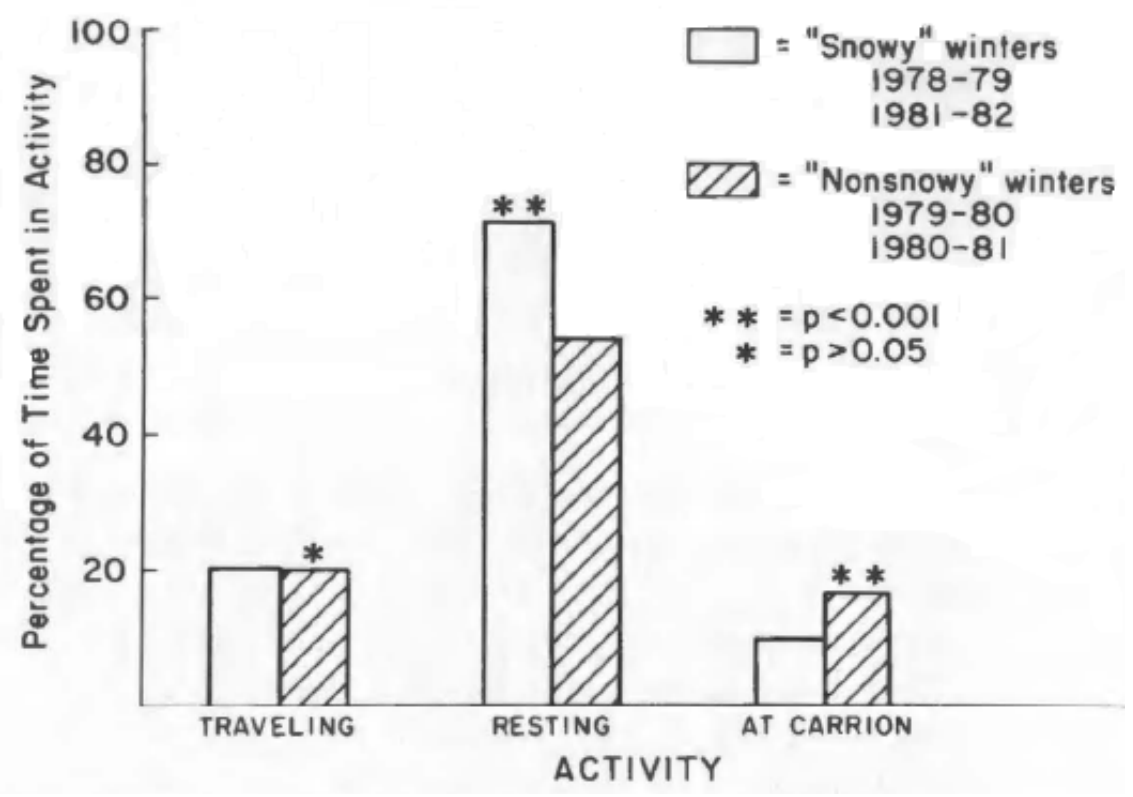


d. At Carrion. Coyotes were observed at carrion most frequently and for the greatest proportion of time during winter when elk carcasses were available for consumption. The mean bout length was also longest during winter. During nonsnowy winters, coyotes spent a significantly greater percentage of time at carrion than during snowy winters (Fig. 8). Monthly trends can be found in Bekoff and Wells (1981).

e. Playing. There were no differences in the relative frequency of play, mean bout length, or the proportion of time devoted to play throughout the year. Coyotes played for a greater proportion of time during nonsnowy (1.5\%) than during snowy winters (0.5\%).

f. Aggression. No seasonal variations were detected in any measure of aggression.

g. Eating. Coyotes were observed eating most frequently during fall but the mean bout length was longest during winter. The percentage of time spent eating was about the same during fall and winter and least during spring/summer.

\section{WINTER ACTIVITY, SNOW CONDITIONS, AND SOCIAL ORGANIZATION}

The above findings did not consider the relationship between activity patterns and social organization. Previous data showed that there was a close association between behavioral budgeting during winter and life style (Bekoff and Wells, 1981), and additional information supports and extends our prior results.

\section{A Comparison of Pack Members and Nongroup Living Coyotes during Winter}

There were clear differences between pack members and nongroup living coyotes with respect to the percentage of time spent traveling, resting, at carrion, and hunting during winter (Fig. 9). Pack members traveled less, rested more, were observed at carrion a greater proportion of time, and hunted less than did nonpack animals. Pack-living coyotes also played a greater percentage of time $(1.1 \%)$ than did other individuals $(0.3 \%)$. Within the pack, there were only small differences among individuals in the proportion of time spent resting, traveling, and at carrion (Bekoff and Wells, 1981). For example, Mother 1, Father 1, and the male helper born in 1977 (Fig. 2) rested 66, 74, and 64\% of the time, respectively, and traveled about the same percentage of time $(16,19$, and 16\%, respectively). Each individual was observed at carrion about $21 \%$ of the time.

There also were differences among non-pack-living coyotes. One resident mated pair was observed to rest and travel more than were solitary residents or transients (Bekoff and Wells, 1981).

Snowy versus Nonsnowy Winters. A comparison of a snowy and a nonsnowy winter showed that when snow was light, pack members, in contrast to nongroup coyotes, traveled more ( 26.0 vs $12.7 \%$ of the time observed), rested proportionately more than twice as much (38.6 vs 18.7\%), and hunted proportionately about one-half as much (31. 7 vs $67.0 \%$ ). Both pack and nonpack individuals ate (1.6\%) and were observed at carrion (5\%) about the same percentage of time. However, when there were considerable amounts of deep snow, pack members traveled proportionately less (25.5 vs 39.5\%), were observed eating (5.5 vs $0.4 \%)$ and at carrion (9.5 vs $2.2 \%)$ more, and rested about the same percentage of time $(60 \%)$ as did nonpack coyotes.

A number of trends are very obvious. When there was a great deal of snow, pack members did not show any increase in the proportion of time spent traveling whereas nonpack animals showed a marked increase to $39.5 \%$ (from $12.7 \%$ in nonsnowy conditions). Traveling in snow is a costly activity and may result in depletion of fat stores (Lindstrom, 1983). 
FIG. 9. The Percentage of time (standardized for coyote-hours of observation) spent traveling, resting, at carrion, and hunting during winter for pack and nonpack coyotes.

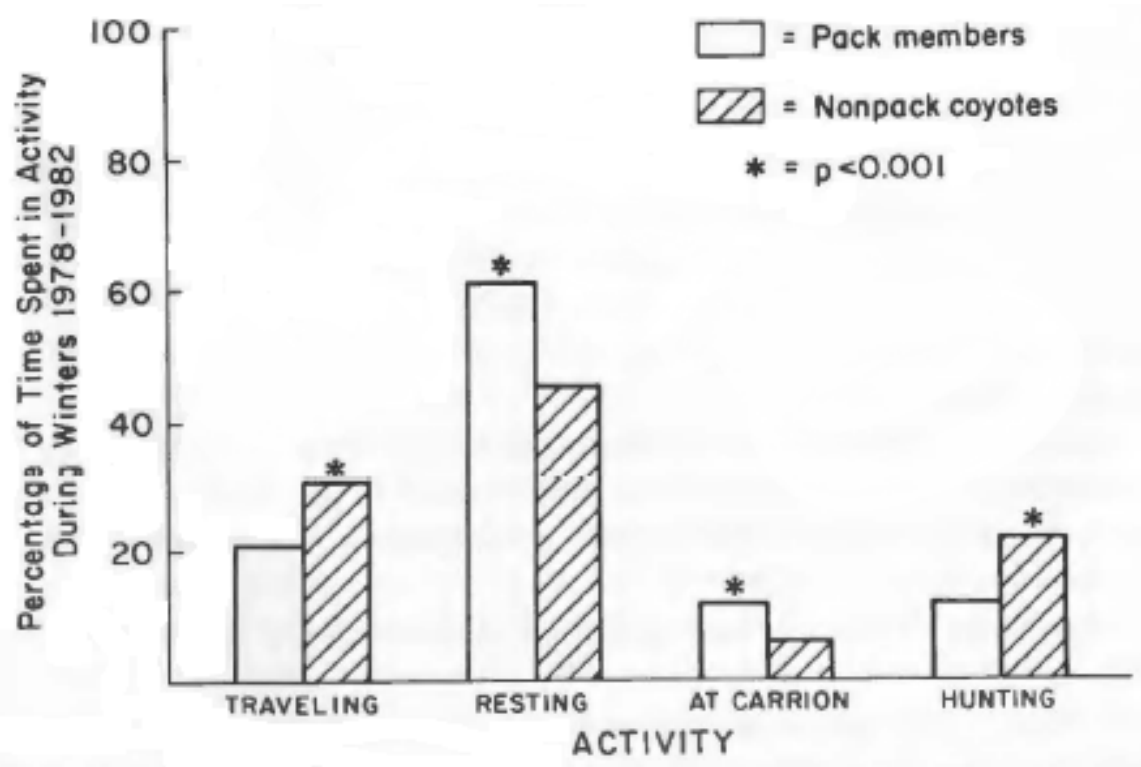

The ratio of the percentage of time spent resting to the proportion of time spent traveling, $R / T$, during nonsnowy conditions was about the same for pack members (1.48) and for nonpack animals (1.47). However, during snowy weather, $R / T=2.39$ for pack animals and 1.49 for nongroup coyotes. Basically, nongroup coyotes showed no change in the ratio of resting to travel whereas pack animals showed a large increase in $R / T$. Therefore, although pack animals rested about the same proportion of time as did nonpack members during snowy winters, and traveled about the same percentage of time during snowy and nonsnowy conditions, they conserved energy by traveling considerably less with respect to the proportion of time spent resting during snowy conditions. Also, when there was a great deal of snow and food was hard to find, pack members showed a marked increase in the proportion of time that they were observed at carrion whereas nonpack coyotes showed a sharp decrease in the percentage of time they were observed at carrion. A similar trend was noted for the proportion of time spent eating.

All in all, it appears that when conditions make it difficult to travel and to find food, pack members are at an advantage when compared to non-group-living coyotes. Bowen (1978) suggested that pack-living coyotes might show greater net energy gains when compared to individuals living other life styles, but did not provide relevant data. Our data suggest that advantages to pack members may become more pronounced during difficult living conditions.

\section{A Comparison of the Pack Mated Pair and a Resident Mated Pair during Winter}

These data pertain to Mother 1 and Father 1 (Fig. 2) and a resident mated pair that was observed between September, 1977 and April, 1980 (Fig. 10). Both the mated pack male and female spent significantly more time resting and less time traveling than did the resident pair male and female. The pack female rested significantly more than her mate, but both individuals traveled about the same percentage of time (Fig. 10). In the resident pair, the female rested significantly more and traveled significantly less than her mate.

a. A Comparison of Females. Overall, the pack female traveled proportionately $22 \%$ less time than did the resident pair female and she showed a more favorable rest/travel ratio. The relative difference between 
the females is probably larger because traveling on snow is more difficult than moving about on solid ground, and during winter 1978-1979 there was heavy snow. In addition, the pack female (and her mate) had access to more readily available winter food than did the resident pair female and her mate, both of whom had to travel widely in search of carrion.

FIG. 10. The percentage of time (standardized for coyote-hours of observation) spent resting and traveling during winter by a mated pair living as part of a pack and by a resident mated pair living alone. (Note that in Bekoff and Wells, 1981, there is an error, corrected here, for the percentage of time spent resting by the pack male.)

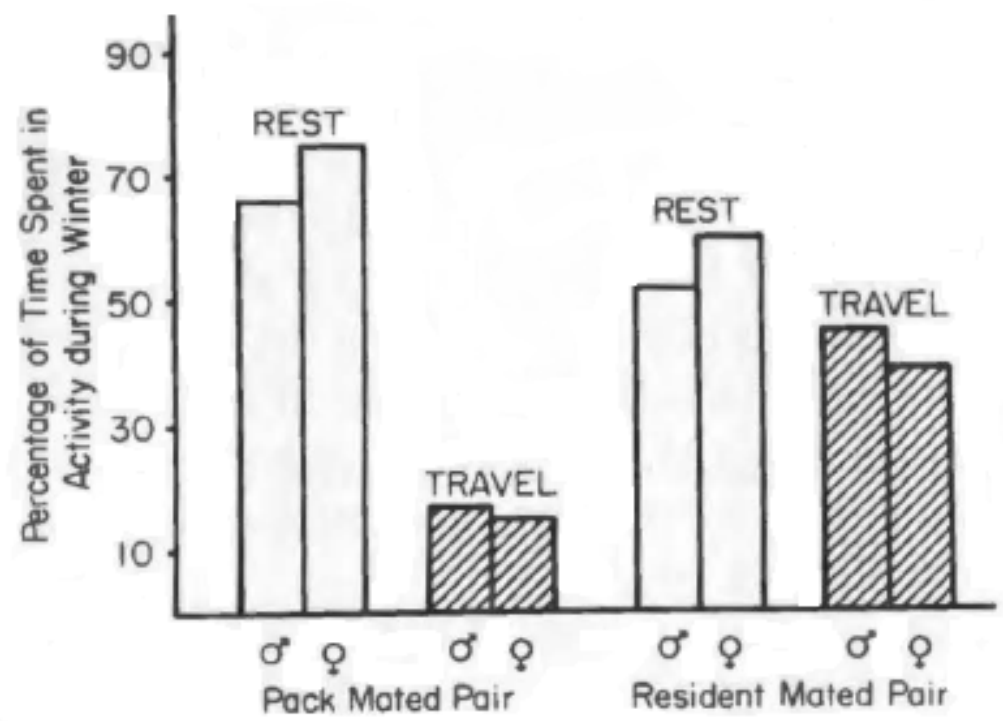

b. Winter Activity Patterns, Energetics, and Reproduction: Some Speculations. It is possible that reproductive processes might be influenced by differences in winter activity patterns displayed by pregnant females living different life styles. Variations in the amount of energy that pregnant females have to use to sustain themselves and their developing young might become important factors influencing reproductive success, especially during harsh winters.

In coyotes and other species, nutritional factors that affect the health of reproductive females play important roles in reproductive processes, including the number of ova shed, and in pup mortality (Gier, 1968; Weaver, 1977; Kennelly, 1978). When the ambient temperature drops below the coyotes' thermoneutral zone (about $-10^{\circ} \mathrm{C}$; Shield, 1972), maintenance costs increase. During winter, temperatures below $-10^{\circ} \mathrm{C}$ occurred frequently on our study area. The basal metabolic rate (BMR) also can increase as much as 1.25 times during pregnancy and 1.5 times during lactation when compared to the BMR of a nonpregnant female (Crampton and Lloyd, 1959). If food became limited during winter, all individuals would experience a precarious balance between available energy and energetic demands. Weaver (1977) found that in his study area in Jackson Hole, differences in coyote population indices as large as sixfold could be attributed to variations in the amount of ungulate carrion available during winter. Where there was more food, coyote populations were more dense.

On our study area, mid-March to mid-April could be a stressful time for coyotes, especially for pregnant females, because carrion is in very low supply and Uinta ground squirrels are not yet up (Fig. 3). Snow cover might also make other small rodents more difficult to catch. Although we have detected no differences in pup productivity or survival between females living in packs and females living only with their mates, the differences in winter activity patterns are real. If food became seriously limited, we would 
predict that pack females would be less affected than resident pair females. In fact, our data show that all pack-living coyotes may show net energy gains when compared to individuals living other lifestyles, as suggested by Bowen (1978). This may not be the case for coyotes living in other areas (Andelt, 1982).

Although our information on activity patterns is limited to one population, the data base is substantial and unique, nonetheless. Also, the seasonal differences that we found and the variations in activity patterns for coyotes living in different types of groups are clear-cut. Data for other carnivores that show intraspecific variations in social organization (Macdonald, 1978, 1979; Bekoff et al., 1984; Lott, 1984; Tilson and Hamilton, 1984) would provide important comparative information. Nighttime activity patterns also need to be elucidated, but these data are difficult to collect. Although our study has spanned about 5.5 years and we have been able to observe directly individual patterns of activity, still more extensive field endeavors are needed in order to explain the long-term effects of variations in behavioral budgeting among individuals, especially reproductive females, living in different types of groups. To date, there appear to be few, if any, data that conclusively show that economizing energy expenditure actually maximizes fitness (Lillywhite, 1984).

\section{SOCIAL ORGANIZATION: SPACE USE AND GROUP COMPOSITION}

In this section we consider two aspects of the social organization of coyotes, specifically (1) space use and (2) group composition (age, sex, and kinship patterns). Social interaction patterns have been, and will be, discussed, with specific topics. General and comparative reviews and syntheses of social organization in various taxa, including carnivores, can be found in many references (Mech, 1970; Kruuk, 1972, 1975; Schaller, 1972; Ewer, 1973; Kleiman and Eisenberg, 1973; Waser and Wiley, 1979; Sunquist, 1981; Macdonald and Moehlman, 1982; Moehlman, 1983; Bekoff et al., 1984; Gittleman, 1984). Reviews, comparative data, and extensive references for coyotes have been compiled by numerous authors, including Young and Jackson (1951), Bekoff (1977a, 1982), Drewek (1980), Andelt (1982), Bowen (1982), Woodruff and Keller (1982), and Laundré and Keller (1984).

\section{A. SPACE USE}

\section{Definitions}

The terms home range and territory will be used conventionally. Home range refers to an area that is regularly frequented, but typically not defended, by one or more individuals (Burt, 1943), whereas the term territory refers to a more or less exclusive area that is usually defended by an individual or a group, especially against conspecifics. Within home ranges and territories, there are impact areas through which a coyote may travel and interact with other animals and core areas, which are small regions of concentrated use (Springer, 1982). Coyotes may occupy the same home range or territory for many years (Camenzind, 1978; Andelt and Gipson, 1979; Andelt, 1982; Bowen, 1982; this study). The main pack of coyotes that we observed remained in the same area throughout the course of our study.

Are Coyotes Territorial? It is impossible to make a general statement regarding territorial behavior in coyotes. Studying space use by, and observing social interaction patterns of, identified individuals in widely ranging, secretive animals are very difficult tasks, and extensive, detailed data are lacking. Differences in opinion about territorial behavior may be based partly on variations in methodology or on the criteria that are used to assess territoriality (Burger, 1984). For example, radio-tracking data may yield some information about territorial behavior, but when used alone and without being supplemented by direct observations, only circumstantial evidence regarding space use patterns is provided. The frequency with which animals are tracked and located, sample size, including both the number of individuals that are tracked and the number of locations that are obtained for each individual, the time interval between 
successive locations, and the accuracy with which locations can be mapped, all need to be accounted for in any study of space use (Mech, 1983; Bekoff and Mech, 1984; Laundre and Keller, 1984).

In addition to practical and methodological problems, age and sex differences along with seasonal variations need to be considered. Using radiotelemetry, Berg and Chesness (1978) reported that the male coyotes they studied did not occupy exclusive territories because neighboring home ranges exhibited considerable overlap. On the other hand, they concluded that females were territorial because they excluded other females from their home ranges. Andelt and Gipson (1979) also concluded that territoriality was expressed by the absence of intrasexual overlap of adult coyotes' ranges, but some of their animals were located very infrequently (see also Messier and Barrette, 1982).

Based on observational data supplemented by radio tracking, Bowen's (1978), Andelt's (1982, 1985), and our results indicated that coyotes of both sexes were territorial. Bowen (1978), Camenzind (1978) and Andelt $(1982,1985)$ reported that resident pairs and group members were territorial, but Bekoff and Wells (1980; see below) found that only pack members regularly defended defined boundaries against intruding coyotes. In contrast to these findings, Danner and Smith (1980) found no evidence of territorial behavior in the coyotes that they monitored and Gipson and Sealander (1972) and Drewek (1980) were unable to determine if the coyotes they studied in Arkansas and southern Arizona, respectively, were territorial.

\section{Sizes, Shapes, and Differential Use of Home Ranges and Territories}

As Brown and Orians (1970), Covich (1976), Waser and Wiley (1979), and Getty (1981) have stressed, researchers must be careful about taking a static approach to space use. The size and shape of home ranges and territories are dynamic variables (elastic discs, Huxley, 1934) that are often influenced by interrelated factors such as age, sex, group size, body size, density, health, season, locale, level of intraspecific and interspecific competition including the intensity of human exploitation, and resource availability.

Representative data for coyotes indicate that home ranges and territories vary greatly in size from about 1 to $100 \mathrm{~km}^{2}$. Details can be found in Young and Jackson (1951), Gier (1968), Gipson and Sealander (1972), Bekoff (1977a, 1978b, 1982), Hibler (1977), Litvaitis (1978), Andelt and Gipson (1979), Cornely (1980), Drewek (1980), Tzilkowski (1980), Andelt (1982), Bowen (1982), and Springer (1982). It frequently is the case that small core areas (Springer, 1982) are used disproportionately (see Section $\mathrm{VIII}, \mathrm{A}, 3)$ and also that ranging areas are overestimated because of the inclusion of a few location points resulting from occasional sallies or the beginning of long-range dispersal. Therefore, instead of reporting data for the size of the entire home range or territory, estimates are usually provided for the area encompassed by $95 \%$ of the total locations (Andelt, 1982; Bekoff and Wells, 1982; Bowen, 1982). Inadequate sample size, a problem that appears to be widespread in many studies of space use by coyotes (Laundré and Keller, 1984; see also Bekoff and Mech, 1984) may also lead to misleading results.

Territories are invariably smaller than undefended home ranges (Bowen, 1978, 1982; Bekoff and Wells, 1980; this study), most probably because there are diminishing returns when a large area has to be patrolled and actively defended (Gosling and Petrie, 1981). It is known that the nature of available food resources can greatly influence social interaction patterns and space use in carnivores (Bekoff et al., 1984) and other taxa. As we will discuss below, when food is abundant, clumped, and economically defendable (Brown, 1964; Gosling and Petrie, 1981 ), coyotes and other carnivores tend to live in groups that defend relatively small territories (Bowen, 1978; Bekoff and Wells, 1982; for review see Bekoff et al., 1984). The size and shape of home ranges and territories may also change during the reproductive season (Andelt and Gipson, 1979; Andelt, 1982; Bekoff and Wells, 1982). 
a. The Relationship between Age, Sex, and Living Area. The only strong relationship that can be derived for the association between age and the size of an individual's ranging area is an obvious one. Namely, as coyotes mature and become increasingly independent of adult care during the first 6-9 months of life, their living space increases to include areas other than the den site (Andelt, 1982; Harrison, 1983). Typically, the movements of pups and juveniles occur within the boundaries of their parents' home range or territory until dispersal from the natal area begins. No obvious sex differences have been detected for the movement patterns of pups and juveniles.

After about 6-9 months of age, individual variations in space use become more apparent, but it is impossible to generalize about sex differences in adult ranging patterns. We found that the mean ranging areas for 10 adult females $\left(35.8 \mathrm{~km}^{2}\right.$; range $\left.=7.5-66.0\right)$ and 7 adult males $\left(31.33 \mathrm{~km}^{2}\right.$; range $\left.=6.8-98.0\right)$, regardless of social status (see below), were about the same $(p>0.05)$. Andelt ( 1982) and Bowen (1982) also reported similar ranging areas for adult males and females. Nonetheless, some researchers have reported that females occupied larger home ranges than males (Litvaitis, 1978; Drewek, 1980; Litvaitis and Shaw, 1980; Tzilkowski, 1980), whereas other noted that male home ranges were larger than those of females (Gipson and Sealander, 1972; Comely, 1980).

Although too few animals and/or locations often preclude meaningful statistical analyses of the data (Bekoff and Mech, 1984; Laundre and Keller, 1984), sex differences are frequently large enough to make such analyses superfluous. For example, Gipson and Sealander (1972) reported that adult males and adult females had home ranges of about 32.8 and $13.1 \mathrm{~km}^{2}$, respectively. Litvaitis (1978) found that the home ranges of adult males and adult females were 15.0 and $27.9 \mathrm{~km}^{2}$, respectively.

FIG. 11. There was extensive overlap among the individual territories occupied by pack members. Here, core areas, represented by polygons in which $50 \%$ of all locations for each pack member are contained, indicate the high level of overlap. The "eye" symbol on the left of the polygons is the observation point on Blacktail Butte (see Fig. 1).

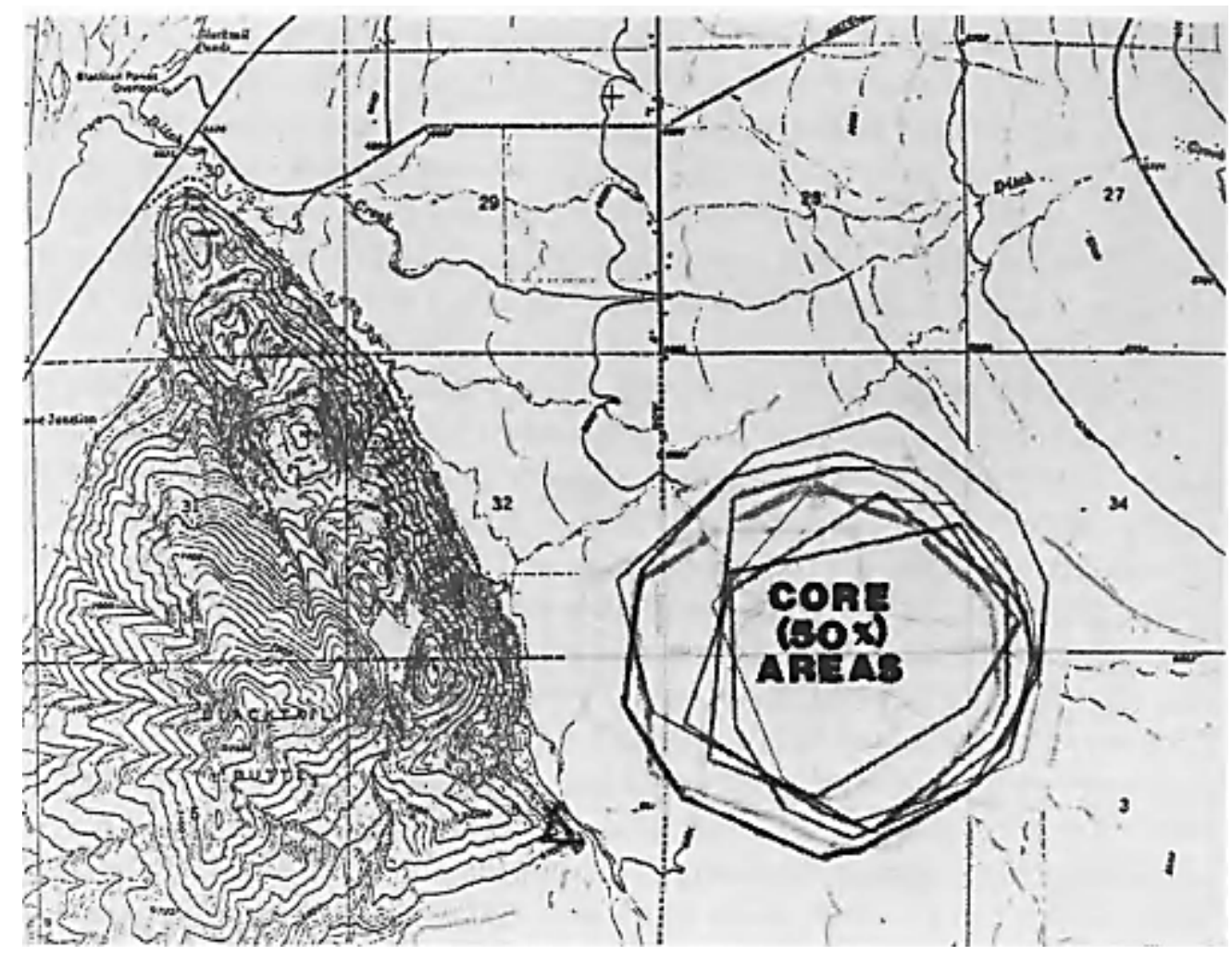


b. Living Area, Social Class, and Group Size. More detailed and reliable estimates of ranging area must take into account at least the current life style of the individual being considered. Overall measurements of home range or territory sizes, such as those provided above for sex differences, obscure significant variation that is found when social organization is included in the analysis. For example, Andelt (1982) reported that the composite home ranges for resident coyotes living on the Welder Wildlife Refuge in Texas were $4.7 \mathrm{~km}^{2}$ for 19 males and $4.3 \mathrm{~km}^{2}$ for 14 females, whereas home range estimates for transient males $(n=10)$ and females $(n=11)$ were 42.8 and $31.2 \mathrm{~km}^{2}$, respectively.

We also found large differences in home range and territory estimates when social organization was considered. As mentioned above, coyotes were classified into four social classes, transients, solitary residents, resident mated pairs, and packs. Overall territory size for 7 pack members based on about 1000 locations was estimated to be $9.3 \mathrm{~km}^{2}\left(3\right.$ males $=8.8 \mathrm{~km}^{2}$ and 4 females $\left.=9.6 \mathrm{~km}^{2}\right)$. There was considerable overlap among the $50 \%$ core areas (about $3-4 \mathrm{~km}^{2}$; Fig. 11) and the area encompassed by each individual's territory (see Bekoff et al., 1984, Fig. 4). Mean home range estimates for one resident mated pair and nine solitary transients were 21.9 and $52.3 \mathrm{~km}^{2}$, respectively. The differences among the area estimates for the pack, resident mated pair, and solitary transients were statistically significant $(H=$ 13.88, $p<0.001)$. One female that was born into the pack but who spent most of her time on the periphery of the pack's territory (referred to as a roamer; Bekoff and Wells, 1980) had a home range (38.2 $\mathrm{km}^{2}$ ) that was intermediate to that of the resident mated pair and solitary transients.

Group size may also influence the size of the ranging area. Although it frequently is argued that because there are more mouths to feed in a larger group, a larger home range or territory is needed to satisfy the nutritional requirements of all group members, supportive data that causally link living area (and some resource contained within it) with group size are lacking in most cases.

The data that are available for coyotes, not surprisingly, do not allow for any generalization concerning the relationship between range size and group size. Bowen (1982) reported that group home ranges increased with group size in the coyotes he studied in Jasper, Alberta, Canada. However, we did not find a direct or consistent relationship between pack size and territory size in our population. Although pack size varied within and between years, there was very little change in overall territory size. Also, as indicated above, the size of the pack's territory was much smaller than the home ranges of resident mated pairs or transients. Similarly, Camenzind (1978) and Andelt (1982) reported that home range size of adult coyotes was not related to group size, and Hersteinsson and Macdonald (1982) noted that group size and territory size varied independently in red foxes.

Andelt (1982) suggested that range size may increase with group size in areas where food is not abundant. In his study area, Camenzind's, and ours, food was not limited. Mills (1982) also found that although territory size and group size of brown hyenas living in the southern Kalahari varied, they were not correlated. Rather, territory size was affected by the distribution of food whereas group size was influenced by the quality of food in the territory (for example, the size of carcasses).

c. Seasonal Variations in Space Use. In addition to social status and other variables that can influence space use, seasonal variations and associated changes in resources, group composition, and behavior (Fig. 3) can affect the sizes and shapes of coyotes' living areas (Andelt and Gipson, 1979; Andelt, 1982; Bekoff and Wells, 1982; Bowen, 1982; Springer, 1982; Harrison, 1983). For example, Andelt and Gipson (1979) reported that the average home range sizes of five adult males were similar during breeding, gestation, and nursing, but tended to increase as pups became older and during the prebreeding season. Average home range sizes for four females remained constant during gestation, nursing, and while pups matured, but increased during the prebreeding and breeding seasons. On the other hand, Camenzind (1978), Andelt (1982), and Bowen (1982) did not find seasonal differences in the sizes of living areas for 
resident coyotes residing on the National Elk Refuge outside Jackson, Wyoming, in Texas, or in Alberta, Canada, respectively.

FIG. 12. Three-dimensional space use plots for the original pack mother (Mother 1, 1977-1980) (a) throughout the year, (b) during fall, (c) during winter, and (d) when pups were present. The numbers on the tops of some of peaks ( $z$ axis) refer to the percentage of total sightings within specific sections of her territory. The observation point is on Blacktail Butte (see Fig. 1). $n=$ sample size (number of locations or radio-tracking locations); the number on the right of the slash (l) with the star is the size of the $95 \%$ territory (from Bekoff and Wells, 1982).
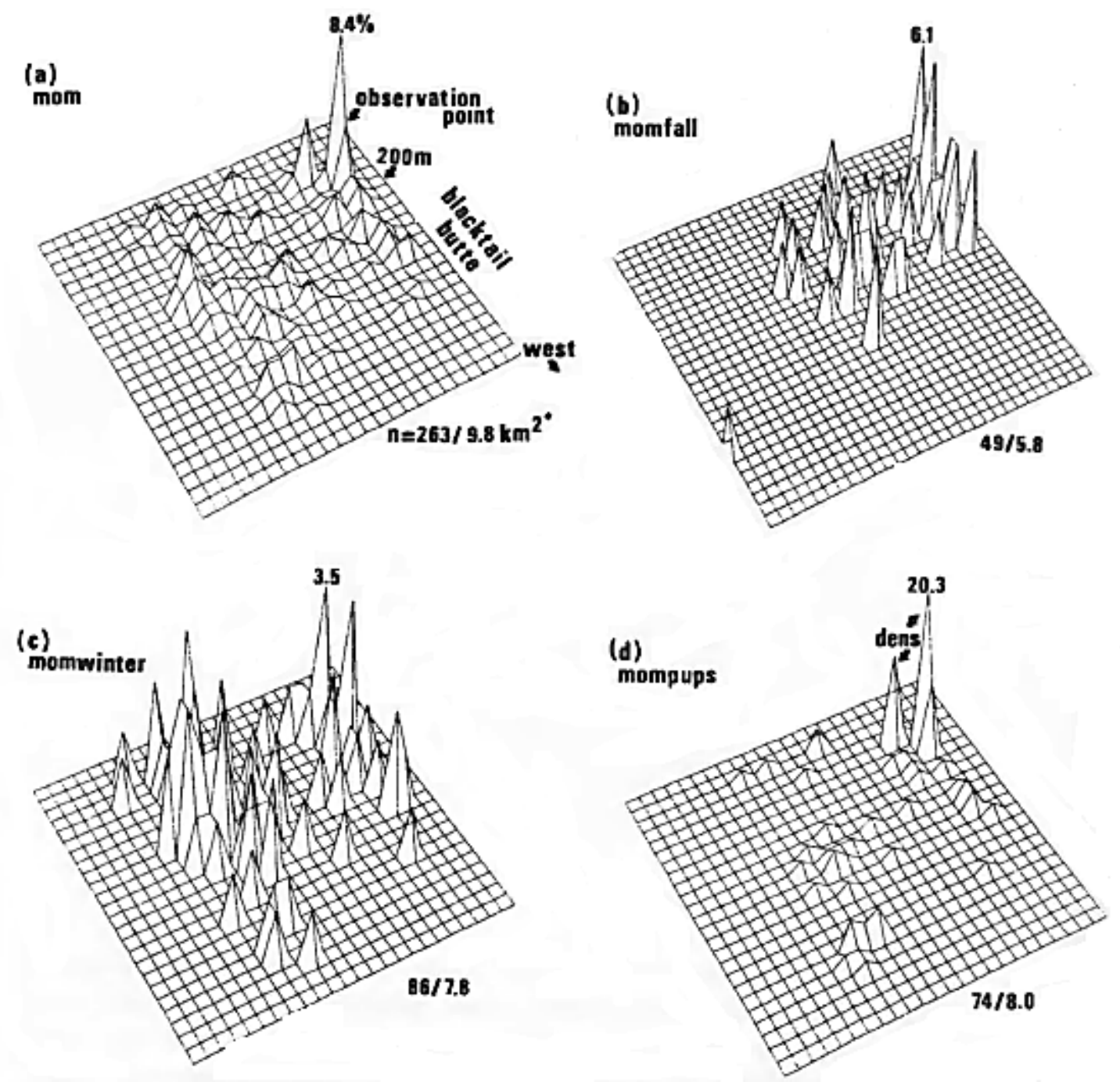

Although it is difficult to determine what constitutes a significant change in home range or territory size or shape, either from a statistical or perhaps a more relevant biological perspective, we found what we interpret to be biologically important and interesting seasonal changes in space use (size estimates and shapes of living areas) for coyotes comprising a resident pack (Fig. 2) and transient individuals (see also Bekoff and Wells, 1982). For example, we detected obvious changes in the way in which one pack reproductive female (Mother 1, Fig. 2) used space throughout the year (Fig. 12). Simply viewing overall space use by this female (Fig. 12a, "mom") did not reveal the more uniform pattern of how she occupied 
her territory during fall (Fig. 12b, "momfall") and winter (Fig. 12c, "momwinter"), nor the changes in territory size. She also showed large changes in space use when her pups were present (Fig. 12d, "mompups"). There was almost a sixfold increase in the relative frequency with which she was sighted within the same $200 \times 200 \mathrm{~m}$ grid square when pups were around as compared to the preceding winter months.

FIG. 13. Three-dimensional space use plot for the pack, when all adults were viewed together, during the period when pups were present (May-August).

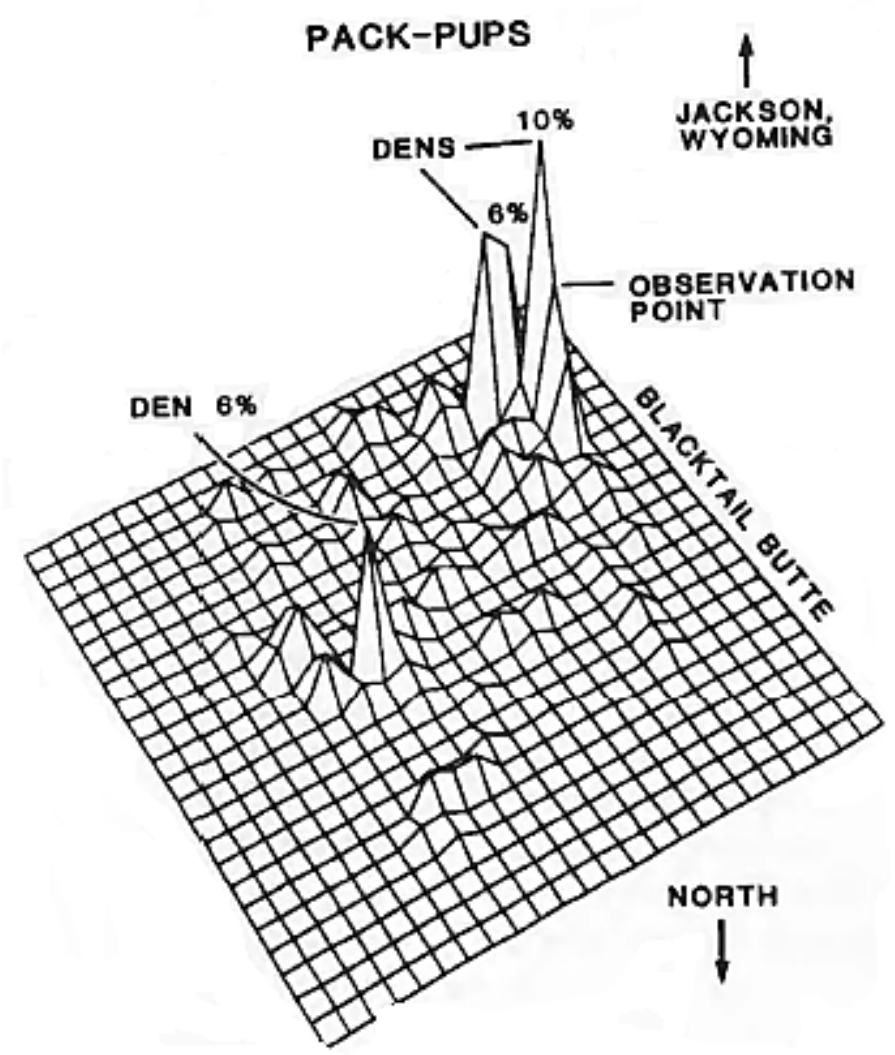

Similar changes in space use were detected for the pack father and various helpers (Bekoff and Wells, 1982). When pack members were sighted together during the period when pups were around, they were located disproportionately more around dens (Fig. 13). Estimated territory size for all pack members was smallest during fall. At this time of the year, juvenile coyotes were more active, but they and other group members spent most of their time around the den site where rodents were very abundant.

Solitary transients also showed seasonal changes in space use. A representative case is shown in Fig. 14 , where the estimated fall home range is much smaller than the winter range. During fall, when rodents were abundant throughout the study area, transients typically wandered about and avoided group members. Note that the fall home range for this transient female overlapped only slightly with the pack's territory, which was located to the right of the observation point indicated on Fig. 14. On the other hand, during winter, when food was difficult to obtain, she, other transients, and the resident mated pair, frequently trespassed onto the pack's territory, where elk carrion was abundant.

d. Space Use, Body Size, and Food. It is obvious that the variations that we observed in space use by coyotes comprising our study population were due to an interaction of different factors. A variable that we 
have not yet considered is body size. Many researchers have shown that space use and body size are related exponentially (McNab, 1963; Baker and Mewaldt, 1979; Harestad and Bunnell, 1979; Eisenberg, 1981; Jenkins, 1981; Gittleman and Harvey, 1982; Clutton-Brock and Harvey, 1983; Mace and Harvey, 1983; Calder, 1984). Gittleman and Harvey (1982) found that home range size increased with metabolic needs regardless of taxonomic affinity, but when the effects of energetic needs were removed, only diet had a significant influence on home range size. Other variables, including activity pattern, habitat, and zonation, did not directly influence space use.

FIG. 14. Changes in the size and shape of the home range of a solitary transient female (B23 + ) during fall and winter.

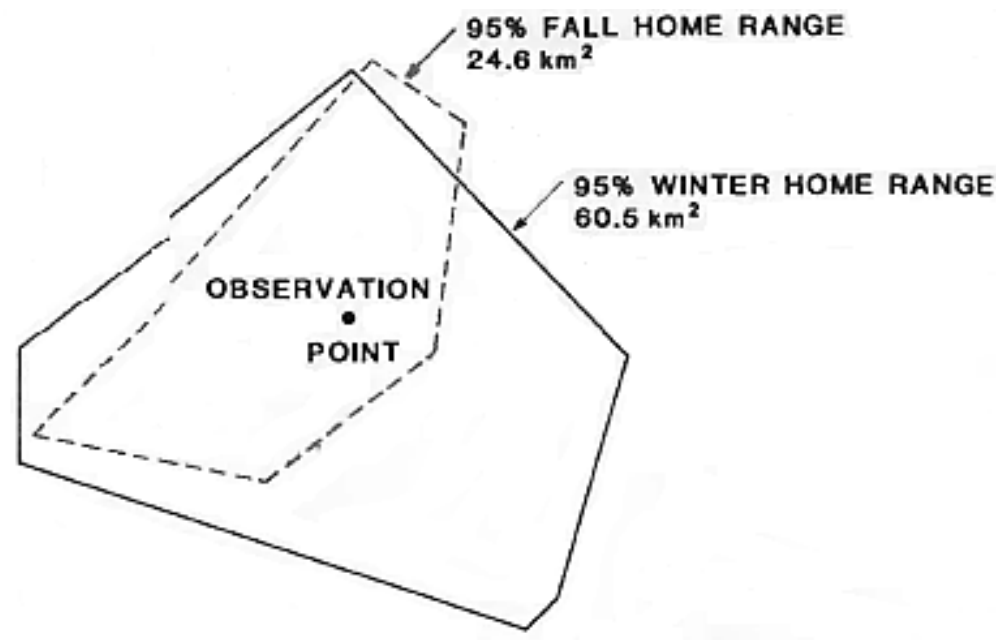

Regression equations relating body size and ranging area have been suggested by various authors. Using the equation home range size measured in hectares $(H)=$ body weight $(W)$ raised to some power, $k$, Harestad and Bunnell (1979) suggested that the general relationship between home range size and carnivore body weight could be expressed as $H=0.11 W^{k}$, where $k=1.36\left(r^{2}=0.81\right)$. Jenkins (1981) correctly cautioned that the use of comparative data to calculate $k$ must be done with care. For example, the way in which ranging area estimates were calculated must be taken into account and the accuracy of these measurements must also be assessed (see Baker and Mewaldt, 1979). In addition, the relative proportion of different species comprising the sample from which the equation was developed needs to be considered (Jenkins, 1981). For example, McNab's (1963) original analysis of the relationship between home range size and body size contained few carnivores.

We analyzed our data on space use to study the relationship between body size and ranging area. We did not find significant differences in the mean weights (about 11-12 kg) for coyotes occupying ranging areas of vastly different sizes (see above). Likewise, Bowen (1982) found similar home range sizes for males and females in the same habitat where males were larger than females.

We also calculated values of $k$ for coyotes of different social status assuming $W=11.36 \mathrm{~kg}$. The values for males, females, the pack as a whole, the resident mated pair, and solitary transients were 1.09, 1.1., $0.99,1.05$, and 1.15 , respectively. Thus, $k$, varied with the life style of the animals sampled, and social status was closely linked with food resources (Bowen, 1978; Camenzind, 1978; Bekoff and Wells, 1982; see below). $k$ also varied seasonally.

In summary, the nature of food resources, rather than body size, was the greater influence on ranging area of the coyotes we studied (also see Jenkins, 1981; Gittleman and Harvey, 1982; Bowen, 1982). 
Gittleman and Harvey (1982) stressed the importance of intraspecific variation in feeding patterns as a major determinant of home range area and Jenkins (1981) pointed out that there is a close association between food abundance and distribution and the exponents of power functions that describe the relationships between ranging area and body size.

e. Core Areas and Centers of Activity. It is a common observation that individuals do not distribute their movements or time equally throughout their home range or territory. Rather, they spend most of their time in core areas, which are relatively small regions of concentrated use (Springer, 1982). Within these core areas there may be biological attraction points (Don and Rennolls, 1983) such as rich food resources, good denning or sleeping spots, or areas that afford protection from predators, that influence space utilization. Therefore, an estimate of the area in which an animal is usually found is but a gross measure of its actual use of space. For example, Hersteinsson and Macdonald (1982) found that the red foxes they studied spent approximately $50 \%$ of their time in an area that occupied about $10 \%$ of their total range. Ables (1969) estimated that $22 \%$ of the area occupied by red foxes in south-central Wisconsin contained $52 \%$ of the fixes and that $57 \%$ of the area contained $84 \%$ of the fixes. Similarly, Springer (1982) reported that $82.9 \%$ of all locations of the coyotes he studied in southcentral Washington were concentrated in only $6.9 \%$ of the total home range (see also Drewek, 1980; Harrison, 1983).

FIG. 15. The exponential relationship showing what percentage of Mom's (Mother 1) and Dad's (Father 1) time was spent in what percentage of their territory during winter.

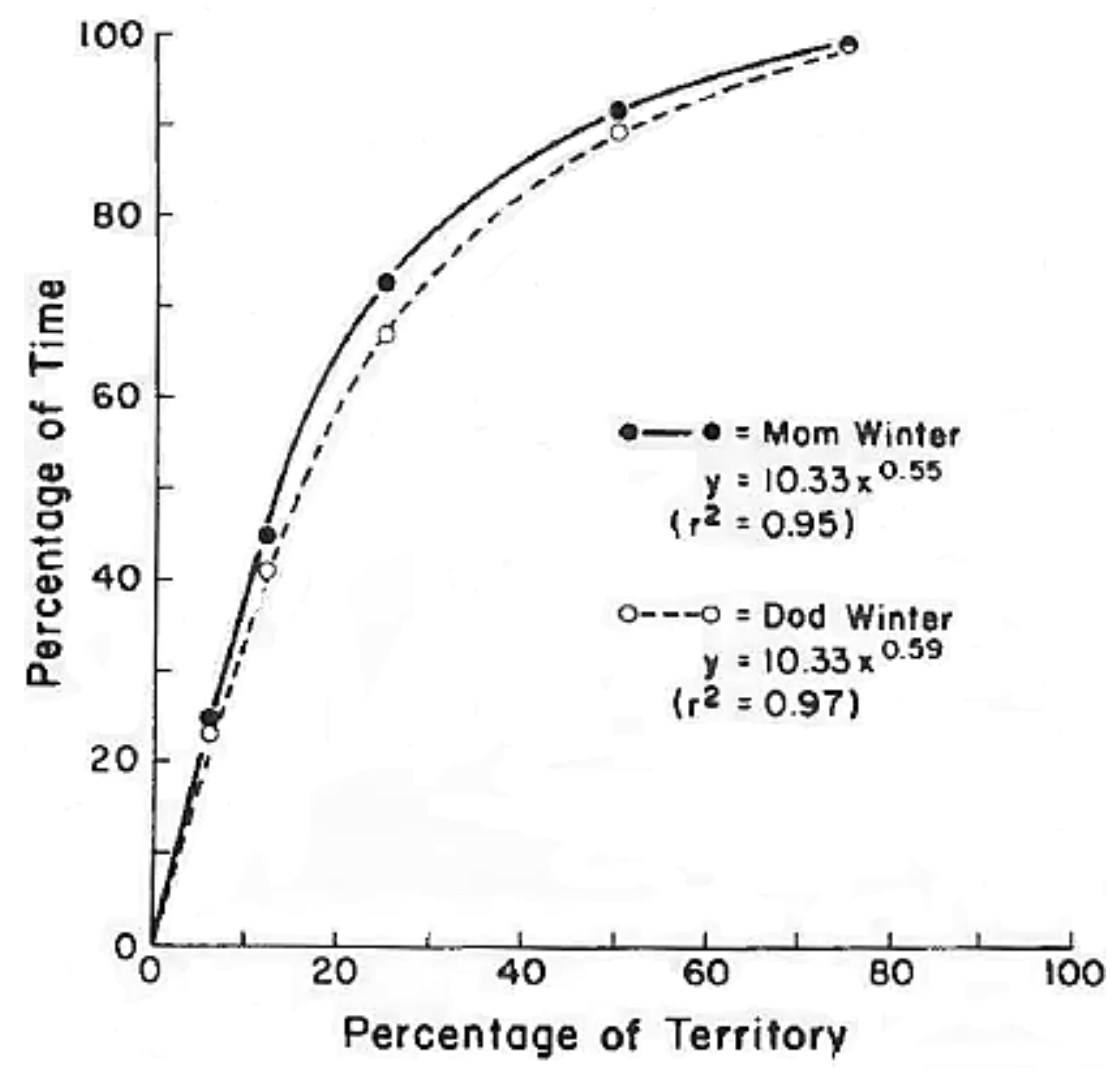

Our results showed that pack-living coyotes used space exponentially. Representative data and regression equations are shown in Fig. 15. Comparative detailed information is provided by Chivers (1973, p. 128, Fig. 13) and Nursall (1981). The regression equation that we calculated based on our reading of Chivers' figure is $y=7.6 x^{0.59}, r^{2}=0.95$. There were no differences among the slopes of his and our equations. 
The data presented in Fig. 15 express percentage of time spent as a function of percentage of territory. A similar relationship was found when percentage of locations was plotted against percentage of territory. For example, 50 and $95 \%$ of all locations for pack members were encompassed within 25.3 and $56.2 \%$ of their territory, respectively. There were no differences in the slopes of the regression equations calculated for individual pack members.

Coyotes living in packs used space differently from less social animals. Two solitary transients for whom we were able to collect sufficient data did not show exponential use of space. Ninety percent of the locations were found in 92 and $86 \%$ of their total home range.

\section{Movement Patterns}

Andelt (1982) presents what appear to be the most detailed radio-tracking data on movement distances for identified wild coyotes. Although our observational data are not as extensive, some interesting patterns were detected among pack members. We were unable to collect sufficient data for other coyotes, nor did we study long-distance movements (for comparative data see Bekoff, 1977a, 1982; Andelt, 1982).

When we measured the mean distance that an identified coyote moved each time it traveled during different seasons, we found that all individuals moved less than an average of $0.50 \mathrm{~km} / \mathrm{move}$ regardless of season. For example, during the nonsnowy winters of 1979-1980 and 1980-1981, the first pack father (Father 1, Fig. 2) traveled an average of of 0.24 and $0.34 \mathrm{~km} / \mathrm{move}$ respectively. His first mate (Mother I, Fig. 2) traveled an average of $0.20 \mathrm{~km} /$ move during the same time periods. One of the main helpers (male B21, Fig. 2; also see Bekoff and Wells, 1982) traveled an average of $0.46 \mathrm{~km} / \mathrm{move}$ during winter and $0.13 \mathrm{~km} / \mathrm{move}$ during summer.

When we calculated approximate rates of movement, seasonal differences were detected but there was still marked consistency among individuals. All individuals moved less than $1.0 \mathrm{~km} / \mathrm{hr}$ during winter. However, during summer, movement rates were higher. For example, male B21 traveled about 0.92 $\mathrm{km} / \mathrm{hr}$ during winter and $1.56 \mathrm{~km} / \mathrm{hr}$ during summer. Winter and summer travel rates for a pack female were approximately 0.90 and $2.76 \mathrm{~km} /$ move, respectively.

Although we were unable to collect detailed information concerning long-range movements during dispersal, we found that when Mother 1 (Fig. 2) left her pack, she gradually traveled farther and farther from the group until she finally disappeared. The gradual expansion of her living area is shown in Fig. 16. Messier (1985) has also shown that dispersal in wolves may be a gradual, protracted process, lasting from a few months to a few years. The same trend appears to apply to other species (Bekoff, 1977c).

\section{B. GROUP COMPOSITION}

\section{Age, Genetic Relationships, and Sex Ratio}

The pedigree of the pack that we studied intensively is shown in Fig. 2. With the exception of Mother 2, the pack was a genetically related extended family in which the mated pair and nondispersing animals (full siblings and half-siblings) of different ages born in previous years were the basic social unit. Other researchers have suggested that coyote packs were made up of close kin (Bowen, 1978; Camenzind, 1978; Drewek, 1980; Andelt, 1982), but they did not have sufficient data to make a definite statement. The overall sex ratio of the pack was slightly biased toward males because 5/6 (83\%) helpers were males (Bekoff and Wells, 1982; see below). 
Fig. 16. This figure, "mom leaving," shows the overall pattern of space use by Mother 1 before she left the pack in late 1980 (see Fig. 2). Her ranging area increased to $30.8 \mathrm{~km}^{2}$; it gradually became larger and larger until she disappeared. $O$, The observation point on Blacktail Butte. Note that she moved into areas into which other pack members did not venture (compare with Figs. 11-13).

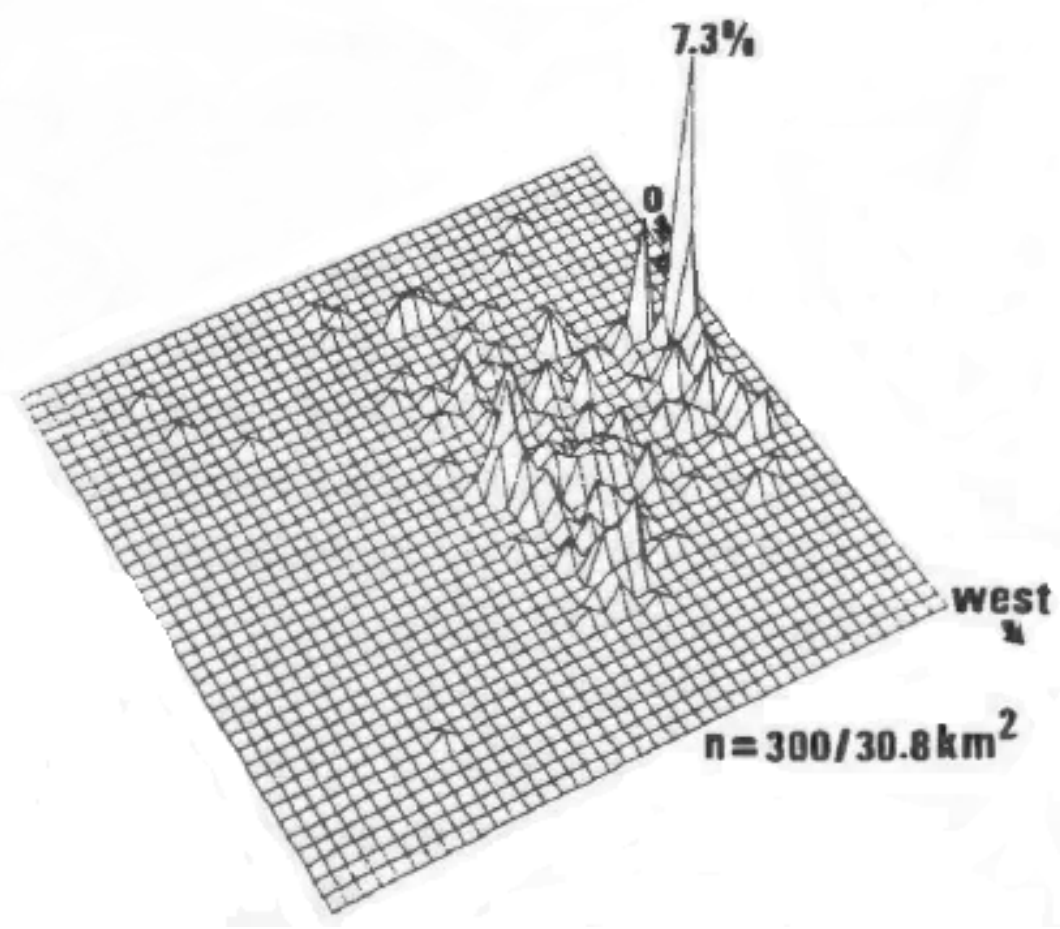

IX. REPRODUCTIVE BEHAVIOR AND CARE GIVING

\section{A. LIFE HISTORY PATTERNS AND REPRODUCTIVE BEHAVIOR}

Coyotes nicely fit into general schemes in which associations among various life history traits and behavior in different canids are summarized (Bekoff et al., 1981a). These include (1) body size (birth and adult weight, minimum female weight), (2) reproduction [gestation period, reproductive effort $(R E)=$ the total resources allocated to bringing a litter to term, irrespective of female weight; Armitage, 1981], (3) development (age at independence and dispersal, age at which females and males first breed), and (4) social behavior ("Coy" on Fig. 17a; Bekoff et al., 198la; also see Bekoff et al., 1984, and Gittleman, 1984, for general trends among carnivores). They fell fairly close but were clearly separated from, canids that are typically characterized as being (highly) social, such as wolves (W), Cape hunting dogs (CHD, or African wild dogs), dingoes (D), and dholes (Dh) with respect to the relationships between minimum female weight and (1) mean birth weight (Fig. 17b), (2) reproductive index [RI = effort by a single female to bring one young to term relative to her weight (Armitage, 1981; Fig. 17c)], and (3) reproductive effort (Fig. 17d). Sociality was best predicted by minimum female weight.

\section{Litter Size and Sex Ratio}

Mean litter size determined at 4-6 weeks of age (when pups were marked and it was first possible to assess litter size without disturbing them greatly) was the same for four litters born into the pack $(\bar{X}=5.5)$ and three litters produced by the resident mated pair $(\bar{X}=5.3)$. Unfortunately, we cannot account for 
possible losses incurred during early life. The litters we studied were about the size of an average coyote litter $(N=6$, Bekoff, 1977a).

Fig. 17. A summary of life history and behavioral patterns in canids (from Bekoff et al., 1981a). (a) Projections of different species on the first two principal axes of a principal-components analysis of life history traits and behavioral patterns. Axis I summarizes variation in size, maturity, reproduction, and sociality and axis II represents female reproductive behaviors. CHD, Cape hunting dog (African wild dog); W, wolf; Dh, dhole; $D$, dingo; BEF, bat-eared fox; Coy, coyote; BD, bush dog; BBJ, black-backed jackal; GJ, golden jackal, GF, gray fox; RD, raccoon dog; PF, pampas fox; SSJ, side-striped jackal; RF, red fox; FF, fennec fox; AF, artie fox . (b) Relationship between mean birth weight and minimum female weight. (c) Relationship between reproductive index (RI) and minimum female weight plotted on a log scale (see text). (d) Relationship between reproductive effort (RE) and minimum female weight plotted on a log scale (see text).

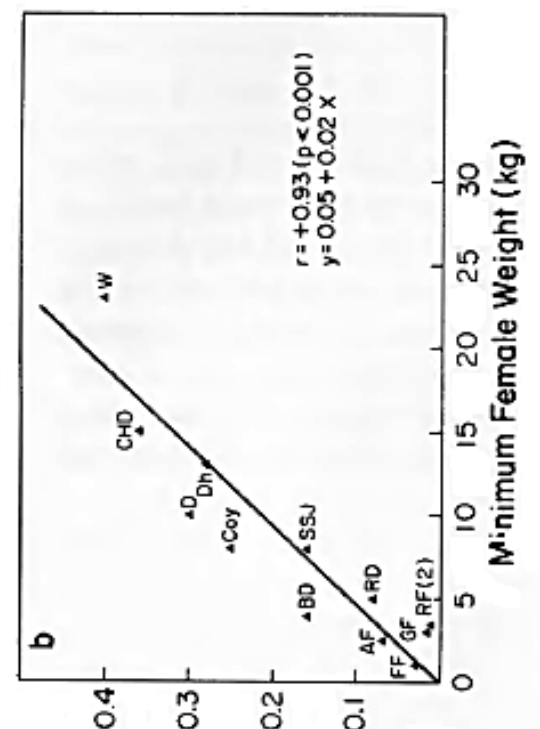

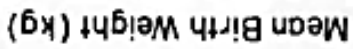

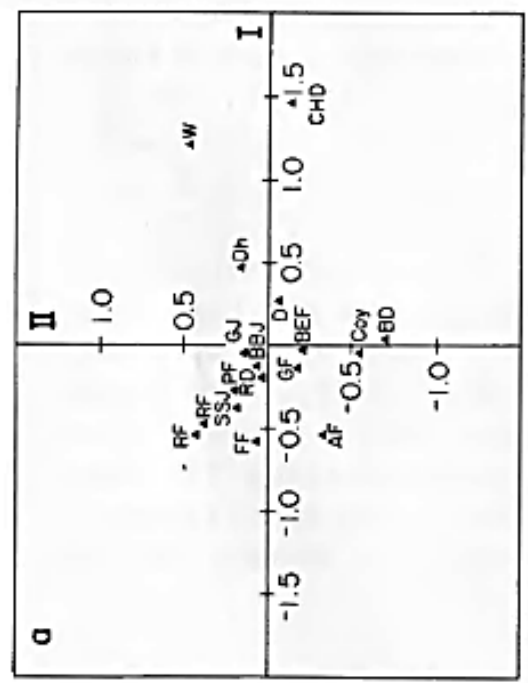

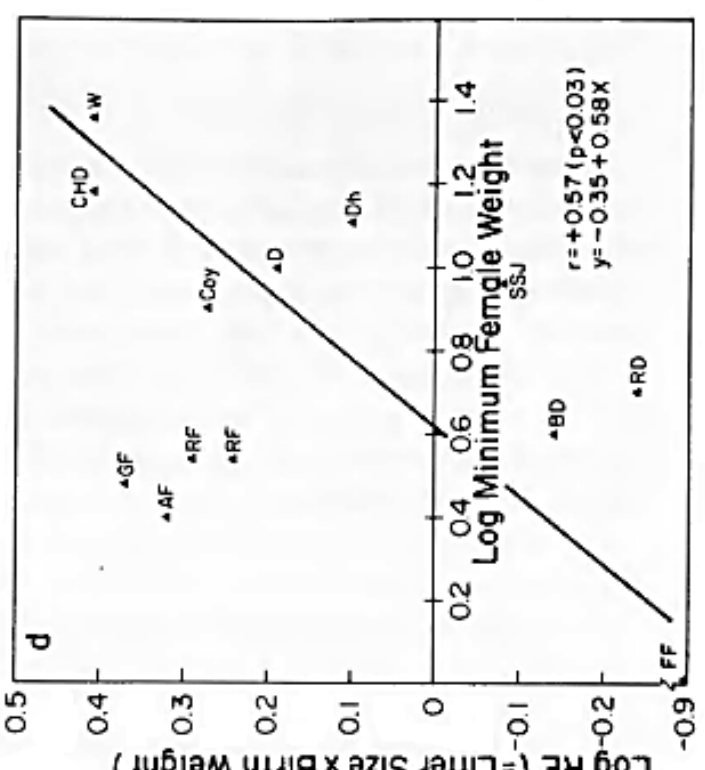

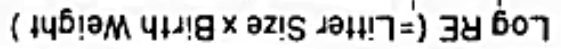

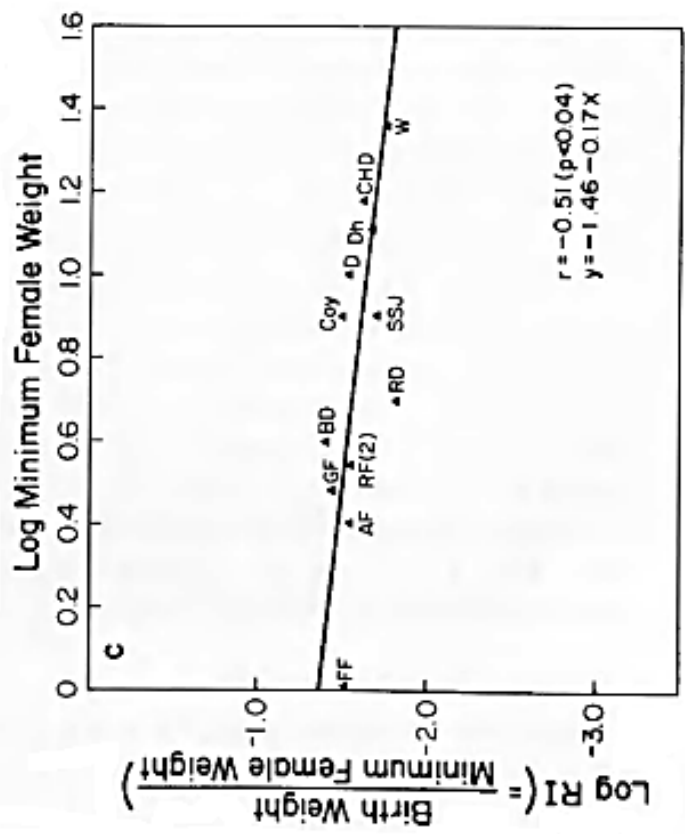


It is important to note that litter size in coyotes may be influenced by the level of exploitation to which a population is subjected, population density, and food resources (Gier, 1968; Knowlton, 1972; Bekoff, 1977a; Andelt, 1982; Jean and Bergeron, 1984). As Andelt (1982) pointed out, the relationships among litter size and population density and exploitation level are complex, and causal associations are difficult to demonstrate. We found that litter size was not significantly correlated with the number of adults in a group nor with the percentage of pups surviving to 5-6 months of age (Bekoff and Wells, 1982).

The sex ratio for 28 pups at about 4-6 weeks of age was 1:1 (14 males and 14 females). An even sex ratio in coyote litters also seems to be the common pattern (Bekoff, 1977a).

\section{The Typical Mating System}

Based on observational data, coyotes, like many other canids (Kleiman, 1977; Bekoff et al., 1984; Gittleman, 1984), appear to be monogamous (Bowen, 1978; Camenzind, 1978; Andelt, 1982; this study). A prolonged association and an essentially exclusive mating relationship is established between one male and a single female (Wittenberger and Tilson, 1980). Furthermore, only one pair per pack typically mates in a given year.

Although yearling coyotes are potentially reproductively active (Gier, 1968; Dunbar, 1973; Kennelly and Johns, 1976; Kennelly, 1978), we did not observe mating by yearling animals. Gipson et al. (1975) and Drewek (1980) also reported that yearling females did not breed. In general, yearling females usually make insignificant reproductive contributions to a population of coyotes (Knowlton, 1972). However, food resources may influence the proportion of yearling females that breed in a population. In a long-term study of coyotes in Kansas, Gier (1968) reported that in years when rodents were abundant, about $75 \%$ of yearling females bred. Todd et al. (1981) noted that breeding by yearling females in Alberta, Canada, decreased by $50 \%$ during 3 years of a decline in a snowshoe hare population.

Because we were able to observe copulations and tieing, we feel fully confident in stating that the coyotes we studied were monogamous and that only one pair in the pack mated each year. Harrington et al. (1982) stressed the difficulty of determining mating patterns under field situations when observation conditions are poor. Circumstantial evidence such as a close association between a pair outside the breeding season or the absence of other adults in the pairs' ranging area does not necessarily mean that monogamous pair bonds are formed. Likewise, associations among a number of potentially reproductive individuals indicated by radio tracking do not mean that monogamy is unlikely (see Preece, 1978).

The Mated Pair. Throughout the year, the mated pair appeared to be the most closely bonded dyad. The mean distances between these two coyotes when they were resting and active were 14 and $58 \mathrm{~m}$, respectively (for comparative data on wolves see Lockwood, 1976; Mech and Knick, 1978; Knick and Mech, 1980). In captivity, wolves that are bonded most strongly tend to sleep closest together (Lockwood, 1976; Zimen, 1976). Although the mated pair spent a lot of time in close contact throughout the year, they still actively courted during the mating season. Other potential suitors might also be dissuaded from pursuing one of these coyotes as a mate.

\section{B. CARE-GIVING PATTERNS: PARENTAL AND HELPING BEHAVIOR}

Coyote pups are born blind and helpless and require direct adult care for about 2 months. [Data on physical development can be found in Gier (1968), Bekoff and Jamieson (1975), and Barnum et al. (1979).] They typically emerge from dens at about 3 weeks of age. Young pups need to be fed, stimulated to urinate and defecate, kept warm, moved from disturbed dens or those infested with ectoparasites, and protected against possible predators. Coyote pups are probably able to live alone when they are weaned at about 6-8 weeks of age (Snow, 1967), but they usually do not become independent until they are about 
4-5 months of age. Recent summaries of parental behavior in diverse carnivores, including paternal care and helping, can be found in Rood $(1978,1983 a, b)$, Owens and Owens (1979, 1984). Kleiman and Malcolm (1981), Andelt (1982), Bekoff and Wells (1982), Macdonald and Moehlman (1982), Malcolm and Marten (1982), Riedman (1982), Harrington et al. (1983), Moehlman (1983), Bekoff et al. (1984), Garrott et al. (1984), and Gittleman (1984); detailed comparative data and discussions are provided by Reyer (1984), Woolfenden and Fitzpatrick (1984), and Taborsky (1984). Andersson (1984) estimated that of 45 carnivore species that have been studied in detail, 13 (29\%) show nonreproductive helpers.

\section{Parents and Helpers}

a. Factors Promoting Helping and What Helpers Do. Detailed data concerning various aspects of care giving by parents and helpers are presented by Bekoff and Wells (1982). Coyote helpers are nonbreeding individuals who remain in their natal territory (they show natal philopatry, Waser and Jones, 1983) for at least 1 year. Brown (1982) has suggested that group territoriality may be one possible origin of helping behavior in vertebrates. The formation of packs resulting from delayed dispersal and the retention of some offspring as helpers, was closely associated with the presence of an abundant, clumped, and defendable winter food source (see also Bowen, 1978; Camenzind, 1978; Pyrah, 1984). Harrington et al. (1983) stressed that ecological factors such as prey availability may affect the willingness or ability of various group members to provide food or other care to pups. It also is possible that the lack of areas into which to disperse (habitat saturation) might result in a reduction in dispersal and the retention of potential helpers (Andelt, 1982, 1985).

Helpers may perform a number of different functions. When pups are around, two major contributions that helpers could potentially make are feeding pups and/or parents and guarding den sites. The helpers that we observed did not play a significant role in food provisioning, unlike African wild dogs (Malcolm, 1979; Malcolm and Marten, 1982) or black-backed jackals (Moehlman, 1983), nor did they move pups from one denning area to another. Helpers did participate in territorial defense both during and outside the breeding season, and their contributions to the group's effort were vital (see Bekoff and Wells, 1982; and Section $X, B, 1, a)$. They also contributed to the pack's scent-marking efforts.

b. Time Allocated to Den Attendance. Parents and helpers showed changes in space use that were associated with the presence of pups around dens (Figs. 12 and 13; also see Bekoff and Wells, 1982). Pack Mothers 1 and 2 allocated slightly more than $50 \%$ of their overall time budget to den attendance. There was no difference in the proportion of time spent around dens between pack mothers and the resident pair female $(\bar{X}=67 \%)$, but overall, pack mothers spent about $15 \%$ less time at dens. There also was no difference between the pack mother and father with respect to the percentage of time spent around dens. However, the resident pair female spent a significantly greater proportion of time around dens than did her mate $(\bar{X}=30.1 \%)$.

Helpers were observed at dens an average of $21 \%$ of the time that they were observed anywhere. In each year, one or more helpers were present for a significantly smaller percentage of time than either parent. Helpers' presence did not affect the proportion of time that pack mothers allocated to den attendance. The amount of time that helpers spent at dens could not be predicted by (1) the number of adults present, (2) litter size, (3) the percentage of time that mothers spent at dens, or (4) the proportion of time that fathers devoted to den sitting.

c. Individual Contributions to the Group's Effort in Den Attendance. The relative proportion of time that individuals devoted to the total group effort involved in den attendance (Fig. 18, top) was determined by calculating the time that each individual was observed at dens given that dens were attended. Pack Mother $1(\bar{X}=65.0 \%)$ and the resident pair female $(\bar{X}=86.4 \%)$ showed little year-to-year variation. Pack 
Mother 2 contributed about 22\% more to the pack's den-sitting effort, but the difference between her contribution and Mother 1's was not statistically significant. Although the percentage of time devoted to den attendance was about the same for pack Mother 1 and the resident pair female, the pack female contributed significantly less to the pack's den attendance effort than did the resident pair female to the joint effort by her and her mate.

FIG. 18. Top: The percentage of time (total time individual was observed at active den sites/total time den was attended) that individuals devoted to the total pack effort involved in den attendance (from Bekoff and Wells, 1982). The new individual (asterisk) is Mother 2 (see Fig. 2). Bottom: The frequency that pups were left alone, the percentage of time pups were unattended, and the mean number of minutes they were alone each time they were left unattended (from Bekoff and Wells, 1982).
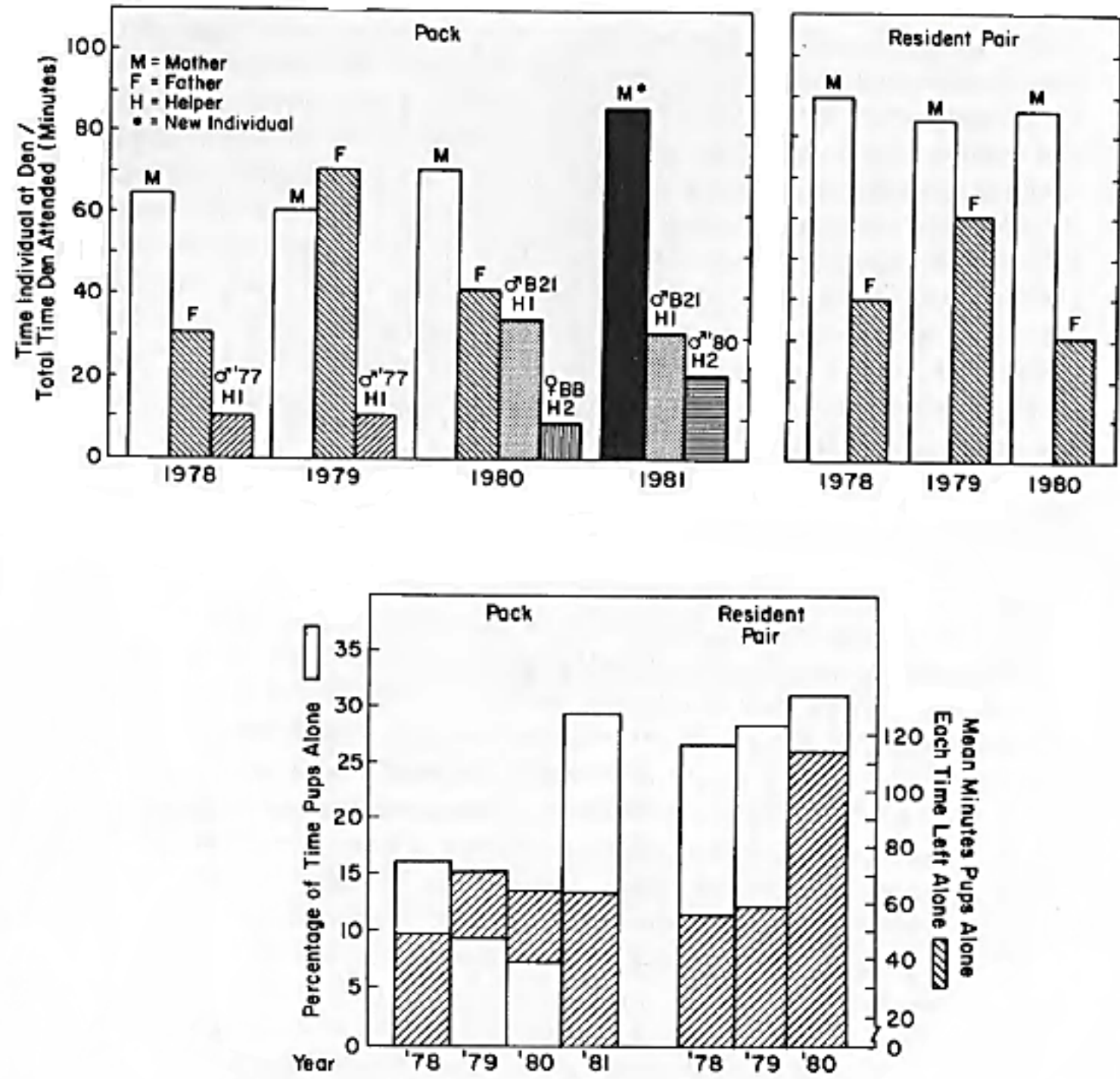

Number of

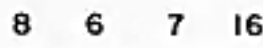

$\begin{array}{lll}4 & 7\end{array}$

Times Pups 
Pack $(\bar{X}=47.6 \%)$ and resident pair fathers $(\bar{X}=42.9 \%)$ contributed about the same percentage of time to the den attendance effort of their respective group. Pack Mother 1 and Father 1 contributed about the same relative effort; however, the resident pair female contributed significantly more than her mate. All helpers $(\bar{X}=19.5 \%)$ contributed less than all parents; male helper B21 contributed more than other helpers $(\bar{X}=32.2 \%)$ but less than his parents.

d. Associations among Adults at Den Sites. Of the total time that Mother 1 was observed at dens, she was accompanied by Father $145.7 \%$ of the time. She was observed at dens in the company of a helper(s) between $4.2-15.2 \%$ of the time. Father 1 was observed at dens with his mate $60.2 \%$ of the time and with a helper(s) between $5.1-13.8 \%$ of the time. Because of the large amount of time that parents spent at dens, helpers were observed at den sites more often with one or both parents than with one another. Departures from, or arrivals at, dens were not synchronized among adults (see also Andelt et al., 1979; Althoff and Gipson, 1981; Andelt, 1982).

e. Frequency and Amount of Time Pups Were Left Alone. When two parents were associated with dens, pups were left alone about equal number of times (Fig. 18, bottom). However, when only one parent was involved in den sitting (1981), pups were left alone significantly more often than when two parents were present. Helpers' presence did not make up for the absence of a parent.

The mean number of minutes that pups were left unattended each time they were alone was not significantly different for the pack $(\bar{X}=77.1 \mathrm{~min})$ or resident pair $(\bar{X}=62.2 \mathrm{~min})$. Nonetheless, pups born to the resident pair were left alone about 15 min longer each time that both parents were gone from the den sites. In 1980, resident pair pups were left alone about $2 \mathrm{hr}$ each time they were unattended.

The number of parents in the pack also influenced the mean percentage of time that pups were left alone (minutes pups were alone/minutes den observed). When there were two parents in the pack (1978-1980), the average proportion of time that pups were left unattended was significantly less than for the resident pair. When only one parent was present in the pack (1981), the percentage of time that pups were left alone increased significantly compared to the percentage when both parents were present, and closely approximated the figures for the resident pair. There was a significant negative correlation $\left(r_{\mathrm{s}}=-0.77, P=\right.$ 0.04 ) between the amount of time that parents spent at dens and the percentage of time that pups were left alone. However, there was no correlation between the amount of time that helpers devoted to den sitting and the proportion of time that pups were left unattended. When both parents were present in both groups, the most important variable discriminating between the pack and the resident pair was the percentage of time that pups were left alone (pack < resident pair).

f. Pup Protection. Although helpers' presence did not have a direct influence on the amount of time that parents devoted to den sitting, the mere presence of a parent and/or helper may be sufficient to provide protection to vulnerable pups (for comparative data see Kruuk, 1972; Saggese and Tullar, 1974; Camenzind, 1978; Rood, 1978, 1983a,b; Lamprecht, 1978; Malcolm, 1979; Owens and Owens, 1979; Garrott and Eberhard, 1982; Macdonald and Moehlman, 1982; Malcolm and Marten, 1982; Moehlman, 1983). Among coyotes, intraspecific killing of pups occurs rarely. However, Camenzind (1978) observed it twice, and on both occasions dens were unattended. In brown hyenas, Owens and Owens (1979) noted that protection of pups was one of the most important functions of communal denning.

g. Relationships between the Survival and Survivorship of Pups and Group Size. Litter size was assessed when pups were 4-6 weeks of age. The number of pups surviving and the weight of juveniles were determined at about 5-6 months of age. There were no significant correlations between litter size and (1) number of adults present, (2) number of pups surviving to 5-6 months of age, or (3) percentage of pups surviving to 5-6 months of age. Litter size was about the same for the pack and resident pair. 
The presence of coyote helpers did not significantly increase the number of pups that survived to 5-6 months of age (Fig. 19a), but there was a positive relationship $\left(r_{\mathrm{s}}=+0.39\right)$ between pup survival and the number of adults attending dens. The regression relationship indicates that a pair of animals was able to raise about three pups to 5-6 months of age and that each helper increased pup survival by a factor of 0.49. The regression coefficient (0.49), or slope of the regression line, indicating the increase in the number of pups surviving as a function of the number of adults attending dens, was nonsignificant. The low value $(0.20)$ of the coefficient of determination, $r^{2}$, suggests that factors other than the number of adults present influenced pup survival. Multiple regression analysis showed that the number of pups surviving could not be predicted either by the number of adults present at dens or by the proportion of time devoted to den attendance by either mothers or fathers.

FIG. 19. Regression analyses between (a) the number and (b) the percentage of pups surviving until at least 5-6 months of age and the number of adult coyotes present at dens (numbers of helpers $=$ number of adults -2 ). $r^{2}=$ coefficient of determination, $\mathrm{SE}_{\mathrm{b}}=$ standard error the regression coefficient (slope), $r_{\mathrm{s}}=$ Spearman's coefficient of rank correlation.
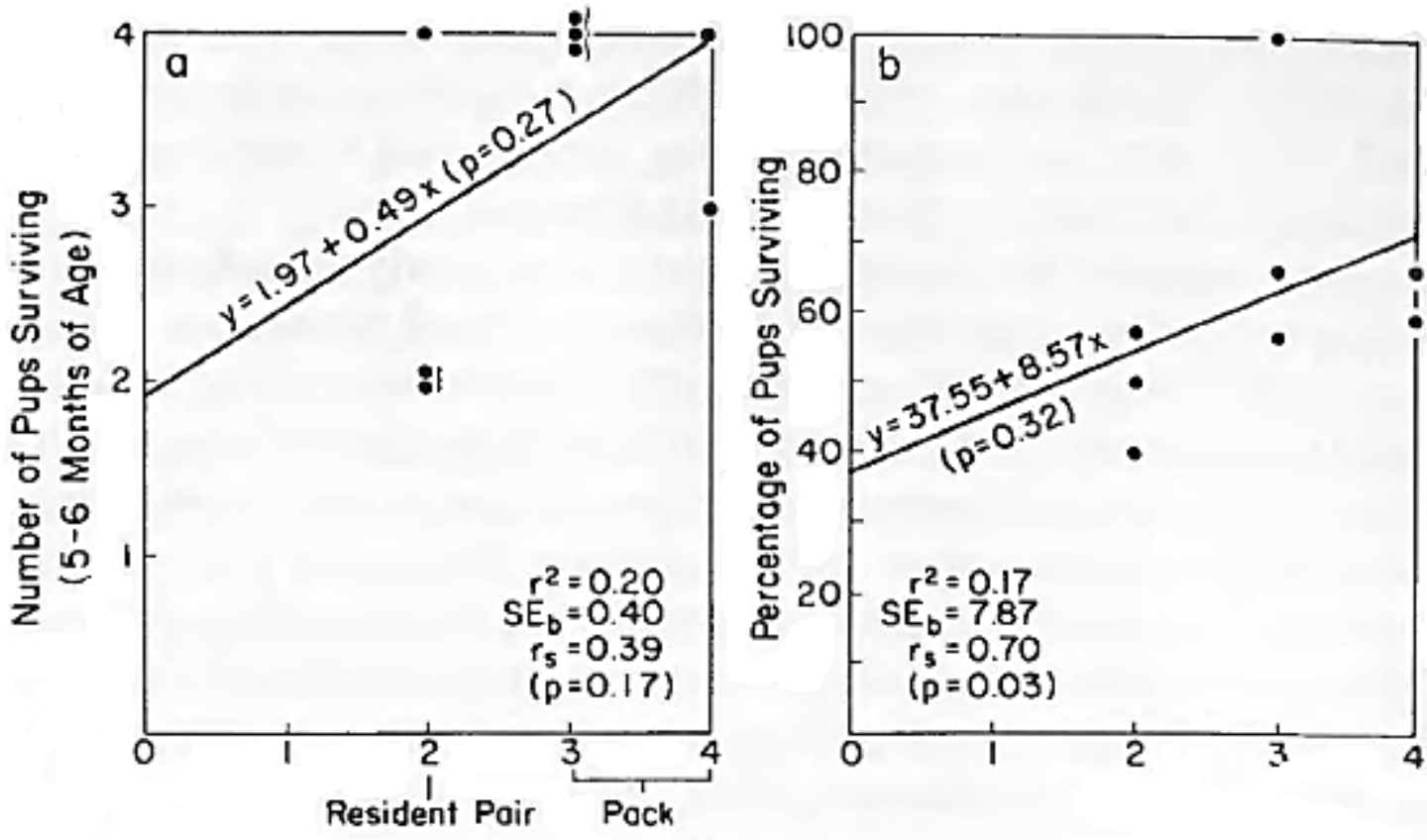

Number of Adults

Although the presence of helpers was associated with high quality winter habitat, even these two variables working in conjunction did not significantly increase pup survival when compared to resident pair pups (also see Brown and Balda, 1977). Helpers' presence did increase the average probability (survivorship) of an individual pup surviving to 5-6 months of age (Fig. 19b). A nonsignificant relationship was found between the weight of juvenile survivors and the number of adults attending dens $\left(r_{\mathrm{s}}=+0.31, p\right.$ = 0.09; see Bekoff and Wells, 1982, Fig. 10).

In various canids, pup survival is positively correlated with the presence of helpers, although the relationship is not always statistically significant. Comparative data can be found in Moehlman (1979, 1981, 1983; see also Montgomerie, 1981); Bekoff and Wells (1982), Macdonald and Moehlman (1982), Malcolm and Marten (1982), and Harrington et al. (1983). However, ecological conditions might influence the interrelationships among pack size, litter size, pup weight, and pup survival (Harrington et al., 1983). For example, when prey were scarce and a wolf population was declining, Harrington et al. (1983) found 
that litter size and pack size were inversely related and pairs produced more surviving young than did packs with one or more potential helpers. On the other hand, when prey were abundant and the wolf population was increasing, positive (although not all statistically significant) correlations were found between pack size and litter size, pack size and pup weight, and pack size and the number of surviving pups. In red foxes, the presence of helpers might negatively influence pup survival when food is scarce (von Schantz, 1981).

\section{The Evolution of Helping}

a. Differential Dispersal. There are many reasons why an individual might remain in its natal territory and help even though it is unable to mate without moving away from the area in which it was born. If (1) dispersal is risky, (2) the availability of potential mates or breeding areas is low, and/or (3) initial reproductive success is low, there might be selection for delayed dispersal by at least some offspring if ecological conditions permit it (Brown, 1969, 1982, 1983; Bekoff, 1977c; Emlen, 1982a,b, 1984; Pyrah, 1984). On the other hand, if dispersal is not risky, the chance of mating is high, and if initial reproductive success also is high, early disposal will be favored.

In coyotes, dispersal by yearlings is risky. Also, newly reproductive animals usually do not make a significant contribution to local populations. Available data are insufficient to determine reliably what proportion of first-year dispersers successfully reproduce, and comparing lifetime reproductive success between young and old dispersers is an exercise in speculation at best. Nonetheless, it is possible that a coyote that delays dispersal and breeding until it is 2 or 3 years old may not necessarily show decreased reproductive success when compared to individuals who disperse as yearlings. Thus, observed patterns of emigration in which some, but not all, individuals disperse (a dispersal polymorphism, Bekoff, 1977c) are not unexpected (Bowen, 1978, 1981; Carnenzind, 1978; Bekoff and Wells, 1982). Substituting our data into Hamilton's rule in the form $r b-c>0$ (Grafen, 1984, p. 71), it is clear that both males and females that are unable to mate should help. Breeding is better than helping, but helping is better than doing nothing at all (see also Reyer, 1984).

b. Kin Selection and Reciprocity. An analysis of male helper B21 (Fig. 2) can be used as a focus for a brief discussion of the evolution of helping behavior. By delaying dispersal, B21 (1) helped to rear fulland half-siblings, (2) inherited a breeding area, (3) mated with an unrelated female (Mother 2) after his mother and father left the pack, and (4) received help from individuals to whom he had previously provided care. Thus, kin selection and reciprocity can be invoked to account for his behavior. It appears that helping in many carnivores and in other vertebrates can also be explained by these two mechanisms often working together (Rood, 1978, 1983b; Macdonald and Moehlman, 1982; Malcolm and Marten, 1982; Brown, 1983; Moehlman, 1983; Owens and Owens, 1984).

Needless to say, additional comparative data are needed for other coyote populations and vertebrates in general. Nonetheless, there is strong agreement among the results of different studies, and some fairly robust trends have been elucidated (Malcolm and Moehlman, 1982; Moehlman, 1983).

\section{THE SOCIAL ECOLOGY OF COYOTES: INTRASPECIFIC VARIATION AND FOOD RESOURCES}

\section{A. GROUP SIZE, RANGING AREAS, AND FOOD}

The way in which food resources are exploited (located, hunted, scavenged, or defended) and the quality, quantity, and spatial distribution of food are closely related to intraspecific variations in social organization, including group size and space use. With very few exceptions, intraspecific variation, or behavioral scaling (Wilson, 1975), in the social organization of carnivores, as an adaptive response to local food resources, is the rule among species in which group living is associated with the exploitation of 
food (see Macdonald and Moehlman, 1982; Macdonald, 1983; Bekoff et al., 1984; Lott, 1984, for extensive references; also see von Schantz, 1984, for a discussion of Macdonald's, 1983, resource dispersion hypothesis). It also is common in species in which the availability of ample food permits aggregations to form, but in which the exploitation of food is not typically a group endeavor (see Bekoff et al., 1984, for references).

Among carnivores, when abundant food is clumped and economically defendable (Brown, 1964; Gosling and Petrie, 1981), coyotes (Bowen, 1978, 1981; Bekoff and Wells, 1982; Camenzind, 1978), golden jackals (Macdonald, 1979), Kalahari desert lions (M. J. Owens and D. D. Owens, personal communication), domestic cats (Izawa et al., 1982), and striped hyenas (Hyaena hyaena; Macdonald, 1978; see also Kruuk, 1976) show increases in group size and decreases in territory size compared to conspecifics for whom food resources are less abundant and scattered.

\section{Variations in Coyote Grouping Patterns}

a. The Relative Occurrence of Different Sized Groups. The relative frequency with which different-sized groups are observed during the course of a study provides useful comparative information concerning intraspecific variability for one component of social organization. These data have been reported for coyote populations occupying different habitats (Bowen, 1978; Camenzind, 1978; Litvaitis and Shaw, 1980; Andelt, 1982; Messier and Barrette, 1982; this study). Because of differences in methodology (observation "versus" radio tracking, sampling techniques), and variations in criteria concerning grouping patterns (for example, how close do two or more individuals have to be to be called a "group"), it is difficult to make precise comparative analyses of the data. Furthermore, the seasonal distribution of observations or tracking periods needs to be considered because of variations in group size that occur throughout the year.

Despite methodological differences, it appears that in areas where food was abundant and concentrated, groups (> 2) of coyotes were observed more frequently than either resident pairs or solitary residents or transients (Bowen, 1978; Camenzind, 1978; Andelt, 1982). For example, the relative frequency of occurrence of groups containing more than two coyotes was $58 \%$ in Alberta, Canada (Bowen, 1978), $61 \%$ on the National Elk Refuge, Jackson, Wyoming (Camenzind, 1978), and 70\% on the Welder Wildlife Refuge, Texas (Andelt, 1982). We observed groups of two or more coyotes only about $40 \%$ of the time. However, we spent a lot of time sampling away from the main area in which the pack resided. The winter food supply on the National Elk Refuge, about $8 \mathrm{~km}$ from Blacktail Butte, is much greater than that around the butte, and we expected to see groups less frequently than did Camenzind. A clear example of great intraspecific variation in this measure is provided by Litvaitis and Shaw's (1980) data. They reported that fewer than $6 \%$ of their observations were of two or more coyotes; lone animals were observed $78 \%$ of the time.

b. Seasonal Variations in Group Size and Their Association with Food Resources. The relative frequencies with which different sized groups are observed, and estimations of overall mean group sizes, can be greatly influenced by how sampling is distributed seasonally. This is especially true when there are large differences in grouping patterns that are influenced by food resources and other environmental factors. Definitions of "seasons" also need to be considered. Moreover, it is essential to clarify sampling techniques, because group sizes can be inflated when pups are still around denning areas and included in the sample.

We observed that mean group sizes varied seasonally, and even within seasons, variations in group sizes appeared to be associated with food resources. Differences in sampling and definitions of seasons 
must be taken into account in comparative analyses, but there are some robust trends that emerge from different field studies in which the nature of the food supply is the critical variable.

On our study site and in other areas as well, the presence of a large, clumped, and abundant food source (elk carrion) during winter influenced pack size. Around Blacktail Butte, mean group sizes in fall and spring/summer, when small rodents were the major food source, were the same (1.4). During winter, mean group size was 1.8. For all Novembers, mean group size was 1.5. It increased to about 1.8 from December to March, and decreased to 1.5 in April. During winter, we found a correlation of +0.98 for the relationship between coyote pack size and the abundance of elk carion. Weaver (1979) also found that coyotes in the Jackson Hole area were most numerous where elk carrion was most abundant $(r=+0.84)$. Furthermore, as discussed above, pack members occupied much smaller living areas than did coyotes for whom food, especially carrion during winter, was less abundant and more scattered. Comely (1980) and Drewek ( 1980) also reported very small ranging areas for coyotes living in areas where food was available in large quantities. Similar results have also been presented for red foxes (Jones and Theberge, 1982).

Comparative and similar data from other field studies on coyotes are available. Bowen (1978) reported mean summer and winter group sizes of 1.4 and 2.0, respectively, and Andelt (1982) found slightly larger groups when the coyotes he studied were feeding on medium-large size mammals ( 1.4 based on observations and 1.5 based on radio tracking) than when they fed on smaller animals (1.2). Camenzind (1978) reported the mean winter group size of coyotes on the National Elk Refuge to be 3.2 animals. The coyotes that he studied had a more abundant supply of elk carrion during winter than did the animals living around Blacktail Butte, and the larger mean group size was expected. Data and references for other carnivores can be found in Zimen (1976), Johnsingh (1982), Mills (1983), and Bekoff et al. (1984).

\section{B. WHY DO SOME COYOTES LIVE IN GROUPS: PACK DEFENSE AGAINST INTRUDERS}

A comparative discussion of carnivore grouping patterns is presented in Bekoff et al. (1984). Although animals that live in groups have attracted a disproportionate amount of attention, group living has only evolved in about $10-15 \%$ of carnivore species. Indeed, we have learned a lot about the evolution of sociality by studying solitary animals, such as felids and small carnivores. Suffice it to say, grouping patterns, including "optimal" size and composition, vary greatly, even among conspecifics. Coyotes provide an excellent example of intraspecific variability in social organization.

In some carnivores, such as wolves, African wild dogs, and lions, group living has evolved primarily as an adaptation for the acquisition of live food, especially prey items that are larger or faster than an individual predator (Mech, 1970; Schaller, 1972; Kleiman and Eisenberg, 1973; Caraco and Wolf, 1975; Nudds, 1978; Bertram, 1978; Lamprecht, 1978, 1981; Rodman, 1981; Parker et al., 1983). Defense of food items also might require a group effort. For example, sociality in lions seems to have evolved along with group hunting and the necessity of defending large kills in open savannah habitats (Schaller, 1972; Bertram, 1978; Elliott and McT. Cowan, 1978). Group living may also be associated with protection against predators (Rood, 1983a; Bekoff et al., 1984).

\section{Coyote Packs and Group Defense}

Pack formation in coyotes appears to be an adaptation for the defense of food, rather than for the acquisition of live prey (Bowen, 1978, 1981; Camenzind, 1978; Bekoff and Wells, 1980, 1982). Andelt (1982) found that the percentage of white-tailed deer in the diet of coyotes was not related to group size. Bowen (1981) reported a positive relationship between the percentage of mule deer in the winter diet of 
coyotes and group size, but did not find a significant relationship when elk were considered. Unfortunately, Bowen was not able to observe directly coyote predation on mule deer.

Patterns of Group Defense Displayed by Pack-Living Coyotes around Blacktail Butte. While it is possible in some cases that coyote packs are more successful than single animals in catching large ungulates, there are insufficient data to argue conclusively that coyote groups have evolved for the acquisition of prey. On the other hand, available data support the idea that coyote groups are important for the defense of food. For example, Bowen (1981) observed that packs of two or more coyotes had better access to, and spent more time feeding at, carcasses than did lone individuals. Groups also defended carcasses more successfully than single coyotes.

We made detailed observations of group defense against intruding coyotes. No fatal encounters were seen (but see Okoniewski, 1982). After an initial confrontation, intruders were usually harassed until they were driven off or the resident coyotes retreated. Similar patterns were reported by Preston (1975) for red foxes.

Intrusions by nongroup coyotes were much more numerous during winter when food was abundant in the pack's territory and scarce throughout the rest of the area around the butte. Of the seven times when there were intrusions into the pack's territory when pups were present, the parents chased the intruders five (71\%) times and one helper (H77, Fig. 2) chased them twice.

We observed pack-intruder encounters 55 times during winter. Pack members "won" [the intruder(s) was driven out of the pack's territory] a significantly greater percentage $(75 \% ; 41 / 55)$ of interactions than did intruders. The mean number of group members involved in successful encounters was 2.5. Significantly fewer pack members (1.3) were involved in pack "losses" [the intruder(s) was not chased off of the pack's territory]. Ten of $15(66.7 \%)$ encounters involving a single pack member were lost. The mean group sizes of intruders when they won and lost were 1.4 and 1.1, respectively.

All pack members participated in territorial and food (elk carrion) defense. At least 1 adult was involved in 52 (95\%) encounters and at least 1 helper was observed in $45(82 \%)$ interactions. One or more pack members initiated 41 (75\%) encounters with intruders, whereas intruders initiated only $14(25 \%)$ interactions. At least 1 parent and at least 1 helper was involved in the initiation of 24 (44\%) and 31 (56\%) interactions, respectively. Clearly, helpers' presence was important in encounters with intruders.

Pack-initiated defense was negatively correlated $(r=-0.94)$ with the number of intruders present at any one time (intruder density) on the pack's winter territory (Bekoff and Wells, 1982). Our data agree with Lamprecht's (1978) suggestion that the amount of defense shown by territorial animals should be negatively related to the physical strength and numbers of aggressive competitors.

We also analyzed the distance between all possible pairs of animals (excluding times when they were resting) as a function of the number of intruders present. In almost all cases, there was a significant negative correlation between intruder density and interindividual distance. For example, the correlations between these two variables for the mated pair, male helper B21 and his mother, B21 and his father, and B21 and an older sibling were $-0.25,-0.22,-0.20$, and -0.27 , respectively.

\section{CONCLUDING REMARKS}

Obviously more detailed comparative data are needed for other coyote populations and for carnivores in general. This is especially true for species living in unexploited habitats (Kleiman and Brady, 1978). There is no substitite for long-term field projects of known individuals (Mech and Hertel, 1983). These research programs require substantial financial backing, and it is our hope that this support will be forthcoming. In 
order to manage and to conserve wild populations of animals, basic data such as those presented here are required. We also may learn something about ourselves by studying one of nature's great survivors (Roessel and Platero, 1974; Lopez, 1977).

\section{Acknowledgments}

We thank the following organizations for support of our research: The National Science Foundation (BNS78-27616, BNS-79-23463, and BNS-79-05770), The National Institute of Mental Health (29571), The John Simon Guggenheim Memorial Foundation, The Harry Frank Guggenheim Foundation, The University of Colorado, and The Grand Teton National Park. We also are deeply indebted and grateful to all of the students who worked on the project, and to Michael C. Grant, Jeffry B. Mitton, Douglas Conner, Fred Wieland, and Tony Lavender for help with various analyses of the data. Stimulating conversations with numerous people, including Joel Berger, John Byers, Dave Mech, Doug Conner, Valerie Lipetz, Carron Meaney, Tom Daniels, Franz Camenzind, John Gittleman, David Macdonald, Patti Moehlman, Lisa Gouse, Bettina Jansen, Don Bowen, Ben Beck, Buford Holt, and Tim Clark were always beneficial. We apologize to those people whom we have inadvertantly omitted. Tom Daniels, David Manry, and the editors of this volume provided helpful comments on a previous draft of the article.

\section{References}

Ables, E. D. (1969). Home-range studies of red foxes (Vulpes vulpes). J. Mammal. 50, 108-120.

Alexander, R. D. (1974). The evolution of social behavior. Annu. Rev. Ecol. Syst. 4, 325-383.

Althoff, D. P., and Gipson, P. S. (1981). Coyote family spatial relationships with reference to poultry losses. J. Wildl. Manage. 45, 641-649.

Altmann, J. (1974). Observational study of behavior. Behaviour 49, 227-265.

Altmann, S. A. (1974). Baboons, time, space, and energy. Am. Zool. 14, 221-248.

Amlaner, C. J., and Macdonald, D. W. (eds.) (1980) . "A Handbook on Biotelemetry and Radio Tracking." Pergamon, Oxford.

Andelt, W. F. (1982). Behavioral ecology of coyotes on the Welder Wildlife Refuge, south Texas. Ph.D. dissertation, Colorado State University, Fort Collins.

Andelt, W. F. (1985). Behavioral ecology of coyotes in South Texas. Wildl. Monogr., in press.

Andelt, W. F., and Gipson, P. S. (1979). Home range, activity, and daily movements of coyotes. J. Wildl. Manage. 43, 944-951.

Andelt, W. F., Althoff, D. P., and Gipson, P. S. (1979). Movements of breeding coyotes with emphasis on den site relationships. J. Mammal. 60, 568-575.

Andersson, M. (1984). The evolution of eusociality. Annu. Rev. Ecol. Syst. 15, 165-189.

Armitage, K. B. (1981). Sociality as a life-history tactic of ground squirrels. Oecologia 48, 36-49.

Baker, M. C., and Mewaldt, L. R. (1979). The use of space by white-crowned sparrows: Juvenile and adult ranging patterns and home range versus body size comparisons in an avian granivore community. Behav. Ecol. Sociobiol. 6, 45-52.

Barklow, W. E., and Chamberlain, J. A. (1984). The use of the tremolo call during mobbing by the common loon. J. Field Ornithol. 55, 258-259.

Barnum, D. A., Green, J. S., Flinders, J. T., and Gates, N. L. (1979). Nutritional levels and growth rates of hand-reared coyote pups. J. Mammal. 60, 820-823.

Barrette, C. (1977). Scent-marking in captive muntjacks, Muntiacus reevesi. Anim. Behav. 25, 536-554.

Barrette, C., and Messier, F. (1980). Scent-marking in free-ranging coyotes. Anim. Behav. 28, 814-819.

Batschelet, E. (1965). "Statistical Methods for the Analysis of Problems in Animal Orientation and Certain Biological Rhythms." Amer. Inst. Bioi. Sci., Washington, D.C.

Beach, F. A. (1974). Effects of gonadal hormones on urinary behavior in dogs. Physiol. Behav. 12, 10051013. 
Bekoff, M. (1972a). An ethological analysis of the development of social interaction in the genus Canis: A dyadic analysis. Ph.D. dissertation, Washington University, St. Louis, Missouri.

Bekoff, M. (1972b). The development of social interaction, play, and metacommunication in mammals: An ethological perspective. Q. Rev. Bioi. 47, 412-434.

Bekoff, M. (1974). Social play and play-soliciting by infant canids. Am. Zoot. 14, 323-340.

Bekoff, M. (1977a). The coyote, Canis latrans Say. Mammal. Spec. 79, 1-9.

Bekoff, M. (1977b). Quantitative studies of three areas of classical ethology: Social dominance, behavioral taxonomy, and behavioral variability. In "Quantitative Methods in the Study of Animal Behavior" (B. A. Hazlett, ed.), pp. 1-46. Academic Press, New York.

Bekoff, M. (1977c). Mammalian dispersal and the ontogeny of individual behavioral phenotypes. Am. Nat. $111,715-732$.

Bekoff, M. (ed.) (1978a). "Coyotes: Biology, Behavior, and Management." Academic Press, New York.

Bekoff, M. (1978b). Behavioral development in coyotes and eastern coyotes. In "Coyotes: Biology, Behavior, and Management" (M. Bekoff, ed.), pp. 97-126. Academic Press, New York.

Bekoff, M. (1978c). A field study of the development of behavior in Adelie penguins: Univariate and numerical taxonomic approaches. In "The Development of Behavior: Comparative and Evolutionary Aspects" (G. Burghardt and M. Bekoff, eds .), pp. 177-202. Garland, New York.

Bekoff, M. (1978d). Social play: Structure, function, and the evolution of a cooperative social behavior. In "The Development of Behavior: Comparative and Evolutionary Aspects" (G. Burghardt and M. Bekoff, eds.), pp. 367-383. Garland, New York.

Bekoff, M. (1979a). Coyote damage assessment in the west: Review of a report. BioScience 29, 754.

Bekoff, M. (1979b). Scent-marking by free-ranging domestic dogs: Olfactory and visual components. Bioi. Behav. 4, 123-139.

Bekoff, M. (1979c). Ground scratching by male domestic dogs: A composite signal. J. Mammal. 60, 847848.

Bekoff, M. (1980). Accuracy of scent-mark identification for free-ranging dogs. J. Mammal. 61, 150.

Bekoff, M. (1981). Mammalian sibling interactions: Genes, facilitative environments, and the coefficient of familiarity.In "Parental Care in Mammals" (D. J. Gubernick and P. H. Klopfer, eds.), pp. 307-346. Plenum, New York.

Bekoff, M. (1982). Coyotes, Canis latrans Say 1823. In "Wild Mammals of North America: Biology, Management, and Economics" (J. Chapman and G. Feldhammer, eds.), pp. 447-459. John Hopkins Univ. Press, Baltimore.

Bekoff, M. (1983). Predatory strategies and behavioral diversity. Am. Bioi. Teacher 45, 334-342.

Bekoff, M. (1984). Social play behavior. Bioscience 34, 228-233.

Bekoff, M. (1985). Patterns of mammalian dispersal: Animals as "bumper cars." In preparation.

Bekoff, M., and Byers, J. A. (1981). A critical reanalysis of the ontogeny and phylogeny of mammalian social and locomotor play: An ethological hornet's nest. In "Behavioral Development: The Bielefeld Interdisciplinary Conference" (K. Immelmann, G. W. Barlow, L. Petrinovich, and M. Main, eds.), pp. 296-337. Cambridge Univ. Press, New York.

Bekoff, M., and Byers, J. A. (1985). The development of behavior from evolutionary and ecological perspectives in mammals and birds. Evol. Bioi. 19, 215-286.

Bekoff, M., and Diamond, J. (1976). Precopulatory and copulatory behavior in coyotes. J. Mammal. 57, 372-375.

Bekoff, M., and Jamieson, R. A. (1975). Physical development in coyotes with a comparison to other canids. J. Mammal. 56, 685-692.

Bekoff, M., and Mech, L. D. (1984). Simulation analyses of space use: Home range estimates, variability, and sample size. Behav. Res. Meth. Instrum. Comput. 16, 32-37.

Bekoff, M., and Wells, M. C. (1980). The social ecology of coyotes. Sci. Am. 242, 130-148. 
Bekoff, M., and Wells, M. C. (1981). Behavioral budgeting by wild coyotes: The influence of food resources and social organization. Anim. Behav. 29, 794-801.

Bekoff, M., and Wells, M. C. (1982). Behavioral ecology of coyotes: Social organization, rearing patterns, space use, and resource defense . Z. Tierpsychol. 60, 281-305.

Bekoff, M., Hill, H. L., and Mitton, J. B. (1975). Behavioral taxonomy in canids by discriminant function analysis. Science 190, 1223-1225.

Bekoff, M., Diamond, J., and Mitton, J. B. (1981a). Life history patterns and sociality in canids: Body size, reproduction, and behavior. Oecologia SO, 386-390.

Bekoff, M., Tyrrell, M., Lipetz, V., and Jamieson, R. (1981b). Fighting patterns in young coyotes: Initiation, escalation, and assessment. Aggressive Behav. 1, 225-244.

Bekoff, M., Wieland, C., and Lavender, W. A. (1982). Space-out: Graphics programs to study and to simulate space use and movement patterns. Behav. Res. Meth. Instrum. Comput. 14, 34-36.

Bekoff, M., Daniels, T. J., and Gittleman, J. L. (1984). Life history patterns and the comparative social ecology of carnivores. Annu. Rev. Ecol. Syst. 15, 191-232.

Berg, W. E., and Chesness, R. A. (1978). Ecology of coyotes in northern Minnesota. In "Coyotes: Biology, Behavior, and Management" (M. Bekoff, ed.), pp. 229-247. Academic Press, New York.

Berger, J. (1979). "Predator harassment" as a defensive strategy in ungulates. Am. Midland Nat. 102, 197-199.

Bertram, B. C. R. (1978). Living in groups: Predators and prey. In "Behavioral Ecology: An Evolutionary Approach" (J. R. Krebs and N. B. Davies, eds.), pp. 64-96. Sinauer, Sunderland, Massachusetts.

Biben, M. (1982). Ontogeny of social behavior related to feeding in the crab-eating fox (Cerdocyon thous) and the bush dog (Speothos venzticus). J. Zool. 196, 207-216.

Boorman, S. A., and Levitt, P. R. (1980). "The Genetics of Altruism." Academic Press, New York.

Bowen, W. D. (1978). Social organization of the coyote in relation to prey size. Ph.D. dissertation, University of British Columbia, Vancouver.

Bowen, W. D. (1981). Variation in coyote social organization: The influence of prey size. Can. J. Zool. 59, 639-652.

Bowen, W. D. (1982). Home range and spatial organization of coyotes in Jasper National Park, Alberta. J. Wildl. Manage. 46, 201-216.

Bowen, W. D., and McT. Cowan, I. (1980). Scent marking in coyotes. Can. J. Zoot. 58, 473-480.

Brown, J. L. (1964). The evolution of diversity of avian territorial systems. Wilson Bull. 76, 160-169.

Brown, J. L. (1980). Fitness in complex avian social systems. In "Evolution of Social Behavior: Hypotheses and Empirical Tests" (H. Markl, ed.), pp. 115-128. Verlag Chemie, Weinheim.

Brown, J. L. (1982). Optimal group size in territorial animals. J. Theor. Bioi. 95, 793-810.

Brown, J. L. (1983). Cooperation-a biologist's dilemma. Adv. Study Behav. 13, 1-37.

Brown, J. L., and Balda, R. P. (1977). The relationship of habitat quality to group size in Hall's babbler (Pomatostomus halli). Condor 19, 312-320.

Brown, I. L., and Orians, G. H. (1970). Spacing patterns in mobile animals. Annu. Rev. Ecol. Syst. 1, 239262.

Burger, J. (1984). Pattern, mechanism and adaptive significance of territoriality in herring gulls (Larus argentatus). Ornithol. Mongr. (4), 1-92.

Burt, W. H. (1943). Territoriality and home range concepts as applied to mammals. J. Mammal. 24, 346353.

Byers, J. A., and Byers, K. Z. (1983). Do pronghorn mothers reveal the locations of their hidden fawns? Behav. Ecol. Sociobiol. 13, 147-156.

Calder, W. A., 111 (1984). "Size, Function, and Life History." Harvard Univ. Press, Cambridge, Massachusetts. 
Camenzind, F. J. (1978). Behavioral ecology of coyotes on the national Elk Refuge, Jackson, Wyoming. In "Coyotes: Biology, Behavior, and Management" (M. Bekoff, ed.), pp. 267-294. Academic Press, New York.

Caraco, T., and Wolf, L. L. (1975). Ecological determinants of group sizes of foraging lions. Am. Nat. 109, 343-352.

Carbyn, L. ( 1982). Coyote population fluctuations and spatial distribution in relation to wolf territories in Riding Mountain National Park, Manitoba. Can. Field. Nat. 96, 176-183.

Carbyn, L. N. (1983). Wolf predation on elk in Riding Mountain National Park, Manitoba. J. Wildl. Manage. 47, 963-976.

Cheeseman, C. L., and Mitson, R. B. (eds.) (1982). Telemetric studies of vertebrates. Symp. Zool. Soc. London 49.

Chivers, D. J. (1973). An introduction to the socio-ecology of Malayan forest primates. In "Comparative Ecology and Behavior of Primates" (R. P. Michael and I. H. Crook, eds.), pp. 101-146. Academic Press, New York.

Clutton-Brock, T. H., and Harvey, P. H. (1976). Evolutionary rules and primate societies. In "Growing Points in Ethology" (P. P. G. Bateson and R. A. Hinde, eds.), pp. 195-237. Cambridge Univ. Press, New York.

Coelho, A.M., Bramblett, C. A., and Quick, L. B. (1979). Activity patterns in howler and spider monkeys: An application of socio-bioenergetic methods. In "Primate Ecology and Human Origins" (I. S. Bernstein and E. 0. Smith, eds.), pp. 175-199. Garland, New York. Colgan, P. (ed.) (1978). "Quantitative Ecology." Wiley, New York.

Connolly, C. E., Timm, R. M., Howard, W. E., and Longhurst, W. M. (1976). Sheep killing behavior of captive coyotes. J. Wildl. Manage. 40, 400-407.

Comely, J. E. (1980). Home ranges and diets of coyotes in Joshua Tree National Monument in relation to prey densities. Ph.D. dissertation, Northern Arizona University, Flagstaff, Arizona.

Covich, A. P. (1976). Analyzing shapes of foraging areas: Some ecological and economic theories. Annu. Rev. Ecol. Syst. 7, 235-257.

Crampton, E., and Lloyd, L. (1959). "Fundamentals of Nutrition." Freeman, San Francisco.

Crook, I. H. (1964). The evolution of social organization and visual communication in the weaver birds (Ploceinae). Behavior Suppl. 10, 1-178.

Crook, J. H. (1965). The adaptive significance of avian social organization. Symp. Zool. Soc. London 14, 181-218.

Cummins, K. W., and Wuycheck, J. C. (1971). Caloric equivalents for investigations in ecological energetics. Int. Vert. Theor. Angew. Limnol. (18).

Curio, E. (1976). "The Ethology of Predation." Springer-Verlag, New York.

Danner, D. A., and Smith, N. S. (1980). Coyote home range, movement, and relative abundance near a cattle feedyard. J. Wildl. Manage. 44, 484-487.

Davenport, J. W., Bowns, J. E., and Workman, J. P. (1973). Assessment of sheep losses to coyotes: A problem to Utah sheepman, a concern to Utah researchers. Agric. Exp. Station, Utah State Univ., Logan pp. 17.

Dobson, F. S. (1982). Competition for mates and predominant juvenile male dispersal in mammals. Anim. Behav. 30, 1183-1192.

Don, B. A. C., and Rennolls, K. (1983). A home range model incorporating biological attraction points. J. Anim. Ecol. 52, 69-81.

Drewek, J. (1980). Behavior, population structure, parasitism, and other aspects of coyote ecology in southern Arizona. Ph.D. dissertation, University of Arizona, Tuscon, Arizona.

Dunbar, I. (1977). Olfactory preferences in dogs. The response of male and female beagles to conspecific odors. Behav. Biol. 20, 471-481. 
Dunbar, M. R. (1973). Seasonal changes in testis morphology and spermatogenesis in adult and youngof-the-year coyotes (Canis latrans). M. A. thesis, Oklahoma State University, Stillwater, Oklahoma.

Dunn, J. E. (1979). A complete test for dynamic territorial interaction. Proc. Sec. Int. Conf. Wildl. Biotelemetry, pp. 159-169.

Eisenberg, J. F. (1981). "The mammalian radiations: An analysis of trends in evolution, adaptation, and behavior." Univ. of Chicago Press, Chicago.

Eisenberg, J. F., and Kleiman, D. G. (1972). Olfactory communication in mammals. Annu. Rev. Ecol. Syst. 3, 1-32.

Eisenberg, J. F., and Leyhausen, P. (1972). The phylogenesis of predatory behaviour in mammals. Z. Tierpsychol. 30, 59-93.

Elliott, J.P., and McT. Cowan, I. (1978). Territoriality, density, and prey of the lion in Ngorongoro Crater, Tanzania. Can. J. Zool. 56, 1726-1734.

Elliott, J.P., McT. Cowan, I., and Holling, C. S. (1977). Prey capture by the African lion. Can. J. Zool. 55, 1811-1828.

Emlen, S. T. (1982a). The evolution of helping. I. An ecological constraints model. Am. Nat. 119, 29-39.

Emlen, S. T. (1982b). The evolution of helping. II. The role of behavioral conflict. Am. Nat. 119, 40-53.

Emlen, S. T. (1984). Cooperative breeding in birds and mammals. In " Behavioural Ecology: An Evolutionary Approach" (J. R. Krebs and N. B. Davies, eds.), 2nd Ed., pp. 305-339. Sinauer, Sunderland, Massachusetts.

Ewer, R. F. (1968). "Ethology of Mammals." Plenum, New York.

Ewer, R. F. (1973). "The Carnivores." Cornell Univ. Press, Ithaca.

Fagen, R. (1981). "Animal Play Behavior." Oxford Univ. Press, New York.

Fisler, G. F. (1969). Mammalian organizational systems. Los Angeles County Mus. (167), 1-32.

Fox, M. W. (1969a). The anatomy of aggression and its ritualization in canidae: A developmental and comparative study. Behaviour 35, 242-258.

Fox, M. W. (1969b). Ontogeny of prey killing behaviour in canidae. Behaviour 35, 259-272.

Fox, M. W. (1970). A comparative study of the development of facial expressions in canids, wolf, coyote, and foxes. Behaviour 36, 49- 73.

Fox, M. W. (1971). " Behaviour of Wolves, Dogs and Related Canids." Harper, New York.

Fox, M. W. (ed.) (1975). "The Wild Canids: Their Systematics Behavioral Ecology and Evolution." Van Nostrand-Reinhold, Princeton, NJ.

Fox, M. W., and Clark, A. (1971). The development and temporal sequencing of agonistic behavior in the coyote (Canis latrans). Z. Tierpsychol. 28, 262-278.

Frame, L. H., Malcolm, J. R., Frame, G. W., and van Lawick, H. (1979). Social organization of African wild dogs (Lycaon pictus) on the Serengeti Plains, Tanzania 1967-1978. Z. Tierpsychol. 50, 225-249.

Fritts, S. H., and Mech, L. D. (1981). Dynamics, movements, and feeding ecology of a newly protected wolf population in northwestern Minnesota. Wild. Mongr. (80), 1-79.

Fuller, T. K., and Keith, L. B. (1980). Wolf population dynamics and prey relationships in northeastern Alberta. J. Wildl. Manage. 44, 583-602.

Fuller, T. K., and Keith, L. B. (1981). Non-overlapping ranges of coyotes and wolves in northeastern Alberta. J. Mammal. 62, 403-405.

Gaines, M.S., and McClenaghan. (1980). Dispersal in small mammals. Annu. Rev. Ecol. Syst. 11, 163196.

Garrott, R. A., and Eberhardt, L. E. (1982). Mortality of arctic fox pups in northern Alaska. J. Mammal. 63, 173-174.

Garrott, R. A., Eberhardt, L. E., and Hanson, W. C. (1984). Arctic fox denning behavior in northern Alaska. Can. J. Zool. 62, 1636-1640. 
Gessaman, J. A. (1973). Methods of estimating the energy cost of free existence. In "Ecological Energetics of Horneotherms" (J. A. Gessaman, ed.), pp. 3-31. Utah State Univ. Press, Logan.

Getty, T. (1981). Structure and dynamics of chipmunk home ranges. J. Mammal. 62, 726-737.

Gier, H. T. (1968). Coyotes in Kansas. Kansas State Coli. Agric. Exp. Station Bull. 393, 1-118.

Gier, H. T. (1975). Ecology and behavior of the coyote (Canis latrans). In "The Wild Canids: Their Systematics, Behavioral Ecology and Evolution" (M. W. Fox, ed.), pp. 247-262. Van NostrandReinhold, Princeton, NJ.

Gipson, P. S., and Sealander, J. A. (1972). Home range and activity of the coyote (Canis latrans frustor) in Arkansas. Proc. Annu. Conf. Southeast Game Fish Comm. 26, 82-85.

Gipson, P. S., I. K. Gipson, and Sealander, I. A. (1975). Reproductive biology of wild Canis in Arkansas. J. Mammal. 56, 605-612.

Gittleman, J. L. (1984). The behavioural ecology of carnivores. Ph.D. thesis, University of Sussex, England.

Gittleman, J. L., and Harvey, P. H. (1982). Carnivore home-range size, metabolic needs and ecology. Behav. Ecol. Sociobiol. 10, 57-63.

Golani, I., and Keller, A. (1975). A longitudinal field study of the behavior of a pair of golden jackals. In "The Wild Canids" (M. W. Fox, ed.), pp. 303-335. Van Nostrand-Reinhold, Princeton, NJ.

Gorman, M. L., and Mills, M. G. L. (1984). Scent marking strategies in hyaenas (Mammalia). J. Zool. 202, 535-547.

Gosling, L. M. (1982). A reassessment of scent marking in territories. Z. Tierpsychol. 60, 89-118.

Gosling, L. M., and Petrie, M. (1981). The economics of social organization. In "Physiological Ecology: An Evolutionary Approach" (C. R. Townsend and P. Calow, eds.), pp. 315-345. Blackwell, Oxford.

Grafen, A. (1982). How not to measure inclusive fitness. Nature (London) 298, 425-426.

Grafen, A. (1984). Natural selection, kin selection and group selection. In "Behavioural Ecology: An Evolutionary Approach" (I. R. Krebs and N. B. Davies, eds.), pp. 62-84. Sinauer, Sunderland, Massachusetts.

Grandage, J. (1972). The erect dog penis: A paradox of flexible rigidity. Vet. Rec. 91, 171-177.

Green, G. E., and Grant, W. E. (1984). Variability of observed group sizes within collared peccary herds. J. Wildl. Manage. 48, 244-248.

Green, J. S., Adair, R. A., Woodruff, R. A., and Stellflug, J. N. (1984). Seasonal variation in semen production by captive coyotes. J. Mammal. 65, 506-509.

Greenwood, P. J. (1980). Mating systems, philopatry and dispersal in birds and mammals. Anim. Behav. 28, 1140-1162.

Hamilton, W. D. (1963). The evolution of altruistic behavior. Am. Nat. 97, 354-356.

Hamilton, W. D. (1964). The genetical evolution of social behaviour. I and II. J. Theor. Biol. 7, 1-52.

Hamlett, G. W. D. (1938). The reproductive cycle of the coyote. U.S. Dept. Agric. Tech. Bull. 616, 1-11.

Hamlin, K. L., and Schweitzer, L. L. (1979). Cooperation by coyote pairs attacking mule deer fawns. J. Mammal. 60, 849-850.

Hamlin, K. L., Riley, S. I., Pyrab, D., Dood, A. R., and Mackie, R. J. (1984). Relationships among mule deer fawn mortality, coyotes, and alternate prey species during summer. J. Wildl. Manage. 48, 489-499.

Harcourt, A. H., and Stewart, K. I. (1984). Gorillas time feeding: Aspects of methodology, body size, competition and diet. Afr. J. Ecol. 22, 207-215.

Harestad, A. S., and Bunnell, F. L. (1979). Home range and body weight-a reevaluation. Ecology 60, 389402.

Harrington, F. H. (1981). Urine marking and caching behaviour in the wolf. Behaviour 16, 280-288.

Harrington, F. H. (1982). Urine marking at food caches in captive coyotes. Can. J. Zool. 60, 776-782. 
Harrington, F. H., Paquet, P. C., Ryon, J., and Fentress, J. C. (1982). Monogamy in wolves: A review of the evidence. In "Wolves of the World: Perspectives of Behavior, Ecology, and Conservation" (F. H. Harrington and P. C. Paquet, eds.), pp. 209-222. Noyes, New Jersey.

Harrington, F. H., Mech, L. D., and Fritts, S. H. (1983). Pack size and wolf pup survival: Their relationship under varying ecological conditions. Behav. Ecol. Sociobiol. 13, 19-26.

Harrison, D. I. (1983). Denning ecology, movements, and dispersal of coyotes in eastern Maine. M.S. thesis, University of Maine, Orono, Maine.

Hastings, A. (1984). Age-dependent predation is not a simple process. II. Wolves, ungulates, and a discrete time model for predation on juveniles with a stabilizing tail. Theor. Pop. Biol. 26, 271-282.

Hazlett, B. A. (ed.) (1977). "Quantitative Methods in the Study of Animal Behavior." Academic Press, New York.

Henry, J. D. (1977). The use of urine marking in the scavenging behavior of the red fox (Vulpes vulpes). Behaviour 61, 82-105.

Henry, J. D. (1985). The little foxes. Nat. Hist. 94, 46-57.

Herbers, J. M. (1981). Time resources and laziness in animals. Oecologia 49, 252-262.

Hersteinsson, P., and Macdonald, D. W. (1982). Some comparisons between red and arctic foxes, Vulpes vulpes and Alopex lagopus, as revealed by radio tracking. Symp. Zool. Soc. London 49, 259-289.

Hewson, R. (1984). Scavenging and predation upon sheep and lambs in West Scotland. J. Appl. Ecol. 21, 843-868.

Hibler, S. I. (1977). Coyote movement patterns with emphasis on home range characteristics. M.S. thesis, Utah State University, Logan.

Hilborn, R., and Stearns, S. C. (1982). On inference in ecology and evolutionary biology: The problem of multiple causes. Acta Biotheor. 31, 145-164.

Hinde, R. A. (1970). "Animal Behavior." McGraw-Hill, New York.

Houston, D. B. (1978). Elk as winter-spring food for carnivores in northern Yellowstone National Park. J. Appl. Ecol. 15, 653-661.

Howard, R. D. (1979). Estimating reproductive success in natural populations. Am. Nat. 114, 221-231.

Howell, R. G. (1982). The urban coyote problem in Los Angeles County. Proc. Vert. Pest Conf., 10th, pp. 21-23.

Hughes, A. L. (1983). Kin selection of complex behavioral strategies. Am. Nat. 122, 181-190.

Huxley, I. S. (1934). A natural experiment on the territorial instinct. Br. Birds 21, 270-277.

Ikeda, H., Ono, Y., Baba, M., Doi, T., and Iwamoto, T. (1982). Ranging and activity patterns of three nocturnal viverrids in Omo National Park, Ethiopia. Afr. J. Ecol. 20, 179-186.

Isley, T. E., and Gysel, L. W. (1975). Sound-source localization by the red fox. J. Mammal. 56, 397-404.

Izawa, M., Doi, T., and Ono, Y. (1982). Grouping patterns of feral cats (Felis catus) living on a small island in Japan. Jpn. J. Ecol. 32, 373-382.

Jean, Y., and Bergeron, J.-M. (1984). Productivity of coyotes (Canis latrans) from southern Quebec. Can. J. Zool. 62, 2240-2243.

Jenkins, S. H. (1982). Common patterns in home range-body size relationships of birds and mammals. Am. Nat. 118, 126-128.

Johnsingh, A. J. T. (1982). Reproductive and social behaviour of the dhole Cuon alpinus (Canidae). J. Zool. London 198, 443-463.

Jones, D. M., and Theberge, J. B. (1982). Summer horne range and habitat utilisation of the red fox (Vulpes vulpes) in a tundra habitat, northwest British Columbia. Can. J. Zool. 60, 807-812.

Jones, J. M., and Woolf, A. (1983). Relationship between husbandry practices and coyote use of swine in west central Illinois. Wildl. Soc. Bull. 11, 133-135.

Kellert, S. R. (1985). Public perceptions of predators, particularly the wolf and coyote. Biol. Conserv. 31, 167-189. 
Kennelly, J. J. (1978). Coyote reproduction. In "Coyotes: Biology, Behavior, and Management" (M. Bekoff, ed.), pp. 73-93. Academic Press, New York.

Kennelly, J. J., and Johns, B. E. (1976). The estrous cycle of coyotes. J. Wildl. Manage. 40, 272-277.

Kennelly, J. J., and Roberts, J. D. (1969). Fertility of coyote-dog hybrids. J. Mammal. 50, 830-381.

Kleiman, D. G. (1966). Scent marking in the canidae. Symp. Zool. Soc. London 18, 167-177.

Kleiman, D. G. (1968). Reproduction in the canidae. Int. Zool. Yearb. 8, 3-8.

Kleiman, D. G. (1977). Monogamy in mammals. Q. Rev. Biol. 52, 39-69.

Kleiman, D. G., and Brady, C. A. (1978). Coyote behavior in the context of recent canid research: Problems and perspectives. In "Coyotes: Biology, Behavior, and Management" (M. Bekoff, ed.), pp. 163-188. Academic Press, New York.

Kleiman, D. G., and Eisenberg, J. F. (1973). Comparisons of canid and felid social systems from an evolutionary perspective. Anim. Behav. 21, 637-659.

Kleiman, D. G., and Eisenberg, J. F. (1983). Introduction. In "Advances in the Study of Mammalian Behavior" (J. F. Eisenberg and D. G. Kleiman, eds.), p. 359. Amer. Soc. Mammal. Spec. Publ. No.7.

Kleiman, D. G., and Malcolm, J. R. (1981). The evolution of male parental investment in mammals. In "Parental Care in Mammals" (D. J. Gubernick and P. H. Klopfer, eds.), pp. 347-387. Plenum, New York.

Knick, S. T., and Mech, L. D. (1980). Sleeping distance in wild wolf packs. Behav. Neural Biol. 28, 507511.

Knight, S. W. (1978). Dominance hierarchies of captive coyote litters. Unpub. M. Sc. thesis, Utah State University, Logan, Utah.

Knowlton, F. F. (1972). Preliminary interpretation of coyote population mechanics with some management implications. J. Wildl. Manage. 36, 369-382.

Korschgen, L. J. (1957). Food habits of the coyote in Missouri. J. Wildl. Manage. 21, 424-435.

Kruuk, H. (1972). "The Spotted Hyena." Univ. of Chicago Press, Chicago.

Kruuk, H. (1975). Functional aspects of social hunting by carnivores. In "Function and Evolution in Behaviour: Essays in Honour of Professor Niko Tinbergen" (G. Baerends, C. Beer, and A. Manning, eds.), pp. 119-141. Oxford Univ. Press, New York.

Kruuk, H. (1976). Feeding and social behaviour of the striped hyaena (Hyaena vulgaris Desrnarest). E. Afr. Wildl. J. 14, 91-111.

Kruuk, H. (1978). Foraging and spatial organisation of the Europoean badger, Meles meles L. Behav. Ecol. Sociobiol. 4, 75-89.

Lamprecht, J. (1978). The relationship between food competition and foraging size group in some larger carnivores. Z. Tierpsychol. 46, 337-343.

Lamprecht, J. (1981). The function of social hunting in larger terrestrial carnivores. Mammal. Rev. 11, 169-179.

Laundre, J. W., and Keller, B. L. (1981). Home range use by coyotes in Idaho. Anim. Behav. 29, 449-461.

Laundre, J. W., and Keller, B. L. (1983). Trappability of coyotes relative to home range boundaries. Can. J. Zool. 61, 1932-1934.

Laundre, J. W., and Keller, B. L. (1984). Home range of coyotes: A critical review. J. Wildl. Manage. 48, 127-139.

Leger, D. W., Owings, D. H., and Coss, R. G. (1983). Behavioral ecology of time allocation in California ground squirrels (Spermophilus beecheyi): Microhabitat effects. J. Comp. Psychol. 97, 283-291.

Lehner, P. N. (1976). Coyote behavior: Implications for management. Wild/. Soc. Bull. 4, 120-126.

Lehner, P. N. (1978a). Coyote communication. In "Coyotes: Biology, Behavior, and Management" (M. Bekoff, ed.), pp. 127-162. Academic Press, New York.

Lehner, P. N. (1978b). Coyote vocalizations: A lexicon and comparisons with other canids. Anim. Behav. 26, 712-722. 
Lehner, P. N. (1979). "Handbook of Ethological Methods." Garland, New York.

Lehner, P. N. (1982). Differential vocal response of coyotes to "group howl" and "group yip-howl" playbacks. J. Mammal. 63, 675-679.

Leyhausen, P. (1965). The communal organization of solitary mammals. Symp. Zool. Soc. London 14, 249-263.

Leyhausen, P. (1979). "Cat behavior: The predatory and social behavior of domestic and wild cats." Garland, New York.

Lillywhite, H. B. (1984). Adaptive strategies. Book review of "Behavioral Energetics." Science 224, 596.

Lindstrom, E. (1982). Population ecology of the red fox (Vulpes vulpes L.) in relation to food supply. Ph.D. thesis, University of Stockholm.

Lipetz, V. E. (1980). Grouping as an antipredatory strategy in the pronghorn antelope (Antilocapra americana Ord.). M.A. thesis, University of Colorado, Boulder, Colorado.

Lipetz, V. E., and Bekoff, M. (1980). Possible functions of predator harassment in pronghorn antelopes. J. Mammal. 61, 741-743.

Lipetz, V. E., and Bekoff, M. (1982). Group size and vigilance in pronghorns. Z. Tierpsychol. 58, 203-216.

Litvaitis, J. A. (1978). Movements and habitat use of coyotes on the Wichita Mountains National Wildlife Refuge. M.S. thesis, Oklahoma State University, Stillwater, Oklahoma.

Litvaitis, J. A., and Mautz, W. W. (1980). Food and energy use by captive coyotes. J. Wildl. Manage. 44, 56-61.

Litvaitis, J. A., and Shaw, J. H. (1980). Coyote movement, habitat use, and food habits in southwestern Oklahoma. J. Wildl. Manage. 44, 62-68.

Lockwood, R. (1976). An ethological analysis of social structure and affiliation in captive wolves. Unpub. Ph.D. Dissertation, Washington University, St. Louis, Missouri.

Lopez, B. H. (1977). "Giving Birth to Thunder, Sleeping with His Daughter: Coyote Builds North America." Sheed Andrews \& McMeel, Mission, Kansas.

Lorenz, K. Z. (1981). "The Foundations of Ethology." Springer-Verlag, New York.

Lott, D. F. (1984). Intraspecific variation in the social systems of wild vertebrates. Behaviour 88, 266-325.

McCarley, H. (1975). Long-distance vocalizations of coyotes. J. Mammal. 56, 847-856.

MacConnell-Yount, E., and Smith, C. (1978). Mule deer-coyote interactions in north-central Colorado. J. Mammal. 59, 422-423.

MacCracken, J. G., and Hansen, R. M. (1982). Seasonal foods of coyotes in southeastern Idaho: A multivariate analysis. Great Basin Nat. 42, 45-49.

McCracken, G. F., and Bradbury, J. W. (1981). Social organization and kinship in the polygynous bat Phyllostomus hastatus. Behav. Ecol. Sociobiol. 8, 11-34.

Macdonald, D. W. (1978). Observations on the behaviour and ecology of the striped hyaena, Hyaena hyaena, in Israel. Isr. J. Zoo!. 27, 189-198.

Macdonald, D. W. (1979). The flexible social system of the golden jackal, Canis aureus. Behav. Ecol. Sociobiol. S, 17-38.

Macdonald, D. W. (1980). "Rabies and Wildlife: A Biologist's Perspective." Oxford Univ. Press, New York.

Macdonald, D. W. (1983). The ecology of carnivore social behaviour. Nature (London) 301, 379-384.

Macdonald, D. W., and Moelhman, P. D. (1982). Cooperation, altruism, and restraint in the reproduction of carnivores. Persp. Ethol. S, 433-467.

Mace, G. M., and Harvey, P. H. (1983). Energetic constraints on home-range size. Am. Nat. 121, 120-132.

McNab, B. K. (1963). Bioenergetics and the determination of home range size. Amer. Nat. 97, 133-140.

Malcolm, J. (1979). Social organization and the communal rearing of pups in African wild dogs (Lycaon pictus). Ph.D. dissenation, Harvard University, Cambridge, Massachusetts.

Malcolm, J., and Manen, K. (1982). Natural selection and the communal rearing of pups in African wild dogs (Lycaon pictus). Behav. Ecol. Sociobiol. 10, 1-13. 
Markstein, P. L., and Lehner, P. N. (1980). A comparison of predatory behavior between prey-naïve and prey-experienced adult coyotes (Canis latrans). Bull. Psychonom. Soc. 15, 271-274.

Martin, P. ( 1984). The time and energy costs of play behaviour in the cat. Z. Tierpsychol. 64, 298-312.

Mech, L. D. (1970). "The Wolf: The Ecology and Behavior of an Endangered Species." Doubleday, New York.

Mech, L. D. (1983). "Handbook of Animal Radio-Tracking." Univ. of Minnesota Press, Minneapolis.

Mech, L. D., and Henel, H. H. (1983). An eight-year demography of a Minnesota wolf pack. Acta Zool. Fenn. 174, 249-250.

Mech, L. D., and Knick, S. T. (1978). Sleeping distances in wolf pairs in relation to the breeding season. Behav. Bioi. 23, 521- 525.

Messier, F. (1985). Solitary living and extraterritorial movements of wolves in relation to social status and prey abundance. Can. J. Zool. 63, 239-245.

Messier, F., and Barrette, C. (1982). The social system of the coyote (Canis latrans) in a forested habitat. Can. J. Zool. 60, 1743-1753.

Mills, M. G. L. (1978). Foraging behaviour of the brown hyaena (Hyaena brunnea Thinberg, 1820) in the southern Kalahari. Z. Tierpsychol. 48, 113-141.

Mills, M. G. L. ( 1982). Factors affecting group size and territory size of the brown hyaena, Hyaena brunnea in the southern Kalahari. J. Zool. London 198, 39-51.

Mills, M. G. L. (1983). Behavioural mechanisms and group maintenance of the brown hyaena, Hyaena brunnea, in the southern Kalahari. Anim. Behav. 31, 503-510.

Mock, D. W. (1983). On the study of avian mating systems.In "Perspectives in Ornithology: Essays Presented for the Centennial of the American Ornithologists' Union" (A. H. Brush and G. A. Clark, Jr., eds.), pp. 55-84. Cambridge Univ. Press, New York.

Moehlman, P. D. (1979). Jackal helpers and pup survival. Nature (London) 277, 382- 833.

Moehlman, P. D. (1981). Reply to Montgomerie (1981). Nature (London) 289, 825.

Moehlman, P. D. (1983). Socioecology of silverbacked and golden jackals (Canis mesomelas and Canis aureus). In " Advances in the Study of Mammalian Behavior" (J. F. Eisenberg, and D. G. Kleiman, eds.), pp. 423-453. Amer. Soc. Mammal. Spec. Publ. No. 7.

Montgomerie, R. D. (1981). Why do jackals help their parents? Nature (London) 289, 824-825.

Moore, J., and Ali, R. (1984). Are dispersal and inbreeding avoidance related? Anim. Behav. 32, 94-112.

Mottus, L. W. (1972). Differential responses of captive coyotes to various canid scents. Ph.D. Dissertation, University of Albena, Albena, Canada.

Murie, A. (1940). Ecology of the coyote in the Yellowstone. Nat. Park Serv. Fauna Ser. 4, 1-206.

Murie, O. I. (1951). "The Elk of Nonh America." Wildlife Management Institute, Washington, D.C.

Nellis, C. H., and Keith, L. B. (1976). Population dynamics of coyotes in central Alberta. J. Wildl. Manage. 40, 389-399.

Nowak, R. (1978). Evolution and taxonomy of coyotes and related Canis. In "Coyotes: Biology, Behavior, and Management" (M. Bekoff, ed.), pp. 3-16. Academic Press, New York.

Nudds, T. D. (1978). Convergence of group size strategies by mammalian social carnivore. Am. Nat. 112, 957-960.

Nursall, J. R. (1981). The activity budget and use of territory by a tropical blennid fish. Zool. J. Linn. Soc. 72, 69-92.

Ogle, T. F. (1971). Predator- prey relationships between coyotes and white-tailed deer. Northwest. Sci. 45, 213-218.

Okoniewski, J. C. (1982). A fatal encounter between an adult coyote and three conspecifics. J. Mammal. 63, 680-682.

Osterholm, H. (1964). The significance of the distance receptors in the feeding behaviour of the red fox Vulpes vulpes L. Acta Zool. Fenn. 106, 1-31. 
Owens, D. D., and Owens, M. J. \{1979). Communal denning and clan associations in brown hyeanas (Hyaena brunnea Thunberg) of the central Kalahari Desen. Afr. J. Ecol. 17, 35-44.

Owens, D. D., and Owens, M. J. (1984). Helping behavior in brown hyenas. Nature (London) 308, 843845.

Ozoga, J. I., and Harger, E. M. (1966). Winter activities and feeding habits of nonhero Michigan coyotes. J. Wildl. Manage. 30, 809-818.

Parker, G. R., Maxwell, J. W. , Monon, L. D., and Smith, G. E. D. (1983). The ecology of the lynx (Lynx canadensis) on Cape Breton Island. Can. J. Zool. 61, 770-786.

Pearl, M. C., and Schulman, S. R. (1983). Techniques for the analysis of social structure in animal societies. Adv. Study Behav. 13, 107-146.

Peters, G. (1984). On the structure of friendly close range vocalizations in terrestrial carnivores (Mammalia: Carnivora: Fissipedia). Z. Saugetierk. 49, 157-182.

Peters, R., and Mech, L. D. (1975). Scent-marking in wolves. Am. Sci. 63, 628-637.

Peterson, E. A., Heaton, W. C., and Wruble, S. D. (1969). Level of auditory response in fissiped carnivores. J. Mammal. 50, 566-587.

Peterson, R. O . (1977). Wolf ecology and prey relationships on Isle Royale. Natl. Park Serv. Mongr. Ser. (11), 1-210.

Polis, G. A., Myers, C. A., and Hess, W. R. (1984). A survey of intraspecific predation within the class Mammalia. Mammal Rev. 14, 187-198.

Preece, K. (1978). Home-range and social behavior of denning female coyotes in north-central Minnesota. Minn. Wildl. Res. Q. 38, 159-182.

Preston, E. M. (1975). Home range defense in the red fox, Vulpes vulpes. J. Mammal. 56,645- 652.

Pyrah, D. (1984). Social distribution and population estimates of coyotes in nonh-central Montana. J. Wildl. Manage. 48, 679-690.

Quayle, C. L. (1983). The behavioral development of scent-marking in captive male coyotes (Canis latrans). M. S. thesis, Central Michigan University, Mount Pleasant, Michigan.

Ralls, K. (1971). Mammalian scent marking. Science 171, 443-449.

Ramaswamy, S. S., Dua, G. L., Raizada, V. K., Dimri, G. P., Viswanathan, Madhaviah, J., and Srivastava, T. N. (1966). Effect of looseness of snow on energy expenditure in marching on snow-covered ground. J. Appl. Physiol. 21, 1747-1749.

Rasa, O. A. E. (1973). Prey capture, feeding techniques, and their ontogeny in the African dwarf mongoose, Helogale undulata rufula. Z. Tierpsychol. 32, 449-488.

Rathbun, A. P., Wells, M. C., and Bekoff, M. (1980). Cooperative predation by coyotes on badgers. J. Mammal. 61, 375-376.

Reich, A. (1981). The behavior and ecology of the African wild dog (Lycaon pictus) in the Kruger National Park. Ph.D. dissertation, Yale University, New Haven, Connecticut.

Reyer, H.-U. (1984). Investment and relatedness: A cost/benefit analysis of breeding and helping in the pied kingfisher (Ceryle rudis). Anim. Behav. 32, 1163-1178.

Reynolds, T. D. (1983). Pronghorn responses to hunting coyotes. Great Basin Nat. 43, 88-92.

Riedrnan, M. L. (1982). The evolution of alloparental care and adoption in mammals and birds. Q. Rev. Bioi. 57, 405-435.

Rodman, P. S. (1981). Inclusive fitness and group size with a reconsideration of group sizes in lions and wolves. Am. Nat. 118, 275-283.

Roessel, Jr., R. A., and Platero, D. (1974). "Coyote Stories." Navajo Curriculum Center Press, Rough Rock, Arizona.

Rood, J.P. (1978). Dwarf mongoose helpers at the den. Z. Tierpsychol. 48, 277-287.

Rood, J. P. (1983a). The social system of the dwarf mongoose. In "Advances in the Study of Mammalian Behavior" (J. F. Eisenberg and D. G. Kleiman, eds.), pp. 454-488. Amer. Soc. Mammal. Spec. Pub!. No.7. 
Rood, J. P. (1983b). Banded mongoose rescues pack member from eagle. Anim. Behav. 31, 1261-1262.

Rothman, R. J., and Mech, L. D. (1979). Scent-marking in lone wolves and newly formed pairs. Anim. Behav. 27, 750-760.

Rowe-Rowe, D. T. (1978). The small carnivores of Natal. Lammergeyer 25, 1-48.

Saggese, E. P., and Tullar, B. F. (1974). Possible predation of a gray fox on a red fox pup. N.Y. Fish Game J. 21, 86.

Schaller, G. B. (1972). "The Serengeti Lion." Univ. of Chicago Press, Chicago, Illinois.

Schenkel, R. (1967). Submission: Its features and function in the wolf and dog. Am. Zool. 7, 319-329.

Schleidt, W. M., Yakalis, G., Donnelly, M., and McGarry, J. (1984). A proposal for a standard ethogram, exemplified by an ethogram of the blue-breasted quail (Coturnix chinensis). Z. Tierpsychol. 64, 193- 220.

Scott, J. P. (1967). The evolution of social behavior in dogs and wolves. Am. Zool. 7, 373-381 .

Scott, J. P., and Fuller, J. L. (1965). "Genetics and the Social Behavior of the Dog." Univ. of Chicago Press, Chicago.

Seidensticker, J. C., Homocker, M.G., Wiles, W. V., and J. P. Messick. (1973). Mountain lion social organization in the Idaho primitive area. Wildl. Monogr. (35), 1-60.

Shield, J. (1972). Acclimation and energy metabolism of the dingo, Canis dingo, and the coyote, Canis latrans. J. Zool. 168, 483-501.

Smith, G. J., Cary, J. R., and Rongstad, O. J. (1981). Sampling strategies for radio-tracking coyotes. Wildl. Soc. Bull. 9, 88-93.

Snow, C. J. (1967). Some observations on the behavioral and morphological development of coyote pups. Am. Zool. 7, 353-355.

Sprague, R. H., and Anisko, J. J. (1973). Elimination patterns in the laboratory beagle. Behaviour 47, 257267.

Springer, J. T. (1980). Fishing behavior of coyotes on the Columbia River, south central Washington. J. Mammal. 61, 373-374.

Springer, J. T. (1982). Movement patterns of coyotes in south central Washington. J. Wildl. Manage. 46, 191-200.

Stains, H. J. (1975). Distribution and taxonomy of the canidae. In "The Wild Canids: Their Systematics, Behavioral Ecology and Evolution" (M. W. Fox, ed .), pp. 3-26. Van Nostrand-Reinhold, Princeton, NJ.

Stearns, S. C. (1983). The influence of size and phylogeny on patterns of covariation among life-history traits in the mammals. Oikos 41, 173-187.

Sterling, B., Conley, W., and Conley, M. R. (1983). Simulations of demographic compensation in coyote populations. J. Wildl. Manage. 47, 1177-1181.

Sunquist, M. E. (1981). The social organization of tigers (Panthera tigris) in Royal Chitawan National Park, Nepal. Smithson. Contrib. Zool. No. 336.

Suthers, R. A. (1978). Sensory ecology of mammals. In "Sensory Ecology: Review and Perspectives" (M. A. Ali, ed.), pp. 253-287. Plenum, New York.

Taborsky, M. (1984). Broodcare helpers in the cichlid fish Lamprologus brichardi: Their costs and benefits. Anim. Behav. 32, 1236-1252.

Telfer, E. S., and Kelsall , J. P. (1984). Adaptation of some large North American mammals for survival in snow. Ecology 65, 1828-1834.

Terborgh, J. (1983). "Five New World Primates: A Study in Comparative Ecology." Princeton Univ. Press, Princeton, NJ.

Tilson, R. L., and Hamilton, W. J., III (1984). Social dominance and feeding patterns of spotted hyenas. Anim. Behav. 32, 715-724.

Todd, A. W., and Keith, L. B. (1976). Responses of coyotes to winter reductions in agricultural carrion. Alberta Rec., Parks and Rec., Wildlife, Fish and Game Div., Wildt. Tech. Bull. No. 5, 1-32. 
Todd, A. W. , Keith, C. B., and Fischer, C. A. (1981). Population ecology of coyotes during a fluctuation of snowshoe hares. J. Wildl. Manage. 45, 629-640.

Truett, J. C. (1979). Observations of coyote predation on mule deer fawns in Arizona. J. Wildl. Manage. 43, 956-958.

Tzilkowski, W. M. (1980). Mortality patterns of radio-marked coyotes in Jackson Hole, Wyoming. Ph.D. dissertation, University of Massachusetts, Amherst, Massachusetts.

van Orsdol, K. G. (1984). Foraging behavior and hunting success of lions in Queen Elizabeth National Park, Uganda. Afr. J. Ecol. 22, 79-99.

van Schaik, C. P., and van Hooff, J. A. R. A. M. (1983). On the ultimate causes of primate social systems. Behaviour 85, 91-117.

Vaughan, C. (1983). Coyote range expansion in Costa Rica and Panama. Brenesia 21, 27- 32.

Vehrencamp, S. L. (1979). The roles of individual, kin and group selection in the evolution of sociality. In "Handbook of Behavioral Neurobiology: Social Behavior and Communication" (P. Marler and J. C. Vandenbergh, eds.), Vol. 3, pp. 351-394. Plenum, ·New York.

Vincent, L., and Bekoff, M. (1978). Quantitative analyses of the ontogeny of predatory behavior in coyotes, Canis ILJtrans. Anim. Behav. 26, 225- 231.

von Schantz, T. (1981). Female cooperation, male competition, and dispersal in the red fox Vulpes vulpes. Oikos 37, 63-68.

von Schantz, T. (1984). Carnivore social behavior-does it need patches? Nature (London) 307, 398-390.

Waser, P. M. (1974). Spatial associations and social interactions in a "solitary" ungulate: The bushbuck Tragelaphus scriptus (Pallas). Z. Tierpsychol. 37, 24-36.

Waser, P. M., and Jones, W. T. (1983). Natal philopatry among solitary mammals. Q. Rev. Bioi. 58, 355390.

Waser, P. M., and Wiley, R. H. (1979). Mechanisms and evolution of spacing in animals. In " Handbook of Behavioral Neurobiology" (P. Marler and J. G. Vandenbergh, eds.), Vol. 3, pp. 159- 223. Plenum, New York.

Weaver, J. L. (1977). Coyote-food base relationships in Jackson Hole, Wyoming. M.Sc. thesis, Utah State University, Logan, Utah.

Weaver, J. L. (1979). Influence of elk carrion upon coyote populations in Jackson Hole, Wyoming. In "North American Elk: Ecology, Behavior, and Management" (M. S. Boyce and L. D. HaydenWing, eds.), pp. 152-157. Univ. of Wyoming Press, Laramie, Wyoming.

Wells, M. C. (1978). Coyote senses in predation: Environmental influences on their relative use. Behav. Proc. 3, 149-158.

Wells, M. C., and Bekoff, M. (1981). An observational study of scent-marking in coyotes, Canis latrans. Anim. Behav. 29, 332-350.

Wells, M. C., and Bekoff, M. (1982). Predation by wild coyotes: Behavioral and ecological analyses. J. Mammal. 63, 118-127.

Wells, M. C., and Lehner, P. N. (1978). The relative importance of the distance senses in coyote predatory behavior. Anim. Behav. 26, 251-258.

West-Eberhard, M. J. (1975). The evolution of social behavior by kin selection. Q. Rev. Bioi. 50, 1-34.

White, M. (1973). Descriptions of remains of deer fawns killed by coyotes. J. Mammal. 54, 291-293.

Williams, B. K. (1983). Some observations on the use of discriminant analysis in ecology. Ecology 64, 1283-1291.

Williams, G. B. (1966). "Adaptation and Natural Selection." Princeton Univ. Press, Princeton, NJ.

Wilson, D. S. (1980). "The Natural Selection of Populations and Communities." Benjamin/Cummings, Palo Alto, California.

Wilson, E. O. (1975). "Sociobiology: The New Synthesis." Harvard Univ. Press, Cambridge, Massachusetts. 
Wirtz, W. O., Keller, M.A., and Meikle, W. G. (1982). Urban coyotes in southern California: A progress report. Annu. Meet. Am. Soc. Mammal., 62nd, Snowbird, Utah.

Wittenberger, J. F., and Tilson, R. L. (1980). The evolution of monogamy: Hypotheses and evidence. Annu. Rev. Ecol. Syst. 11, 197-232.

Woodruff, R. A., and Keller, B. L. (1982). Dispersal, daily activity, and home range of coyotes in southeastern Idaho. Northwest Sci. 56, 199-207.

Woolfenden, G. E., and Fitzpatrick, J. W. (1984). "The Florida scrub jay: Demography of a cooperativebreeding bird." Princeton Univ. Press, Princeton, NJ.

Young, S. P., and Jackson, H. H. T. (1951). "The Clever Coyote." Wildlife Management Institute, Washington, D.C.

Zimen, E. (1975). Social dynamics of the wolf pack. In "The Wild Canids: Their Systematics, Behavioral Ecology and Evolution" (M. W. Fox, ed.), pp. 336-362. Van Nostrand-Reinhold, Princeton, NJ.

Zimen, E. (1976). On the regulation of pack size in wolves. Z. Tierpsychol. 40, 300-341.

Zimen, E. (1981). "The Wolf: A Species in Danger." Delacorte, New York. 